\title{
Drug Resistance in Epilepsy: Clinical Impact, Potential Mechanisms, and New Innovative Treatment Options
}

\author{
Wolfgang Löscher, Heidrun Potschka, Sanjay M. Sisodiya, and Annamaria Vezzani
}

Department of Pharmacology, Toxicology, and Pharmacy, University of Veterinary Medicine, Hannover, Germany (W.L.); Center for Systems Neuroscience, Hannover, Germany (W.L.); Institute of Pharmacology, Toxicology and Pharmacy, Ludwig-Maximilians-University, Munich, Germany (H.P.); Department of Clinical and Experimental Epilepsy, UCL Queen Square Institute of Neurology, London, United Kingdom (S.S); and Department of Neuroscience, Mario Negri Institute for Pharmacological Research Istituto di Ricovero e Cura a Carattere Scientifico, Milano, Italy (A.V.)

Abstract.........................................................6607

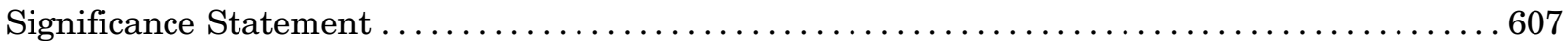

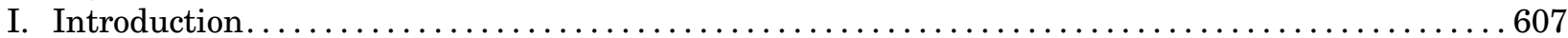

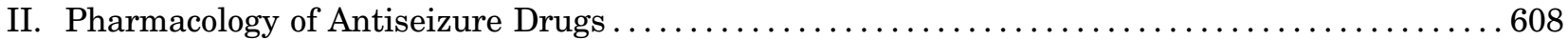

III. In Vivo and In Vitro Models of Drug Resistance............................... 610

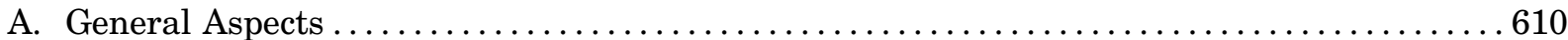

B. Rodent and Zebrafish Models with Poor Responsiveness to Antiseizure Drugs...........6 610

C. Rodent Models with Selection of Responder and Nonresponder Subgroups . . . . . . . . . . 614

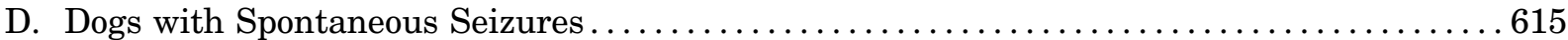

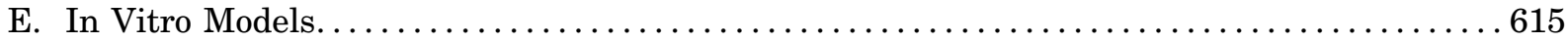

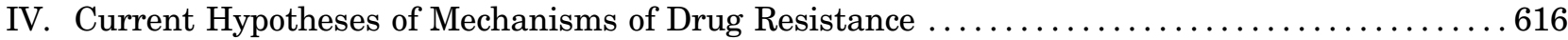

A. Alteration of Drug Targets in the Brain ..................................... 618

B. Alteration of Drug Uptake into the Brain ................................ 620

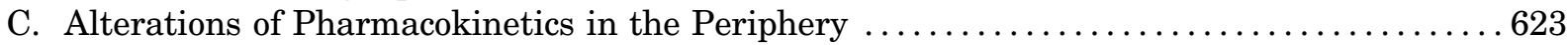

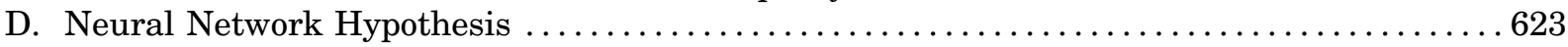

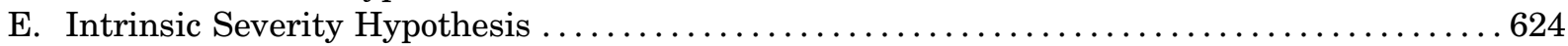

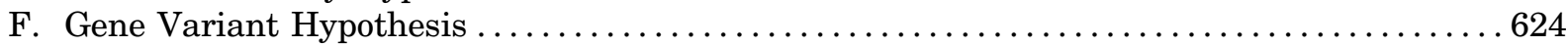

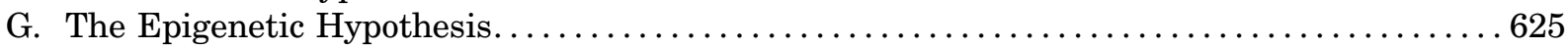

H. Neuroinflammation and Blood-Brain Barrier Dysfunction as Potential Mechanisms ...... 626

1. Pathophysiological Link between Neuroinflammation and Blood-Brain Barrier

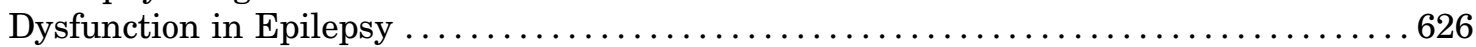

2. Neuroinflammation and Blood-Brain Barrier Dysfunction: Role in Drug Resistance . . 627

3. Cyclooxygenase 2-Prostaglandin E2-Prostaglandin E2 Receptor 1 Axis............6 627

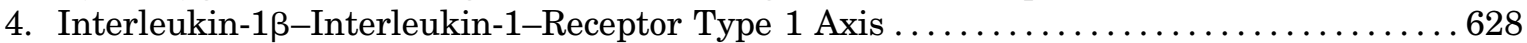

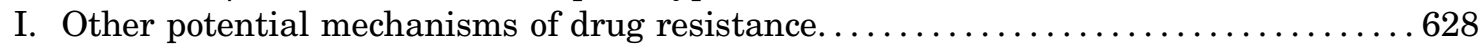

V. How to Overcome Drug Resistance?.................................... 628

A. Development of New Antiseizure Drugs by Using New Drug-Screening Paradigms . . . . . 628

B. Precision Medicine ............................................ 630

Address correspondence to: Dr. Wolfgang Löscher, Department of Pharmacology, Toxicology and Pharmacy, University of Veterinary Medicine, Bünteweg 17, D-30559 Hannover, Germany. E-mail: wolfgang.loescher@tiho-hannover.de

W.L.'s work has been supported by the Deutsche Forschungsgemeinschaft and the European Union's Seventh Framework Programme [FP7/2007-2013] under grant agreement $n^{\circ} 602102$ (EPITARGET) and $n^{\circ} 201380$ (EURIPIDES). S.S. is supported by the UK Epilepsy Society. This work was supported by European Community [Grant 279062], EpiPGX. This work was partly carried out at National Institute for Health Research (NIHR) University College London Hospitals Biomedical Research Centre, which receives a proportion of funding from the UK Department of Health's NIHR Biomedical Research Centres funding scheme. H.P.'s work has been supported by the Deutsche Forschungsgemeinschaft, the European Union's Seventh Framework Programme [Grant agreement n ${ }^{\circ} 201380$ EURIPIDES], and European Union-Innovative Medicines Initiative (European Quality In Preclinical Data). A.V.'s work has been supported by the European Union's Seventh Framework Programme [FP7/2007-2013] under grant agreement n602102 (EPITARGET) by Fondazione AICE-FIRE and Fondazione Monzino.

https://doi.org/10.1124/pr.120.019539. 
C. Development of More Effective Antiseizure Drugs by Revised Target-Based Drug

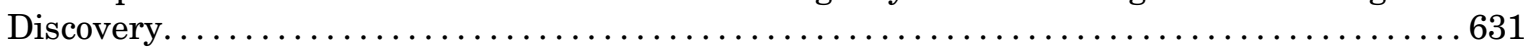

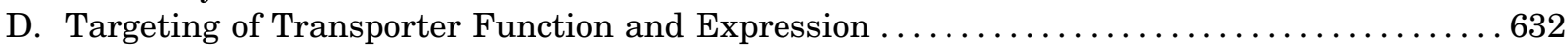

E. Anti-Inflammatory Drugs and Strategies to Repair the BBB ...................6 633

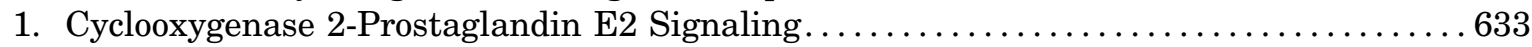

2. Interleukin-1 $\beta$-Interleukin-1-Receptor Type 1 Signaling $\ldots \ldots \ldots \ldots \ldots \ldots \ldots \ldots \ldots 63$

3. Other Anti-Inflammatory Strategies . . . . . . . . . . . . . . . . . . . . . . . . . 633

4. Molecular Mechanisms of Therapeutic Effects ........................... 633

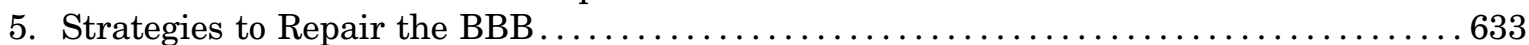

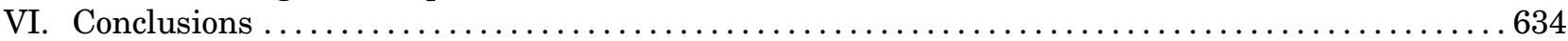

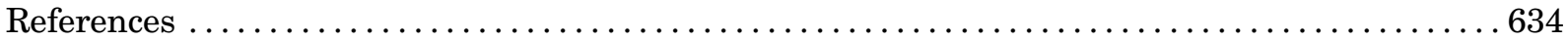

\begin{abstract}
Epilepsy is a chronic neurologic disorder that affects over 70 million people worldwide. Despite the availability of over 20 antiseizure drugs (ASDs) for symptomatic treatment of epileptic seizures, about one-third of patients with epilepsy have seizures refractory to pharmacotherapy. Patients with such drug-resistant epilepsy (DRE) have increased risks of premature death, injuries, psychosocial dysfunction, and a reduced quality of life, so development of more effective therapies is an urgent clinical need. However, the various types of epilepsy and seizures and the complex temporal patterns of refractoriness complicate the issue. Furthermore, the underlying mechanisms of DRE are not fully understood, though recent work has begun to shape our understanding more clearly. Experimental models of DRE offer opportunities to discover, characterize, and challenge putative mechanisms of drug resistance. Furthermore, such preclinical models are important in developing therapies that may overcome drug resistance. Here, we will review the current
\end{abstract}

understanding of the molecular, genetic, and structural mechanisms of ASD resistance and discuss how to overcome this problem. Encouragingly, better elucidation of the pathophysiological mechanisms underpinning epilepsies and drug resistance by concerted preclinical and clinical efforts have recently enabled a revised approach to the development of more promising therapies, including numerous potential etiology-specific drugs ("precision medicine") for severe pediatric (monogenetic) epilepsies and novel multitargeted ASDs for acquired partial epilepsies, suggesting that the long hoped-for breakthrough in therapy for as-yet ASD-resistant patients is a feasible goal.

Significance Statement_-Drug resistance provides a major challenge in epilepsy management. Here, we will review the current understanding of the molecular, genetic, and structural mechanisms of drug resistance in epilepsy and discuss how the problem might be overcome.

\section{Introduction}

Epilepsy is one of the most common and most disabling chronic neurologic disorders (Devinsky et al., 2018). People with epilepsy have recurrent unprovoked (spontaneous) seizures, which can be focal or generalized in nature. Seizures cannot be fully controlled in about a third of people with epilepsy, even though multiple antiseizure drugs (ASDs) may have been employed singly or in various combinations; this phenomenon is drug resistance. In theory, at least four clinical patterns of drug resistance can be observed: 1) de novo (or ab initio) ASD resistance, whereby the patient never enters a useful period of seizure freedom from the onset of the epilepsy; 2) delayed resistance, which is when the patient initially becomes seizure-free but seizures recur and become uncontrollable; 3) a waxing-and-waning (or fluctuating) pattern, which occurs when the epilepsy alternates between being controlled and uncontrolled; or 4) the epilepsy is initially drugresistant but with time responds to treatment (Schmidt and Löscher, 2005). Long-term outcome studies in newly treated patients with epilepsy suggest that, after failure of two well-tolerated ASD schedules appropriately chosen for the seizure type(s), the chance of success with further drug manipulation becomes progressively less likely (Chen et al., 2018). Thus, drug-resistant

ABBREVIATIONS: ASD, antiseizure drug; ASP, Anticonvulsant Screening Program; BBB, blood-brain barrier; BCRP, breast cancer related protein; CA1, Cornu Ammonis sector 1; COX, cyclooxygenase; CSF1R, colony-stimulating factor receptor 1; DRE, drug-resistant epilepsy; EP1R, prostaglandin E2 receptor 1; ETSP, Epilepsy Therapy Screening Program; GAT1, GABA transporter 1; IL, interleukin; IL-1Ra, IL1 receptor antagonist; IL-1R1, IL-1 receptor type 1; ILAE, International League Against Epilepsy; iPSC, induced pluripotent stem cell; KCC, K ${ }^{+}$ $\mathrm{Cl}^{-}$cotransporter; lncRNA, long noncoding RNA; MAM, methylazoxymethanol acetate; MDR, multidrug resistance; MES, maximal electroshock seizure; MRP, multidrug resistance protein; mTOR, mammalian target of rapamycin; NAT, natural antisense transcript; NIH, National Institutes of Health; NINDS, National Institute of Neurologic Disorders and Stroke; NKCC, $\mathrm{Na}^{+} \mathrm{K}^{+} 2 \mathrm{Cl}^{-}$cotransporter; NMDA, N-methyl-Daspartate; OXC, oxcarbazepine; PET, positron emission tomography; PG, prostaglandin; Pgp, P-glycoprotein; PTZ, pentylenetetrazole; RED, recurrent epileptiform discharge; SE, status epilepticus; SNP, single nucleotide polymorphism; SV, synaptic vesicle protein; TGF, tumor growth factor; TLE, temporal lobe epilepsy; TNF, tumor necrosis factor; TSC, tuberous sclerosis complex; VEGF, vascular endothelial growth factor; VEGFR, VEGF receptor; ZO, zonula occludens. 
(medically refractory) epilepsy can often be identified early in the course of treatment, supporting the suggestion that drug resistance is present de novo in many patients.

Developing novel treatments and management strategies for drug resistance has been a longstanding goal set by the National Institute of Neurologic Disorders and Stroke (NINDS) in the United States (Kelley et al., 2009). For clinicians, it represents one of the major challenges in epilepsy. Despite many years of research, the mechanisms underlying drug resistance remain largely unknown, though recent work has begun to shape our understanding more clearly. In the absence of clear understanding, definitions of drug resistance tend to be operational. An ad hoc Task Force of the International League Against Epilepsy (ILAE) defined drug resistance as "failure of adequate trials of two tolerated, appropriately chosen and used antiepileptic drug schedules (whether as monotherapies or in combination) to achieve sustained seizure freedom" and considered this a testable, working hypothesis to be refined with time (Kwan et al., 2010). We can expect that this definition will change, especially in light of the current tension between the clinically observed phenomenon of multidrug resistance (MDR), an understanding of common mechanisms in epileptogenesis and the generation of seizures shared across the epilepsies, large-scale genetic studies that also indicate shared susceptibility across the epilepsies, and the growing data on the separate biologies of the many conditions that together constitute the epilepsies. In due course, we may come to discover that there are many mechanisms or contributors to drug resistance. For now, it is reassuring that categorization according to the definition has proven to be dependable in practice (Mula et al., 2019; Zaccara et al., 2019).

Drug resistance is common. A review of 35 studies showed that the pooled prevalence proportion was 0.30 and pooled incidence proportion was 0.15 (although few studies employ the ILAE definition of drug resistance) (Kalilani et al., 2018). Clinical factors associated with drug resistance were noted to be age at onset, symptomatic epilepsy, abnormal neuroimaging, abnormal electroencephalography, history of mental retardation, neuropsychiatric disorders, prolonged febrile seizure, and status epilepticus (SE) (Kalilani et al., 2018). A single-center 30-year longitudinal cohort study found a similar proportion of people not seizure-free at terminal outcome, identifying as risk factors for this outcome the number of seizures occurring in the year before treatment began, previous recreational drug use, and a family history of epilepsy in first-degree relatives (Chen et al., 2018). Other risk factors have been proposed and models predicting drug resistance generated, but, as with many studies in this area, there is typically a lack of replication and robust evidence for many such suggestions.
These factors probably point to underlying causes yet to be established and which might mediate both drug resistance and the epilepsy with its concurrent features, or there may be other causal models. Studies of drug resistance may be complicated by unexplained temporal dynamics; the same person may have prolonged periods of seizure freedom, with intervals during which seizures cannot be controlled (Berg et al., 2003), making classification challenging. It may be better to speak of a spectrum of drug resistance.

The known clinical risk factors for drug resistance in epilepsy also indicate that drug resistance is often associated with comorbidities that increase the overall disease burden for affected individuals; seizure control can ameliorate comorbidities and vice versa (Keezer et al., 2016). Moreover, drug resistance means that seizures are not controlled and continue to occur; ongoing seizures, especially tonic-clonic seizures, are the best recognized risk factor for sudden unexplained death in epilepsy (Ryvlin et al., 2019) and also increase the risk of direct negative consequences from seizures, including injuries (Mahler et al., 2018) and drowning (Watila et al., 2018).

The personal burden of drug resistance in epilepsy is reflected in its economic impact for health care systems and beyond. There is associated loss of productivity and employment, for example. The socioeconomic burden is sizeable; older studies show that in the United States, the estimated total cost is about $\$ 4$ billion per annum (Murray et al., 1996), whereas in Europe, drug resistance accounts for a substantial proportion of an estimated total cost of epilepsy, $€ 15.5$ billion per annum (Pugliatti et al., 2007).

Overall, therefore, drug resistance is a key challenge in the epilepsies. This review focuses on existing data, the prevailing concepts, and future prospects for tackling drug resistance.

\section{Pharmacology of Antiseizure Drugs}

ASDs, previously also termed antiepileptic or anticonvulsant drugs, are the main form of symptomatic treatment of people with epilepsy. About 30 ASDs are currently used, of which most were approved over the last 30 years (Fig. 1). Most ASDs were discovered by initial demonstration of their antiseizure activity in simple, classic rodent seizure models, such as the maximal electroshock (MES) and pentylenetetrazol (PTZ) tests, which are highly predictive of clinical efficacy in epilepsy but not in drug-resistant epilepsy (DRE) (Löscher et al., 2013a). ASDs are administered chronically with the intent of preventing the occurrence of epileptic seizures in a person with already diagnosed epilepsy. The symptomatic relief from seizures by ASDs occurs through interactions with a variety of cellular targets (Rogawski et al., 2016; Sills and Rogawski, 2020). The actions on these targets can be categorized 


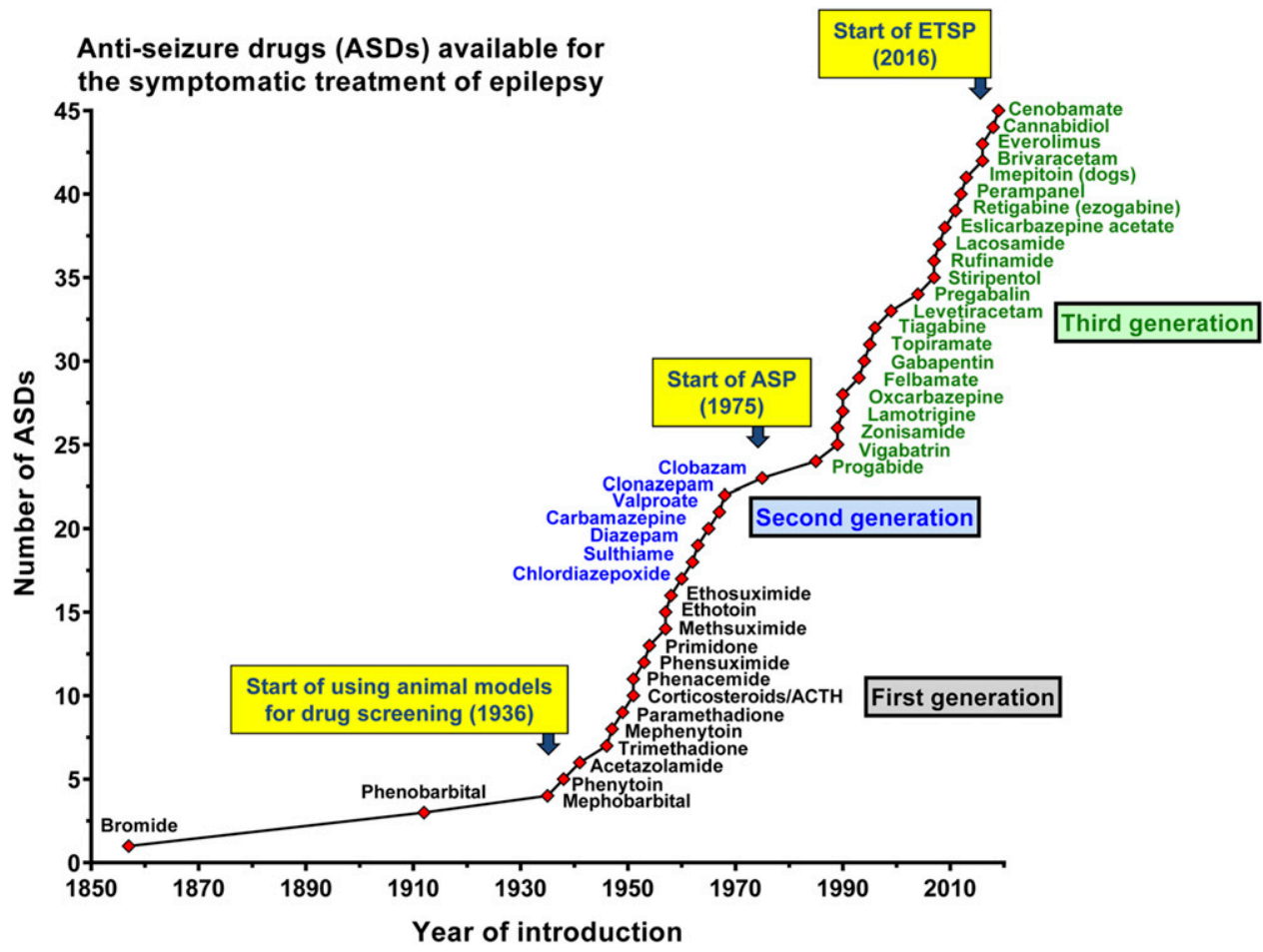

Fig. 1. Introduction of antiseizure drugs (ASDs) to the market from 1853 to 2019. Licensing varied from country to country. We give here the year of first licensing or the first mention of clinical use in a country of Europe, the United States, or Japan. We have not included all derivatives of listed ASDs nor ASDs used solely for treatment of status epilepticus. The first generation of ASDs, entering the market from 1857 to 1958, includes potassium bromide, phenobarbital, and a variety of drugs that were mainly derived by modification of the barbiturate structure, including phenytoin, primidone, trimethadione, and ethosuximide. The second-generation ASDs, including carbamazepine, valproate, and the benzodiazepines, which were introduced between 1960 and 1975, differed chemically from the barbiturates. The era of the third-generation ASDs started in the 1980s with "rational" (targetbased) developments such as progabide, vigabatrin, and tiagabine, i.e., drugs that were designed to selectively target a mechanism that was thought to be critical for the occurrence of epileptic seizures. The figure also illustrates the impact of preclinical seizure models on ASD development. The use of seizure models for drug screening started with the experiments performed by Merritt and Putnam in the 1930s, who used an electroshock seizure model in cats, leading to the discovery of phenytoin. Subsequently, the electroshock model was adapted to rodents and, together with chemical seizure models, used for drug screening in diverse laboratories, leading to discovery of various additional ASDs. In 1975, the NIH/NINDS ASP was established in the United States as part of a larger Antiepileptic Drug Development program to promote industry interest in ASD development. Since its start, the seizure tests have been performed at a contract facility based at the University of Utah, using three rodent models, i.e., the maximal electroshock seizure (MES) test, the pentylenetetrazole (PTZ) seizure test, and the rotarod test for assessing neurotoxicity. Later, other seizure models were added. The seizure tests were performed on a blinded and confidential basis and at no cost to the ASP participants, thus providing opportunities for researchers from academia and industry in the United States and abroad to submit compounds for screening in a battery of well established rodent seizure models. Approximately 32,000 compounds from more than 600 participants from 38 countries have been screened by this program, and the ASP has contributed to bringing nine currently available ASDs to market since 1990 (Kehne et al., 2017). More recently (2016), the ASP has been renamed Epilepsy Therapy Screening Program (ETSP) with the refocused mission to identify novel agents that will help address the considerable remaining unmet medical needs in epilepsy, particularly ASD-resistant seizures (Kehne et al., 2017). Figure modified from Löscher and Schmidt (2011). For further details, see text and Löscher et al. (2013a).

into four broad groups: 1) modulation of voltage-gated ion channels, including sodium, calcium, and potassium channels; 2) enhancement of GABA-mediated inhibition through effects on $\mathrm{GABA}_{\mathrm{A}}$ receptors, the GABA transporter 1 (GAT1), the GABA-sythesizing enzyme glutamic acid decarboxylase, or the GABA-metabolizing enzyme GABA transaminase; 3) direct modulation of synaptic release through effects on components of the release machinery, including synaptic vesicle protein (SV) $2 \mathrm{~A}$ and the $\alpha 2 \delta$ subunit of voltage-gated calcium channels; and 4) inhibition of synaptic excitation mediated by ionotropic glutamate receptors, including $\alpha$-amino-3-hydroxy-5-methyl-4-isoxazole-propionate receptors (Table 1 ). The result of the interactions at these diverse targets is to modify the intrinsic excitability properties of neurons or to alter fast inhibitory or excitatory neurotransmission (Rogawski et al., 2016). These actions reduce the probability of seizure occurrence by modifying the bursting properties of neurons and reducing synchronization in localized neuronal ensembles. In addition, ASDs inhibit the spread of abnormal firing to adjacent and distant brain sites.

As shown in Table 1, several ASDs act by more than one mechanism. Most ASDs were discovered by screening, structural alterations of known ASDs, or serendipity, whereas only relatively few, more recent, ASDs were the result of rational, target-based drug discovery (Löscher et al., 2013a). For most ASDs, mechanisms of action were only identified after their discovery or clinical approval. Target-based strategies have been based on previously presumed mechanisms of seizure generation, that is, impaired GABAergic inhibition and increased glutamatergic excitation, resulting in ASDs that either potentiate GABA transmission (such as vigabatrin and tiagabine) or inhibit glutamate receptors (such as perampanel). However, the old reductionistic 
TABLE 1

Molecular targets of clinically used ASDs

Adapted from Rogawski and Löscher (2004), Rogawski et al. (2016), and Sills and Rogawski (2020)

\begin{tabular}{|c|c|}
\hline Molecular target & ASDs that act on target \\
\hline \multicolumn{2}{|l|}{$\begin{array}{l}\text { Voltage-gated ion } \\
\text { channels }\end{array}$} \\
\hline $\begin{array}{l}\text { Voltage-gated sodium } \\
\text { channels }\end{array}$ & $\begin{array}{l}\text { Phenytoin, fosphenytoin, }{ }^{a} \text { carbamazepine, } \\
\text { oxcarbazepine, }{ }^{b} \text { eslicarbazepine acetate, } \\
\text { lamotrigine, lacosamide; possibly } \\
\text { topiramate, zonisamide, rufinamide }\end{array}$ \\
\hline $\begin{array}{l}\text { Voltage-gated calcium } \\
\text { channels (T-type) }\end{array}$ & Ethosuximide \\
\hline $\begin{array}{l}\text { Voltage-gated potassium } \\
\text { channels }\left(\mathrm{K}_{\mathrm{v}} 7\right)\end{array}$ & Retigabine (ezogabine) \\
\hline \multicolumn{2}{|l|}{$\begin{array}{l}\text { GABA-mediated } \\
\text { inhibition }\end{array}$} \\
\hline $\mathrm{GABA}_{\mathrm{A}}$ receptors & $\begin{array}{l}\text { Phenobarbital, primidone, stiripentol, } \\
\text { benzodiazepines, (including diazepam, } \\
\text { lorazepam, midazolam and clonazepam), } \\
\text { possibly topiramate, felbamate, } \\
\text { retigabine (ezogabine) }\end{array}$ \\
\hline GAT1 GABA transporter & Tiagabine \\
\hline GABA transaminase & Vigabatrin \\
\hline $\begin{array}{l}\text { Glutamic acid } \\
\text { decarboxylase }\end{array}$ & Possibly valproate, gabapentin, pregabalin \\
\hline \multicolumn{2}{|l|}{$\begin{array}{l}\text { Presynaptic release } \\
\text { machinery }\end{array}$} \\
\hline SV2A & Levetiracetam, brivaracetam \\
\hline $\begin{array}{l}\alpha 2 \delta \text { subunit of calcium } \\
\text { channels }\end{array}$ & Gabapentin, pregabalin \\
\hline \multicolumn{2}{|l|}{$\begin{array}{l}\text { Ionotropic glutamate } \\
\text { receptors }\end{array}$} \\
\hline AMPA receptor & Perampanel \\
\hline $\begin{array}{l}\text { Carbonic } \\
\text { anhydratase } \\
\text { inhibition }\end{array}$ & $\begin{array}{l}\text { Acetazolamide, topiramate, zonisamide, } \\
\text { possibly lacosamide }\end{array}$ \\
\hline \multicolumn{2}{|l|}{ Disease-specific } \\
\hline mTORC1 signaling $^{d}$ & Everolimus \\
\hline $\begin{array}{l}\text { Lysosomal enzyme } \\
\text { replacement }\end{array}$ & $\begin{array}{l}\text { Cerliponase alfa (recombinant tripeptidyl } \\
\text { peptidase 1) }\end{array}$ \\
\hline Mixed/unknown & $\begin{array}{l}\text { Valproate, felbamate, topiramate, } \\
\text { zonisamide, rufinamide, } \\
\text { adrenocorticotrophin (ACTH), } \\
\text { cannabidiol, cenobamate }\end{array}$ \\
\hline
\end{tabular}

AMPA, $\alpha$-amino-3-hydroxy-5-methyl-4-isoxazole-propionate.

${ }^{a}$ Fosphenytoin is a prodrug for phenytoin.

${ }^{b}$ Oxcarbazepine serves largely as a prodrug for licarbazepine, mainly S-licarbazepine.

${ }^{c}$ Eslicarbarbazepine acetate is a prodrug for S-licarbazepine.

${ }^{d}$ In patients with epilepsy because of tuberous sclerosis complex (TSC).

${ }^{e}$ In patients with epilepsy because of neuronal ceroid lipofuscinosis type 2 .

view that seizures or epilepsy are due to an imbalance between GABAergic inhibition and glutamatergic excitation ignores the complexity of the alterations within these neurotransmitter systems in the brain of a person suffering from epileptic seizures (Löscher et al., 2013a). In view of the various limitations and challenges of previous ASD development, it is mandatory to revisit conventional ASD discovery and development, which will be discussed in section V. A. Development of New Antiseizure Drugs by Using New Drug Screening Paradigms and V. B. Precision Medicine. The more complex experimental models of drug-resistant seizures discussed in the following sections are important in this respect. Furthermore, models of severe pediatric epilepsies that allow the development of etiology-specific drugs have recently become important in ASD development (Baraban and Löscher, 2014; Galanopoulou and Moshé, 2015; Grone and Baraban, 2015; Demarest and
Brooks-Kayal, 2018; Griffin et al., 2018). Two recently approved etiology-specific treatments are listed in Table 1.

\section{In Vivo and In Vitro Models of Drug Resistance}

\section{A. General Aspects}

In vivo and in vitro models have significantly contributed to our current understanding of the mechanisms of DRE. As further discussed below, analysis of epilepsy-associated molecular, cellular, and network alterations, and of their association with drugresponsiveness, has resulted in the formulation of different hypotheses. These hypotheses received important support by findings from comparative studies exploring differences between ASD responder and nonresponders in animal models of DRE.

Models of DRE (Table 2) are not only considered key tools for the identification of the pathophysiological mechanisms of therapeutic failure but also for the selection of novel drug candidates targeting difficultto-treat epilepsy with refractoriness to available ASDs. The importance of these models is underlined by the fact that they became a mainstay in the recently reorganized screening program of the NINDS/National Institutes of Health (NIH), which has been renamed the Epilepsy Therapy Screening Program (ETSP) (Kehne et al., 2017, Löscher, 2017a). One main focus of the ETSP is the pharmacoresistant epilepsy workflow (Fig. 2), which integrates several models with a poor responsiveness to selected or several available ASDs. Such in vivo models belong to the first category of models introduced in the following section.

More elaborate models build on the selection of subgroups of responders and nonresponders from a group of animals with interindividual variation in ASD responsiveness. These models form the second category of in vivo models, which is further introduced below.

One main limitation of the majority of studies, except for some with responder and nonresponder selection, is that they do not consider the ILAE definition of pharmacoresistant epilepsy. Moreover, many studies fail to report and consider effective dose limitations because of adverse effects as, for instance, calculated by the protective index (i.e., the median minimal "neurotoxic" dose, $\mathrm{TD}_{50}$, divided by median effective dose, $\mathrm{ED}_{50}$ ), which is relevant for conclusions about responsiveness of a paradigm.

\section{B. Rodent and Zebrafish Models with Poor Responsiveness to Antiseizure Drugs}

A wide variety of preclinical models of seizures or epilepsy is in common use for evaluating novel compounds for antiseizure effects (Löscher, 2016). Some of these models, e.g., the MES and PTZ rodent models, have been discussed in section II (Pharmacology of Antiseizure Drugs); such models are particularly important in identifying novel compounds with antiseizure 
TABLE 2

In vivo models of drug-resistant seizures

For references, see text.

\begin{tabular}{|c|c|c|c|c|c|c|}
\hline Seizure or epilepsy model & Species & Mode of seizure or epilepsy induction & $\begin{array}{l}\text { Chronic } \\
\text { model }\end{array}$ & $\begin{array}{l}\text { Development of } \\
\text { spontaneous } \\
\text { seizures }\end{array}$ & $\begin{array}{l}\text { Selection of } \\
\text { responders and } \\
\text { nonresponders } \\
\text { reported }\end{array}$ & Throughput \\
\hline $6-\mathrm{Hz}$ seizure model & Mouse & Transcorneal electrical stimulation & No & No & n.a. & High \\
\hline $6-\mathrm{Hz}$ seizure model & Rat & Transcorneal electrical stimulation & No & No & n.a. & High \\
\hline $\begin{array}{l}\text { Allylglycine-induced } \\
\text { seizures }\end{array}$ & Mouse & $\begin{array}{l}\text { Intraperitoneal administration of } \\
\text { chemoconvulsant }\end{array}$ & No & No & n.a. & High \\
\hline $\begin{array}{l}\text { Allylglycine-induced } \\
\text { seizures }\end{array}$ & $\begin{array}{l}\text { Zebrafish } \\
\text { larvae }\end{array}$ & Bath application of chemoconvulsant & No & No & n.a. & Very high \\
\hline 6-Hz kindling & Mouse & Transcorneal electrical stimulation & Yes & No & No & Intermediate \\
\hline $\begin{array}{l}\text { Lamotrigine-resistant } \\
\text { kindled animals }\end{array}$ & Rat & $\begin{array}{l}\text { Repeated electrical stimulation of the } \\
\text { amygdala }\end{array}$ & Yes & No & No & Intermediate \\
\hline $\begin{array}{l}\text { Lamotrigine-resistant } \\
\text { kindled animals }\end{array}$ & Mouse & $\begin{array}{l}\text { Repeated electrical stimulation of the } \\
\text { amygdala }\end{array}$ & Yes & No & No & Intermediate \\
\hline $\begin{array}{l}\text { Intrahippocampal } \\
\text { kainate model }\end{array}$ & Mouse & Intracerebral injection of kainate & Yes & Yes & Yes & Intermediate \\
\hline Post-traumatic seizures & Rat & Fluid percussion injury & Yes & Yes & No & Low \\
\hline Cortical dysplasia model & Rat & $\begin{array}{l}\text { In utero exposure to methylazoxymethanol } \\
\text { acetate plus kainate exposure }\end{array}$ & Yes & No & No & Low \\
\hline Dravet models & Mice & Genetic modulation & Yes & Yes & No & Low \\
\hline $\begin{array}{l}\text { NMDA model of epileptic } \\
\text { spasms }\end{array}$ & $\begin{array}{c}\text { Rat } \\
\text { (immature) }\end{array}$ & $\begin{array}{l}\text { Intraperitoneal administration of } \\
\text { chemoconvulsant }\end{array}$ & No & No & No & High \\
\hline $\begin{array}{l}\text { Multiple-hit model of } \\
\text { infantile spasms }\end{array}$ & Rat & $\begin{array}{l}\text { PN3 unilateral i.c.v. doxorubicin and } \\
\text { intracortical lipopolysaccharide plus PN5 } \\
\text { intraperitoneal p-chlorophenylalanine } \\
\text { ( } \rightarrow \text { increases spasm frequency) }\end{array}$ & Yes & Yes & No & Low \\
\hline $\begin{array}{l}\text { Phenytoin-selected } \\
\text { kindled animals }\end{array}$ & Rat & $\begin{array}{l}\text { Repeated electrical stimulation of the } \\
\text { amygdala }\end{array}$ & Yes & No & Yes & Low \\
\hline $\begin{array}{l}\text { Phenobarbital-selected } \\
\text { animals with } \\
\text { spontaneous seizures }\end{array}$ & Rat & $\begin{array}{l}\text { Prolonged electrical stimulation of } \\
\text { amygdala induction of a status } \\
\text { epilepticus }\end{array}$ & Yes & Yes & Yes & Low \\
\hline $\begin{array}{l}\text { Canine patients with } \\
\text { DRE }\end{array}$ & Dog & $\begin{array}{l}\text { Natural disease (structural or idiopathic } \\
\text { according to IVETF guidelines) }\end{array}$ & Yes & Yes & $\begin{array}{l}\text { Yes (based on } \\
\text { clinical response) }\end{array}$ & Very low \\
\hline
\end{tabular}

i.c.v., intracerebroventricular; IVETF, International Veterinary Epilepsy Task Force; n.a., not applicable; PN, postnatal day.

efficacy but are not likely to discover new compounds with higher efficacy against DRE. In the following, we will focus on a subset of preclinical seizure or epilepsy models that exhibit poor responsiveness to standard ASDs.

The mouse $6-\mathrm{Hz}$ model was first described by Brown et al. (1953). In this acute seizure model, a low frequency $(6 \mathrm{~Hz})$ and long duration (3 seconds) corneal stimulation triggers a minimal clonic seizure with forelimb clonus and twitching of vibrissae and subsequent stereotyped behavioral patterns (Brown et al., 1953; Barton et al., 2001). Early pharmacological studies demonstrated a response to phenobarbital, phenurone, mebaral, mesantoin, trimethadione, and paradione with acute transcorneal electrical stimulation (Brown et al., 1953). In contrast, the hydantoins phenytoin and thiantoin remained without a relevant effect on ictogenesis in this model (Brown et al., 1953). Because of the lack of phenytoin sensitivity, the paradigm was discarded shortly after its first description by Brown et al. (1953).

The fact that a relevant percentage of patients did not respond to standard ASDs including phenytoin and carbamazepine resulted in increasing efforts to develop screening programs aiming to select ASDs with superior efficacy. In this context, the $6-\mathrm{Hz}$ model has been reactivated in 2001 (Barton et al., 2001). Barton et al. (2001) demonstrated that the effects of ASDs depend on the stimulation strength. At a high stimulation strength of $44 \mathrm{~mA}$, only levetiracetam and valproate exerted relevant anticonvulsant effects, whereas a series of other ASDs failed to protect from seizure induction (Barton et al., 2001). Interestingly, an unexpected variation in potency of drugs became evident when different mouse strains were compared in the $6-\mathrm{Hz}$ model. Despite the lack of relevant pharmacokinetic differences, the responsiveness of NMRI (Naval Medical Research Institute) mice to levetiracetam and phenytoin exceeded that of $\mathrm{C} 57 \mathrm{Bl} / 6 \mathrm{~J}$ mice (Leclercq and Kaminski, 2015). These findings suggest that strain comparisons may provide information about the molecular mechanisms of differences in pharmacodynamics and drug resistance. Based on these data and its ease of use, it was decided to implement the mouse $6-\mathrm{Hz}$ model (in CF-1 [Carworth Farms] mice) as an early screening tool and "high-hurdle" seizure assay in the identification phase of the pharmacoresistant epilepsy workflow of the ETSP (Kehne et al., 2017; Löscher, 2017a) (Fig. 2).

Recently, it has been suggested that a rat $6-\mathrm{Hz}$ paradigm might serve as an alternate model (Metcalf et al., 2017). The availability of a comparable model in a different species can be of particular relevance considering species differences in pharmacodynamics and pharmacokinetics. Moreover, the rat $6-\mathrm{Hz}$ screening model can provide important guidance for dose selection and study design for subsequent drug candidate 


\section{ETSP Flow Chart for Refractory Epilepsy}

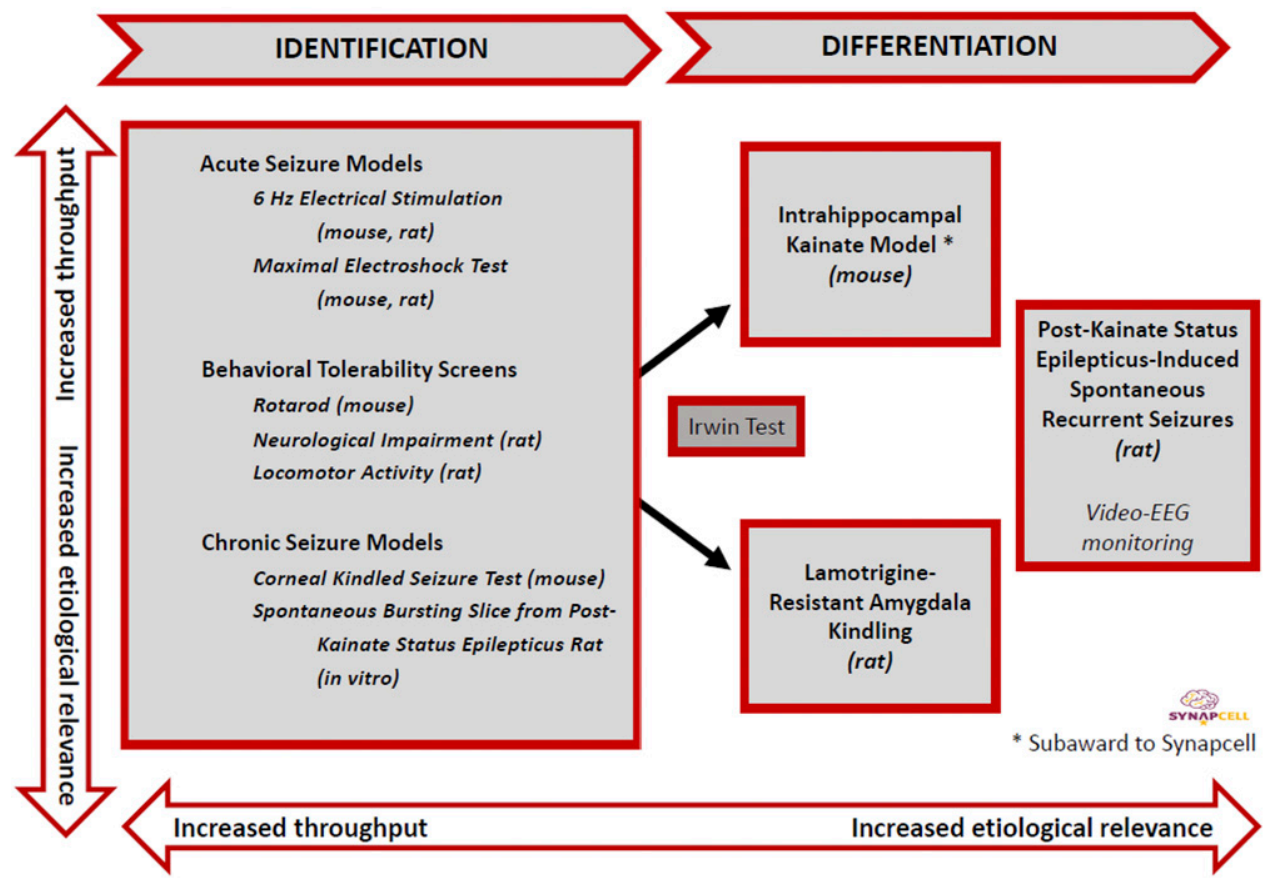

Fig. 2. Pharmacoresistant epilepsy workflow for the Epilepsy Therapy Screening Program (ETSP). The figure has been provided by John Kehne and slightly modified for consistency with the text of this review. For details, see text and Kehne et al. (2017) and Wilcox et al. (2020).

assessment in chronic rat models. With head nodding, jaw clonus, and forelimb clonus, behavioral seizure patterns proved to be comparable to "psychomotor" seizures described in the mouse model (Metcalf et al., 2017). Metcalf et al. (2017) assessed the efficacy of 16 standard ASDs in this new rat seizure model. At the highest stimulus intensity, i.e., twice the convulsive current that elicits seizures in $97 \%$ of the rats, compounds that were effective with a protective index $>1$ comprised ezogabine, phenobarbital, and sodium valproate (Metcalf et al., 2017).

As an alternate to electrical seizure induction, the administration of chemoconvulsants has always been a mainstay of seizure model generation. However, the fact that chemoconvulsants induce seizures by interfering with different neurotransmitter systems (e.g., GABA, glutamate, glycine) will necessarily lead to different efficacy of drugs against chemoconvulsantinduced seizures, depending on the mechanism of action of the drug and the chemoconvulsant to be tested. For instance, allylglycine modulates GABAergic neurotransmission by weak inhibition of glutamate decarboxylase, resulting in the induction of electrographic and behavioral seizure events (Leclercq et al., 2015). Leclercq et al. (2015) compared the pharmacoresponsiveness of allylglycine-induced seizures in mice and larval zebrafish. While diazepam and valproate protected against chemically induced seizures, levetiracetam, phenytoin, and topiramate exhibited only a limited protective effect (Leclercq et al., 2015). The fact that the cross-species validation indicated a comparable responsiveness profile of the allylglycine model in zebrafish led the authors to conclude that the zebrafish model might serve as a high-throughput model of treatment-resistant seizures (Leclercq et al., 2015).

In contrast to acute seizure models, chronic rodent models may better reflect the situation following epilepsy manifestation with a multitude of molecular, cellular, and network alterations. Kindling paradigms are based on repeated seizure induction resulting in a progressively increasing seizure severity and duration and a persistent lowering of seizure threshold. Repeated $50-\mathrm{Hz}$ corneal stimulations in mice resulted in a fully kindled state with a good responsiveness to most of the ASDs tested in this paradigm (Matagne and Klitgaard, 1998; Rowley and White, 2010). As these data indicated that the model provides a sensitive screening tool, the paradigm has been integrated in the identification phase of the ETSP (Fig. 2).

In this context, it of interest that Leclercq et al. (2014) addressed the hypothesis that a corneal kindling paradigm with twice daily $6-\mathrm{Hz}$ stimulations (3 seconds, 44 $\mathrm{mA}$ ) in mice may provide a better tool concerning robustness and responsiveness. The authors reported a kindling progression with seizure activity evolving in severity and duration in response to repeated stimulations, finally resulting in a reproducible induction of generalized seizure activity (Leclercq et al., 2014). A direct comparison with a traditional $50-\mathrm{Hz}$ corneal kindling paradigm revealed that the $6-\mathrm{Hz}$ model proved to be advantageous regarding the persistence of the kindled state (Leclercq et al., 2014). Moreover, the ASDs 
clonazepam, valproate, carbamazepine, and levetiracetam all showed a relatively lower potency in the $6-\mathrm{Hz}$ than the $50-\mathrm{Hz}$ kindling paradigm (Leclercq et al., 2014). Thus, as concluded by the authors, the new $6-\mathrm{Hz}$ corneal kindling model may serve as a new tool for selection of ASDs targeting DRE (Leclercq et al., 2014). Considering the relevance of chronic models for the selection process of new drug candidates, it has been decided to additionally implement further chronic models in the differentiation phase of the ETSP (Fig. 2).

The lamotrigine-resistant kindling model in rats was first described by Postma et al. (2000). In this paradigm, exposure to lamotrigine during kindling acquisition with repeated electrical stimulations of the amygdala results in a fully kindled state characterized by a poor drug responsiveness to lamotrigine and some other ASDs (Postma et al., 2000; Srivastava et al., 2013). Interestingly, ASD resistance in this model proved to extend from lamotrigine to carbamazepine, phenytoin, and topiramate (Postma et al., 2000; Srivastava et al., 2013). In contrast, valproate exerted potent anticonvulsant effects in lamotrigine-resistant kindled rats. More recently, Metcalf et al. (2019) described the dose response effects of numerous ASDs in this model. Five sodium channel blockers (eslicarbazepine, lacosamide, lamotrigine, phenytoin, and rufinamide) were either not efficacious or effective only at doses that were not well-tolerated in this model. Similarly, topiramate and levetiracetam were not effective at the doses tested, indicating that pharmacoresistance is not limited to sodium channel blockers. In contrast, compounds targeting either GABA receptors (clobazam, clonazepam, phenobarbital) or GABA-uptake proteins (tiagabine) produced dose-dependent efficacy against convulsive seizures. Similarly, ezogabine and valproate were also highly effective. Compounds acting to modulate $\mathrm{Ca}^{2+}$ channels (ethosuximide, gabapentin) showed differential activity. Taking into account that ASD exposure in combination with seizure elicitation results in the poor responsiveness of lamotrigine-resistant kindled rats, the failure of these animals to respond to selected ASDs may also reflect contingent or cross-tolerance.

More recently, efforts have been made to establish and characterize a comparable model in mice (Koneval et al., 2018). Therefore, the rat protocol was adapted to the $60-\mathrm{Hz}$ corneal-kindling mouse model. Lamotrigine exposure during the kindling phase did not affect kindling progression (Koneval et al., 2018). However, fully kindled mice failed to respond to lamotrigine, carbamazepine, retigabine, and valproate (Koneval et al., 2018). Interestingly, drug resistance in these kindled mice proved to be associated with more pronounced kindling-associated behavioral alterations with increased hyperexcitability and anxiety-associated behavior (Koneval et al., 2018). The paradigm has been suggested as a moderate-throughput platform, which can be applied for early compound selection (Koneval et al., 2018).
Seizures in kindling paradigms are elicited by repeated electrical or chemical stimulation. This approach allows a precise determination of an impact of a test compound on seizure threshold and seizure characteristics at threshold stimulation. Spontaneous seizures only occur following several weeks to months of repeated stimulation, thus rendering it impractical to study drug effects on generation of spontaneous seizures in kindling paradigms. This is in contrast to postSE models, in which electrical or chemical induction of SE results in the manifestation of epilepsy with spontaneous recurrent seizures. One of the available models is standing out with a high nonconvulsive seizure frequency, which renders the model suitable for rapid screening of ASD candidates. The model is induced by intrahippocampal kainate injection in mice, which results in a limbic SE followed by the development of spontaneous recurrent electrographic and electroclinical seizures. Though generalized convulsive seizures occur occasionally in this model, nonconvulsive electrographic seizures recorded in the Cornu Ammonis sector 1 (CA1) region typically occur multiple times per hour (Lévesque and Avoli, 2013; Löscher, 2016). Pharmacoresponsiveness of the paradigm has been intensely studied. Riban et al. (2002) reported a resistance of electrographic seizures to different ASDs, including phenytoin, carbamazepine, and valproate. Further support for a poor drug responsiveness of focal electrographic seizures in the intrahippocamal kainate model of mesial temporal lobe epilepsy (TLE) came from a recent comprehensive study, which confirmed resistance to phenytoin and carbamazepine (Klein et al., 2015). Although the group observed only moderate effects of valproate and phenytoin, they demonstrated a relevant response to phenobarbital and diazepam (Klein et al., 2015). In line with these studies, Duveau et al. (2016) reported that valproate, carbamazepine, and lamotrigine suppressed electrographic seizures only at high doses that were associated with adverse effects, such as drowsiness and reduced locomotion, whereas levetiracetam, pregabaline, tiagabine, vigabatrin, diazepam, and phenobarbital all suppressed the seizures at doses that were not associated with obvious adverse effects. As described in more detail below, the study by Klein et al. (2015) also revealed pronounced interindividual differences in the effects of ASDs in this paradigm.

Considering the efforts to develop precision medicine approaches tailored to the etiology and pathogenesis of the epilepsy (see section V. B. Precision Medicine), it is of interest to characterize epilepsy models with different constructive validity. There are numerous rodent epilepsy models reflecting different types of etiopathogenesis in human patients. However, the drug responsiveness and predictive validity of the majority of these paradigms has so far been only poorly characterized with a focus on single or selected ASDs. 
In a rat fluid percussion model of head injury with posttraumatic development of spontaneous seizures, carisbamate exerted only limited and transient anticonvulsant effects (Eastman et al., 2011). The fact that this finding is rather in line with the compound's limited efficacy in patients with drug-resistant TLE and in contrast with the broad spectrum anticonvulsant activity in conventional ASD screening tests resulted in the authors' conclusion that the paradigm may serve as a valuable model of DRE for preclinical drug development (Eastman et al., 2011).

In utero exposure of rats to methylazoxymethanol acetate (MAM) causes cortical molecular and cellular alterations reflecting pathologic hallmarks of cortical dysplasia (Smyth et al., 2002). In hippocampal slices from MAM-exposed rats, 4-aminopyridine-induced epileptiform bursts proved to be resistant to high concentrations of valproate, ethosuximide, and lamotrigine (Smyth et al., 2002). Moreover, seizure activity triggered in MAM-exposed rats by kainate administration failed to respond to valproate (Smyth et al., 2002).

As recently reviewed by Griffin et al. (2018), different ASDs have been assessed in genetic zebrafish and mouse models of Dravet syndrome. The pharmacological profile in scn1la $b^{\mathrm{s5} 52}$ zebrafish larvae indicated a response to ASDs currently recommended for patients with Dravet syndrome (Griffin et al., 2018). Moreover, ASDs, which are not recommended or are considered contraindicated in Dravet syndrome patients with lossof-function mutations in SCN1A, failed to exert relevant effects in scn1la $b^{\text {s552 }}$ zebrafish larvae (Griffin et al., 2018). At the first glimpse, this profile might suggest a perfect predictive validity of the model. However, the model does not seem to reflect the high rate of drug resistance of the Dravet syndrome. In mouse models of Dravet syndrome, spontaneous seizures proved to be difficult to suppress, and hyperthermia-induced seizures exhibited a pharmacological profile that is not completely consistent with efficacy profiles in Dravet patients (Griffin et al., 2018).

In models of infantile spasms, preclinical drug testing has been performed with administration prior to acute induction of seizures or in chronic multiple-hit models (Galanopoulou and Moshé, 2015). As comprehensively reviewed by Galanopoulou and Moshé (2015), several studies indicate a poor response to ASDs, suggesting that some of the experimental paradigms might be valuable tools to identify drugs with superior efficacy to currently recommended ASDs. Unfortunately, the need for elaborate seizure monitoring approaches limits the throughput of models with spontaneous seizures. Therefore, efforts have been made to establish seizure threshold determination in the chronic phase of a postSE model with development of spontaneous seizures and lowered threshold following exposure to the chemoconvulsant pilocarpine (Blanco et al., 2009; Bankstahl et al., 2013; Leclercq and Kaminski, 2015; Löscher, 2017b). The authors reported that electrical or chemical induction of seizures in these animals can provide reliable information about ASD responses.

\section{Rodent Models with Selection of Responder and Nonresponder Subgroups}

Taking into account that patient populations exhibit a heterogenous ASD responsiveness, animal models with interindividual differences in drug responses may provide a more realistic picture of efficacy. As further discussed below, the comparison between responder and nonresponder subgroups can provide valuable information about mechanisms of drug resistance. In addition, such paradigms can guide the identification of biomarkers of drug resistance [reviewed by Koepp (2014), Koepp et al. (2017)]. Although the models may be applied for assessment of preselected drug candidates, they are not suitable for early drug screening purposes because of their elaborate nature with timeconsuming procedures to select responders and nonresponder animals (Löscher, 2016).

The concept of selecting subgroups with divergent responsiveness to standard ASDs has been developed by Löscher et al. (1993), with early studies focused on the rat amygdala-kindling model. Allocation of animals to subgroups was based on repeated testing of maximum tolerated doses of the ASD phenytoin (Löscher et al., 1993). A retrospective analysis of a series of studies revealed that about $16 \%$ of kindled rats exhibit a reproducible response to phenytoin or its prodrug fosphenytoin and can thus be categorized as responders (Löscher, 2016). In contrast, about $61 \%$ and $23 \%$ show a variable response or no relevant response, respectively (Löscher, 2016). These animals are referred to as variable responders and nonresponders. A failure to respond to an ASD can be related to pharmacokinetic aspects such as rapid metabolization and excretion. Thus, it was of utmost relevance to assess the plasma concentrations at the time of drug testing in responder and nonresponder rats. The fact that plasma concentrations proved to be in a comparable range in all subgroups strongly argued against pharmacokinetic differences (Löscher et al., 1993).

In a series of follow-up studies, the value of the paradigm as a DRE model received further support. Comparative assessment of different standard ASDs in phenytoin responders and nonresponders demonstrated either a reduced efficacy or no effect for all examined ASDs except for levetiracetam (Löscher, 2016).

A successful selection procedure resulting in the identification of responders and nonresponders has also been reported with repeated valproate testing in fully amygdala-kindled rats (Töllner et al., 2011). These findings suggest that the general approach allows studying resistance mechanisms specific for a selected ASD. The promising findings in the kindling paradigm motivated efforts to test selection of ASD responders 
and nonresponders in an electrical post-SE model with development of spontaneous recurrent seizures (Brandt et al., 2004). Rats with spontaneous seizures were selected based on their responsiveness to prolonged phenobarbital exposure. Therefore, drug efficacy was evaluated based on a 2 -week video/electroencephalogram seizure-monitoring phase in comparison with preand/or postdrug monitoring data (Brandt et al., 2004). Animals, which exhibited an at least $50 \%$ or $75 \%$ reduction in seizure frequency, were considered phenobarbital responders. Groups of responders and nonresponders did not differ with regard to phenobarbital plasma concentrations or adverse effects of phenobarbital (Brandt et al., 2004). These findings indicated that the interindividual variation in drug responsiveness are neither related to differences in drug distribution to the brain nor to differences in drug metabolism and excretion. The success of the selection procedure proved to be reproducible in internal and external follow-up studies (Löscher, 2016). Interestingly, exposure to other ASDs revealed that the majority of phenobarbital nonresponders also do not respond to phenytoin (Bethmann et al., 2007).

In subsequent experiments, it was shown that ASD responders and nonresponders can also be selected in the rat pilocarpine model of TLE (Bankstahl et al., 2012). In epileptic rats of this model, 50\% did not adequately respond to prolonged treatment with phenobarbital, whereas this ASD significantly decreased seizure frequency and severity in another $50 \%$ of the animals. Responders and nonresponders did not differ in predrug seizure frequency, drug plasma levels, or hippocampal neurodegeneration, but behavioral differences were observed in anxiety models.

As already mentioned above, interindividual variation in the effect of ASDs has also been described in the intrahippocampal kainate model in mice (Klein et al., 2015). ASD responders and nonresponders were identified with exposure of mice to diazepam, levetiracetam, phenobarbital, phenytoin, and valproate (Klein et al., 2015). When using $>75 \%$ decrease in seizure frequency as criterion for response, the highest number of responders was observed with diazepam and phenobarbital, whereas only few responders were observed with valproate and phenytoin and no responder with carbamazepine. With levetiracetam, $30 \%$ and $60 \%$ of the epileptic mice responded to doses of 400 and $800 \mathrm{mg} / \mathrm{kg}$, respectively. In the majority of nonresponders to the different ASDs, resistance proved to extend to one or more other ASDs (Klein et al., 2015).

\section{Dogs with Spontaneous Seizures}

As species differences in pharmacokinetics and pharmacodynamics need to be considered as confounding factors in preclinical drug testing, assessment in different species can be of particular relevance for preclinical efficacy testing. Moreover, the high level of standardization in animal facilities and in the design of preclinical studies in laboratory animals can contribute to a poor reproducibility and limited translation of preclinical findings to clinical application (Richter et al., 2009). Though multilaboratory designs and intentional heterogenization of experimental conditions can improve the accuracy of effect size estimates, robustness, and predictive validity (Richter et al., 2009; Voelkl et al., 2018), testing in veterinary patients has been discussed as an alternate option (Potschka et al., 2013; Löscher, 2016). Epilepsy is a frequent disorder in dogs, with an estimated prevalence of $0.6 \%-0.75 \%$ in the canine population (Berendt et al., 2015). Studies in canine patients with DRE have been discussed for identification of biomarkers and assessment of the efficacy of novel therapeutic strategies (Potschka et al., 2013; Löscher, 2016). Although ethical approval and enrollment of patients is often easier to achieve for veterinary studies compared with clinical trials in humans, the expenditure of time and complexity of a veterinary clinical trial with enrollment according to inclusion and exclusion criteria and with sequential clinical visits and examinations should not be underestimated. Thus, testing of drug candidates in canine DRE is not suitable for screening purposes and can only be considered for promising preselected compounds. Further major limitations need to be taken into account, including the uncertainties related to owner-based monitoring and reporting and the tendency for rapid compound excretion in dogs.

\section{E. In Vitro Models}

In line with the principles of the $3 \mathrm{R}$ concept (replace, reduce, refine in vivo models), efforts have been made to develop and validate in vitro models of DRE. Respective models can serve as valuable tools to study selected mechanisms of drug resistance. Moreover, the models can be applied for screening purposes during early drug development. However, considering the complexity of drug-resistance mechanisms, limitations of in vitro models need to be kept in mind. In particular, the fact that one can only study part of the epileptic network with preparation of selected brain regions and that the function of the blood-brain barrier (BBB) is compromised as a consequence of the preparation procedure should be taken into account when drawing conclusions. These limitations imply that in vitro models can serve as a screening tool but cannot fully replace in vivo studies.

Interestingly, the responsiveness of chemically induced epileptiform activity in brain slice preparations largely depends on the type of the convulsive trigger. Though exposure to low-Ca ${ }^{2+} /$ high- $\mathrm{K}^{+}$results in epileptiform discharges responding well to available ASDs, discharges and seizure-like events triggered by prolonged low- $\mathrm{Mg}^{2+}$ or 4-aminopyridine exposure failed to be controlled by ASDs, including phenytoin, carbamazepine, and valproate (Wahab et al., 2010; Kovács and 
Heinemann, 2014). The responsiveness can be further reduced by combining low- $\mathrm{Mg}^{2+}$ with bicuculline exposure, resulting in immediate resistance (Wahab et al., 2010; Kovacs and Heinemann, 2014). Hippocampal and combined entorhinal cortex-hippocamal slice preparations from adult or juvenile rats have been used for these studies.

Comparable approaches using high- $\mathrm{K}^{+}$, low- $\mathrm{Mg}^{2+}$ with or without picrotoxin or bicucullin as a convulsive trigger have also been applied to brain slice preparations from chronic epileptic rodents or from epilepsy patients (Kovacs and Heinemann, 2014; Doeser et al., 2015). Tissue from these preparations is characterized by epilepsy-associated molecular and cellular alterations. Therefore, studies in tissue from epileptic animals and patients may provide more meaningful results. In this respect, a recent study by West et al. (2018) is of interest, in which the effect of 20 ASDs on recurrent epileptiform discharges (REDs) in entorhinal cortex slices derived from epileptic rats of the kainate model of TLE were examined. ASDs targeting sodium and potassium channels (carbamazepine, eslicarbazepine, ezogabine, lamotrigine, lacosamide, phenytoin, and rufinamide) attenuated REDs at concentrations near their average therapeutic plasma concentrations. ASDs modulating GABAergic synaptic transmission (clobazam, midazolam, phenobarbital, stiripentol, tiagabine, and vigabatrin) attenuated REDs only at higher concentrations and, in some cases, prolonged RED durations. ASDs (and other drugs) with other/mixed mechanisms of action (bumetanide, ethosuximide, felbamate, gabapentin, levetiracetam, topiramate, and valproate) and glutamate receptor antagonists weakly or incompletely inhibited RED frequency, increased RED duration, or had no significant effects. The authors suggested that the different sensitivities of REDs to these ASDs may reflect persistent molecular, cellular, and/or network-level changes resulting from disease (West et al., 2018). This in vitro model has been added to the ETSP flowchart for refractory epilepsy (Fig. 2).

Selected mechanisms of DRE can be studied in less complex in vitro or ex vivo setups such as dissociated hippocampal neurons or brain capillaries (e.g., Remy and Beck, 2006; Löscher et al., 2011; Avemary et al., 2013). Moreover, patient-derived induced pluripotent stem cells (iPSCs) provide an elegant basis to develop and analyze precision medicine approaches targeting specific genetic deficiencies. As reviewed recently by Lybrand et al. (2019), different imaging-based, electrophysiological, and molecular assays can be applied to patient-derived iPSCs exploring the impact of drug candidates on cell morphology and viability, neuronal hyperexcitability, and gene expression. Thus, options have become available to apply drug screening in a patient-specific manner. In genetic epilepsies, respective studies will provide valuable information about the responsiveness of cells from patients with different types of mutations.
In addition, the fact that patient-derived iPSCs can be differentiated to generate multiple cell types opens up opportunities to explore the role of both neuronal and non-neuronal cells in DRE (Lybrand et al., 2019). Development of three-dimensional organoid structures from iPSCSs provides a basis to study neuronal network function and its modulation (Lybrand et al., 2019).

\section{Current Hypotheses of Mechanisms of Drug Resistance}

The mechanisms of drug resistance are likely to be variable and multifactorial according to the underlying cause of DRE and, in theory, to the drug's site of action (Kwan et al., 2011). As it has occurred in oncology, studying the basis of DRE is important to predict poor response to ASD treatment and hopefully offer new treatment approaches (Margineanu and Klitgaard, 2009; Dalic and Cook, 2016; Tang et al., 2017). However, in view of the likely possibility that several of the mechanisms outlined in the following could act together and possibly even interact in an individual patient or a group of patients (Löscher and Schmidt, 2016), overcoming drug resistance remains a challenge.

Mechanistic hypotheses of drug resistance can be broadly categorized into three groups (Fig. 3), i.e., disease-related mechanisms, drug-related mechanisms, and genetic mechanisms, which may be interlinked. Among the various mechanisms that have been proposed (Fig. 3), the target hypothesis and transporter hypothesis are the most deeply explored theories of ASD resistance, but neither can fully explain the neurobiological basis of this phenomenon (Schmidt and Löscher,

Potential mechanisms of drug resistance in epilepsy

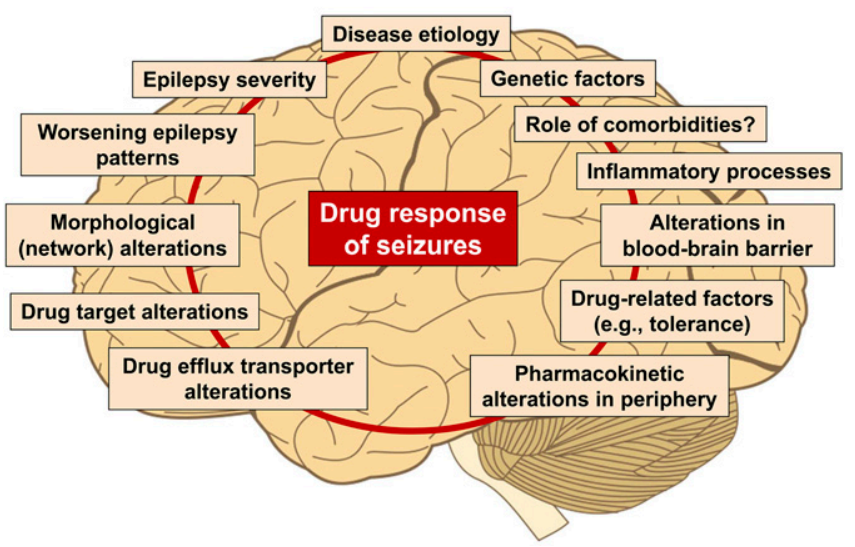

Fig. 3. Various potential mechanisms of ASD resistance or factors predicting poor outcome have been implicated in patients with epilepsy and animal models of medically resistant seizures, indicating that intrinsic or acquired resistance to ASDs is a multifactorial phenomenon. Based on these findings, a number of hypotheses of ASD resistance, including the target, transporter, network, intrinsic severity, and genetic variant hypotheses, have been suggested (see text). These hypotheses are not mutually exclusive but may be relevant for the same patient, thus complicating any strategy to counteract or reverse pharmacoresistance. Modified from Löscher et al. (2013a). 
TABLE 3

Proof-of-concept of drug resistance hypotheses

As suggested by Sisodiya (2003), at least four criteria must be satisfied for a proposed drug-resistance mechanism of epilepsy to be accepted; the mechanism must 1) be

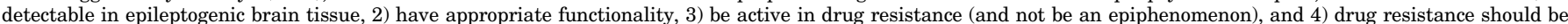

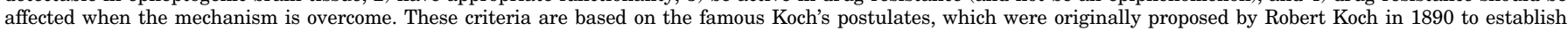
a causal relationship between a bacterium and a disease.

\begin{tabular}{|c|c|c|c|c|}
\hline Drug-resistance hypothesis in epilepsy & $\begin{array}{l}\text { Detectable in brain (or peripheral) } \\
\text { tissues of nonresponders }\end{array}$ & Appropriate functionality & Active in ASD resistance & $\begin{array}{l}\text { Resistance reversed when } \\
\text { mechanism is overcome }\end{array}$ \\
\hline \multirow[t]{2}{*}{ Target hypothesis } & $+($ rat $)$ & $+($ rat $)$ & ? (rat) & ? (rat) \\
\hline & + (human) & + (human) & ? (human) & ? (human) \\
\hline \multirow[t]{2}{*}{ Transporter hypothesis } & $+($ rat $)$ & $+($ rat $)$ & $+($ rat $)$ & $+($ rat $)$ \\
\hline & + (human) & + (human) & + (human) & ? (human) \\
\hline \multirow[t]{2}{*}{ Pharmacokinetic hypothesis } & - (rat) & - (rat) & ? (rat) & $?$ (rat) \\
\hline & + (human) & ? (human) & ? (human) & ? (human) \\
\hline \multirow[t]{2}{*}{ Neural network hypothesis } & $+($ rat $)$ & ? (rat) & ? (rat) & ? (rat) \\
\hline & + (human) & ? (human) & ? (human) & + (human) \\
\hline \multirow[t]{2}{*}{ Intrinsic severity hypothesis } & $+(\mathrm{rat})^{a}$ & ? (rat) & ? (rat) & ? (rat) \\
\hline & $+(\text { human })^{a}$ & ? (human) & ? (human) & ? (human) \\
\hline \multirow[t]{2}{*}{ Gene variant hypothesis } & $+($ rat $)$ & $+($ rat $)$ & ? (rat) & ? (rat) \\
\hline & + (human) & + (human) & +/? (human) & +/? (human) \\
\hline \multirow[t]{2}{*}{ Epigenetic hypothesis } & $+($ rat/mouse $)$ & $+/ ?($ rat/mouse $)$ & $+/ ?($ rat/mouse $)$ & $+/ ?($ rat/mouse $)$ \\
\hline & + (human) & ? (human) & ? (human) & ? (human) \\
\hline \multirow[t]{2}{*}{ Neuroinflammation/blood-brain barrier } & $+($ rat, mouse $)$ & + (rat) & + (rat) & + (rat) \\
\hline & + (human) & ? (human) & ? (human) & ? (human) \\
\hline
\end{tabular}

${ }^{a}$ Increased seizure frequency/density compared with ASD responders.

2005; Kwan et al., 2011; Potschka, 2013; Löscher and preclinical and, more importantly, clinical evidence Schmidt, 2016; Tang et al., 2017). Although, several is quite limited (Table 3). One approach to identify alternative hypotheses have been proposed (Fig. 3), potential mechanisms of drug resistance in epilepsy has

\section{Cross-species similarities in factors that may be involved in resistance}

\section{Differences between ASD-nonresponders and -responders (rats)}

Phenytoin-resistant and -responsive kindled rats

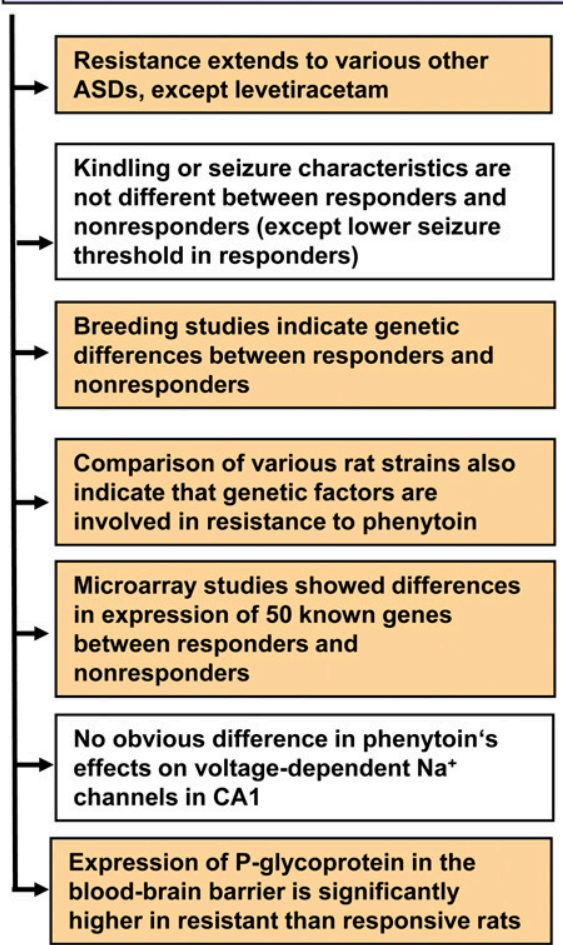

Phenobarbital-resistant and -responsive epileptic rats (BLA post-SE model)

Resistance extends to phenytoin

Average seizure frequency is higher in nonresponders before onset of ASD treatment

Behavioral and cognitive changes are more severe in ASD resistant rats

Hippocampal damage is only observed in resistant rats

Diazepam-insensitive $\mathrm{GABA}_{A}$ receptor binding in the dentate gyrus is significantly increased in resistant rats, indicating target alterations

Complex alterations in the expression of $\mathrm{GABA}_{A}$ receptor subunits are observed In the hippocampal formation of resistant rats

Expression of P-glycoprotein in the blood-brain barrier is significantly higher in resistant than responsive rats

\section{Comparable alterations in patients with refractory temporal lobe epilepsy}

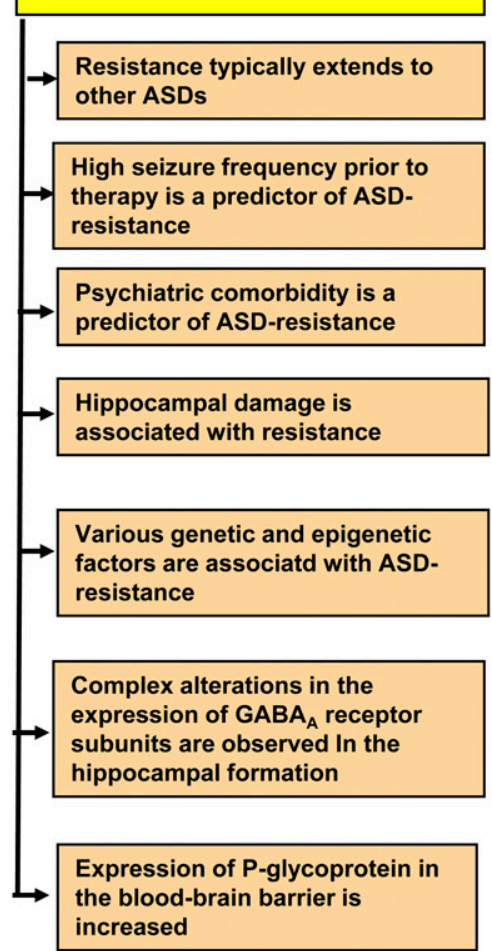

Fig. 4. Differences between ASD responders and nonresponders in two animal models of DRE. For comparison, alterations associated with ASD resistance in patients are shown. Those alterations that occur both in the models and in patients are highlighted by the colored boxes. For details, see Löscher (2011), Löscher et al. (2013a), and Löscher (2016). 
been to develop rat models of TLE in which ASD responders and nonresponders can be selected, followed by mechanistic studies in the two subgroups (Löscher, 1997; Löscher, 2002; Potschka, 2013; Löscher, 2017c). Findings in such animal models and commonalities in patients with drug-resistant TLE are summarized in Fig. 4. In the following sections, the most prominent hypotheses of ASD-resistance mechanisms are discussed. It is interesting to note that some of these hypotheses, e.g., the transporter and gene variant hypotheses, are thought to also be relevant in other brain diseases, including brain cancer and depression (Löscher and Potschka, 2005; O’Brien et al., 2012; Brückl and Uhr, 2016).

\section{A. Alteration of Drug Targets in the Brain}

The "target hypothesis" postulates that acquired (epilepsy-induced) alterations to the structure and/or functionality of brain targets of ASDs lead to a reduction in their sensitivity to treatment (Remy and Beck, 2006). To exhibit antiseizure activity, a drug must act on one or more target molecules in the brain. As shown in Table 1, these targets include voltage-dependent ion channels, neurotransmitter receptors, and transporters or metabolic enzymes involved in the release, uptake, and metabolism of neurotransmitters (Rogawski et al., 2016). The target hypothesis is primarily based on studies with carbamazepine on voltage-gated sodium channels in hippocampal neurons. Remy et al. (2003a) showed that the use-dependent block of voltagedependent $\mathrm{Na}^{+}$channels of dentate granule cells by carbamazepine is completely lost in patients with carbamazepine-resistant TLE in comparison with patients clinically responsive to this ASD. In addition to the loss of use-dependent inhibition of $\mathrm{Na}^{+}$channels by carbamazepine, the fast recovery from inactivation of the fast $\mathrm{Na}^{+}$current was carbamazepine-insensitive in pharmacoresistant patients, whereas recovery was markedly slowed in cells from carbamazepineresponsive patients. Consistent with these data from patients with intractable TLE, Remy et al. (2003a) also showed that use-dependent block of $\mathrm{Na}^{+}$channels by carbamazepine in dentate granule cells is absent in the pilocarpine rat model of TLE. Based on these data, the authors suggested that a loss of $\mathrm{Na}^{+}$channel drug sensitivity could explain the development of DRE, which formed the core of the target hypothesis. In a subsequent study in the rat pilocarpine model of TLE, Remy et al. (2003b) demonstrated that the effects of phenytoin on fast recovery from inactivation of $\mathrm{Na}^{+}$channels of hippocampal granule neurons were significantly reduced, though not as pronounced as observed with carbamazepine, substantiating the concept that reduced pharmacosensitivity of $\mathrm{Na}^{+}$channels may contribute to the development of drug resistance. In contrast to carbamazepine and phenytoin, lamotrigine slowed the time course of recovery from fast inactivation both in epileptic and control rats without significant intergroup difference (Remy et al., 2003b). In the pilocarpine model, a loss of sensitivity of sodium channels to carbamazepine and phenytoin was also found in hippocampal CA1 neurons, although the loss of ASD sensitivity was less pronounced in CA1 neurons than in dentate granule neurons (Schaub et al., 2007). Thus, these results suggested that target mechanisms of drug resistance are cell type- and ASD-specific. More recently, Doeser et al. (2015) reported that eslicarbazepine may possess advantages over conventional $\mathrm{Na}^{+}$ channel modulators such as carbamazepine because it maintained activity in chronically epileptic tissue.

Which mechanisms can account for altered sensitivity of $\mathrm{Na}^{+}$channels in CA1 or dentate granule cells in epileptic tissue? One possibility is that the subunit composition of these channels is altered, resulting in channels with lower ASD sensitivity (Remy and Beck, 2006). Several changes in $\mathrm{Na}^{+}$subunit expression have been observed in both human and experimental epilepsy. For instance, in the pilocarpine model of TLE, the accessory $\beta 1$ and $\beta 2$ subunits were downregulated, which was suggested to play a role in the altered pharmacosensitivity of $\mathrm{Na}^{+}$channels (Ellerkmann et al., 2003). A critical question in studying target alterations in epilepsy is the relation of changes at the cellular level in vitro to ASD sensitivity in vivo. Although such a correlation has been observed in patients with TLE (Remy et al., 2003a; Jandová et al., 2006), such a correlative analysis has not been performed for the pilocarpine model of TLE, which has been used in most studies. Jeub et al. (2002) used the amygdala kindling model of TLE to study whether ASD responders and nonresponders differ in pharmacological sensitivity of voltage-dependent sodium channels (Jeub et al., 2002). Responders and nonresponders were selected by repeated testing with phenytoin in vivo, followed by evaluation of phenytoin's in vitro effects on voltage-gated $\mathrm{Na}^{+}$channels of hippocampal CA1 neurons isolated from the kindled subgroups (Fig. 4). The in vivo resistance to phenytoin was not associated with altered tonic block of $\mathrm{Na}^{+}$channels by phenytoin, but recovery from $\mathrm{Na}^{+}$channel inactivation and usedependent blocking effects were not analyzed in this study (Jeub et al., 2002). Although ASD responders and nonresponder can also be selected from the pilocarpine model (Bankstahl et al., 2012), these subgroups have not yet been analyzed with respect to alterations in ASD sensitivity of $\mathrm{Na}^{+}$channels or other ASD targets.

Apart from voltage-dependent $\mathrm{Na}^{+}$channels, other drug targets, such as $\mathrm{GABA}_{\mathrm{A}}$ receptors, may be altered in patients and animal models with intractable epilepsy. Using the rat pilocarpine model of TLE, BrooksKayal et al. (1998) demonstrated that expression of $\mathrm{GABA}_{\mathrm{A}}$ receptor subunit mRNAs is substantially altered in hippocampal dentate granule cells of pilocarpinetreated rats versus controls. These changes in $\mathrm{GABA}_{\mathrm{A}}$ 
receptor subunit expression correlated with profound alterations in receptor function and pharmacology (Coulter, 2000, 2001). In epileptic rats, expression of the $\alpha 1$ and $\beta 1$ subunits of the GABA $\mathrm{A}_{\mathrm{A}}$ receptor decreases and expression of $\alpha 4$ and $\delta$ subunits increases, leading to an assembly of $\mathrm{GABA}_{\mathrm{A}}$ receptors that are strikingly zinc-sensitive. In addition to the enhanced zinc sensitivity, GABA $A_{A}$ receptors from the epileptic hippocampus lose their sensitivity to augmentation by the benzodiazepine site modulator zolpidem. However, none of these studies examined whether ASD-resistant epileptic rats differ from responsive rats in these changes in $\mathrm{GABA}_{\mathrm{A}}$ receptor function.

Thus, subsequent studies examined whether ASDresistant epileptic rats differ from ASD responders in expression and pharmacological sensitivity of $\mathrm{GABA}_{\mathrm{A}}$ receptors, using a model in which epilepsy develops after sustained electrical stimulation of the basolateral amygdala, followed by responder/nonresponder selection with phenobarbital (Volk et al., 2006; Bethmann et al., 2008). As shown in Fig. 4, striking differences were found in phenobarbital-resistant epileptic rats when compared with responsive rats in autoradiographic imaging of diazepam-sensitive and diazepam-insensitive $\mathrm{GABA}_{\mathrm{A}}$ receptor binding in the dentate gyrus, with greater diazepam-insensitive binding in nonresponders (Volk et al., 2006). To address the hypothesis that diazepam-insensitive receptors contain the $\alpha 4$ and $\delta$ subunits that mediate tonic inhibition in the dentate gyrus, the expression of various $\mathrm{GABA}_{\mathrm{A}}$ receptor subunits was determined in ASD responders and nonresponders (Bethmann et al., 2008). In nonresponders, decreased expression of several subunits, including $\alpha 1$, $\beta 2 / 3$, and $\gamma 2$, was observed in CA1, CA2, CA3, and dentate gyrus, whereas much less widespread alterations were determined in responders. Furthermore, upregulation of the $\alpha 4$ subunit was observed in CA1 pyramidal cells of nonresponders. Phenobarbital's antiseizure effect is thought to be primarily related to enhancement of GABA-mediated inhibitory synaptic transmission via modulation of $\mathrm{GABA}_{\mathrm{A}}$ receptors (Löscher and Rogawski, 2012). Although the effects of barbiturates on the $\mathrm{GABA}_{\mathrm{A}}$ receptor depend largely on the $\beta$ subunit, their agonist activity is substantially influenced by the $\alpha$-subunit subtype. The marked decreases in $\beta$ and $\alpha$ subunits observed in phenobarbital nonresponders are likely to reduce the effect of phenobarbital on $\mathrm{GABA}_{\mathrm{A}}$ receptors and thus could be involved in the lack of antiseizure efficacy of phenobarbital in these animals. Profound alterations in $\mathrm{GABA}_{\mathrm{A}}$ receptor subtype expression have also been reported in adult patients with ASD-resistant TLE and pediatric epilepsy patients undergoing epilepsy surgery (Loup et al., 2000; Pirker et al., 2003; Porter et al., 2005).

Further evidence that changes in $\mathrm{GABA}_{\mathrm{A}}$ receptors can lead to ASD resistance came from studies in the pilocarpine model, showing that internalization of $\mathrm{GABA}_{\mathrm{A}}$ receptors, i.e., trafficking of these receptors from the synaptic membrane to submembranous compartments, causes a decrease in the number of functional postsynaptic $\mathrm{GABA}_{\mathrm{A}}$ receptors that could explain the pharmacoresistance to ASDs that act via the $\mathrm{GABA}_{\mathrm{A}}$ receptor (Goodkin et al., 2005; Naylor et al., 2005). Apart from alterations in $\mathrm{GABA}_{\mathrm{A}}$ receptor subunit expression and receptor trafficking, a third potential mechanism to explain loss of pharmacological sensitivity of these receptors is a shift from adult hyperpolarizing (inhibitory) to neonatal depolarizing (excitatory) $\mathrm{GABA}_{\mathrm{A}}$ receptors during epileptogenesis (Ben-Ari et al., 2012). Such a shift in GABAergic response polarity from hyperpolarizing to depolarizing was first described in human epileptic neurons recorded in the subiculum of hippocampal slices obtained from resections in adult patients suffering from mesial TLE (Cohen et al., 2002). This shift is thought to be a result of increased intraneuronal $\mathrm{Cl}^{-}$levels caused by increased neuronal expression of NKCC1, an inwardly directed $\mathrm{Na}^{+} \mathrm{K}^{+}$ $2 \mathrm{Cl}^{-}$cotransporter that facilitates the accumulation of intracellular $\mathrm{Cl}^{-}$, and downregulation of $\mathrm{KCC} 2$, an outwardly directed $\mathrm{K}^{+} \mathrm{Cl}^{-}$cotransporter (Ben-Ari et al., 2012). Upregulation of NKCC1 and downregulation of KCC2 in the hippocampus have been described both in patients with TLE and the kindling and pilocarpine models of TLE (Löscher et al., 2013b). Furthermore, the GABA shift is thought to be involved in the resistance of neonatal seizures to GABAmimetic ASDs such as phenobarbital and benzodiazepines (Puskarjov et al., 2014). Inhibition of NKCC1 by bumetanide has been proposed as a strategy for overcoming ASD resistance in neonates (Kahle et al., 2008); however, a clinical trial with bumetanide as an add-on to phenobarbital for treatment of neonatal seizures did not support this proposal (Pressler et al., 2015).

As a proof-of-principle for the target hypothesis, it will be important to demonstrate that ASD-resistant subgroups of patients differ from ASD-responsive subgroups in their ASD-target sensitivity. Such a proof-ofprinciple is difficult to obtain because, in contrast to patients with intractable epilepsy, patients responding to ASDs in general do not undergo surgical treatment of their epilepsy. Although Remy et al. (2003a) obtained surgical "reference" specimens from two patients who responded well to treatment with carbamazepine for comparison with 10 patients with carbamazepineresistant TLE, differences in age, gender, history of epilepsy and ASD treatment, and various other variables could bias this comparison. As illustrated by our previous studies, animal models of TLE that permit the selection of age-matched ASD responders and nonresponders could be useful in further evaluating the target hypothesis. Furthermore, mechanisms leading to target changes (transcriptional or posttranslational or both, role of seizures and cell loss, etc.) need to be further explored. Although the target hypothesis is a biologically 
plausible theory to explain drug resistance, the fact that most drug-resistant patients are resistant to several ASDs acting on different therapeutic targets undermines the general utility of the target hypothesis and instead supports the existence of a mechanism nonspecific to individual ASDs (Tang et al., 2017).

In summary, clinical evidence for the target hypothesis is restricted to loss of carbamazepine's effect on voltage-dependent $\mathrm{Na}^{+}$channels in carbamazepineresistant patients, whereas such data are lacking for ASD nonresponders in animal models. Instead, alterations in the expression and pharmacological sensitivity of $\mathrm{GABA}_{\mathrm{A}}$ receptors have been described in ASD-resistant epileptic rats, which would be in line with the target hypothesis. Thus, although at first glance the target hypothesis appears scientifically plausible, the available evidence is quite limited (Table 3 ).

\section{B. Alteration of Drug Uptake into the Brain}

The "transporter hypothesis" suggests resistance is due to inadequate penetration of ASDs across the BBB because of increased expression of multidrug efflux transporters (Löscher and Potschka, 2005; Tang et al., 2017). Multidrug resistance (MDR) because of efflux transporters, which was first demonstrated in chemotherapyresistant cancer, has attracted significant interest as a putative mechanism to explain resistance to multiple ASDs, irrespective of their mechanism of action (Tang et al., 2017). However, since it was first postulated by Tishler et al. (1995), the transporter hypothesis has also been a matter of debate.

The role of multidrug efflux transporters, such as P-glycoprotein (Pgp), at the BBB in restricting brain entry of multiple drugs is widely accepted (Giacomini et al., 2010; Neuwelt et al., 2011; Abbott, 2013; König et al., 2013; Saunders et al., 2016). Indeed, such transporters are involved in the emergence of MDR, which plays an important role in the failure of treatments of brain tumors, brain infections, and several other brain disorders (Löscher and Potschka, 2005; Mahringer and Fricker, 2016). Pgp, the product of the human multidrug-resistance-1 (MDR1; $A B C B 1)$ gene is of particular clinical relevance in that this transporter has a broad substrate specificity (which led to the term "multidrug transporter"), including a variety of structurally divergent drugs in clinical use today (König et al., 2013; Saunders et al., 2016).

In the BBB, multidrug transporters such as Pgp, members of the multidrug resistance protein (MRP) family and breast cancer-related protein (BCRP) are located in brain capillary endothelial cells that form the $\mathrm{BBB}$ and act in concert to reduce the brain penetration of many drugs to protect the brain from intoxication by lipophilic xenobiotics that otherwise would cross the BBB by passive diffusion (König et al., 2013).

Using brain specimens removed from patients during surgery for intractable epilepsy, Tishler et al. (1995) were the first to report that brain expression of $M D R 1$, which encodes Pgp in humans, is markedly increased in the majority of patients. Based on their findings, Tishler et al. (1995) proposed that increased Pgp expression may play a clinically significant role by limiting access of ASDs to the brain parenchyma, thereby contributing to the refractoriness of seizures. Following the report by Tishler et al. (1995), the finding of MDR1 (or Pgp protein) overexpression in epileptogenic brain tissue of patients with DRE was confirmed by several other groups (Tang et al., 2017). Furthermore, it was shown that in addition to Pgp, several MRPs are overexpressed in brain capillary endothelial cells and/or astrocytes of pharmacoresistant patients, whereas data on BCRP were inconsistent (Tang et al., 2017). In some of these studies, the overexpression of drug efflux transporters in astrocytes appeared most marked around blood vessels. In view of data indicating that the endothelial barrier function of the BBB is transiently and locally disrupted during seizures (van Vliet et al., 2015), overexpression of multidrug transporters in astroglial endfeet covering the blood vessels may represent a "second barrier" under these conditions. As a consequence, overexpressed multidrug transporters may lower the extracellular concentration of ASDs in the vicinity of the epileptogenic pathology and thereby render the epilepsy caused by these pathologies resistant to ASD treatment.

An open question is whether the overexpression of Pgp and MRPs in epileptogenic brain tissue of patients with intractable epilepsy is intrinsic (constitutive) or acquired, i.e., a consequence of epilepsy, of uncontrolled seizures, of chronic treatment with ASDs, or combinations of these factors. Because treatment-resistant patients have no fewer neurotoxic side effects under ASD treatment as patients who are controlled by ASDs, the overexpression of drug transporters in treatmentresistant patients is most likely restricted to the epileptic focus or circuit. This has been substantiated by Sisodiya et al. (2002), in that overexpression of Pgp and MRP1 was found in epileptogenic tissue but not in adjacent normal tissue of the same patients. Furthermore, the same group studied the expression of Pgp in postmortem brains from patients with drug-sensitive or drug-resistant chronic epilepsy and nonepileptic controls (Liu et al., 2012). They found that: 1) there is a highly localized overexpression of Pgp in the epileptogenic hippocampus of patients with DRE; 2) this overexpression appears specific to Pgp and does not affect other transporters; and 3) Pgp is expressed on the vascular endothelium and end-feet of vascular glia (forming a "double cuff") in drug-resistant epileptic cases but not in drug-sensitive patients or postmortem controls. In another study using positron imaging tomography (PET) with the Pgp substrate $(R)-\left[{ }^{11} \mathrm{C}\right]$ verapamil to study the functionality of Pgp in the brain of patients with ASD-resistant and -responsive epilepsy 
and controls, data demonstrated higher Pgp functionality in epileptogenic brain regions of drug-resistant patients (Feldmann et al., 2013), which is consistent with the Pgp expression data reported by Liu et al. (2012). Interestingly, in the ASD-resistant patients, higher seizure frequency was significantly correlated with higher Pgp activity in the hippocampus, maybe suggesting that increased Pgp plays a role in the "intrinsic severity hypothesis" of Rogawski and Johnson (2008), which will be discussed below. In a subsequent PET study, it was shown that the increased Pgp function in the temporal lobe of patients with drug-resistant TLE was reduced after epilepsy surgery in patients responding to surgery compared with nonoptimal surgery outcome (Bauer et al., 2014).

In animal models of TLE, such as the kindling and kainate models, a transient overexpression of Pgp was found in capillary endothelial cells, astroglia, and neurons of limbic brain regions following seizures (Löscher and Potschka, 2005; Tang et al., 2017), indicating that seizures themselves can induce overexpression of drug transporters. This could explain that one of the major predictors of drug resistance is high seizure frequency (or density) prior to initiation of treatment (Regesta and Tanganelli, 1999; Hitiris et al., 2007; Dalic and Cook, 2016). However, constitutive rather than induced or acquired overexpression of multidrug transporters has been reported in patients with malformations of cortical development (Sisodiya et al., 1999). In addition to intrinsic or acquired overexpression of multidrug transporters in the BBB of patients with epilepsy, polymorphisms in transporter genes may play a role in drug resistance, which will be discussed in a separate section on the gene variant hypothesis below.

In view of the emerging evidence that multidrug transporters are overexpressed in epileptogenic brain tissue, particularly in capillary endothelial cells and astrocytes contributing to $\mathrm{BBB}$ permeability, it is obviously important to know whether ASDs are substrates for these transporters. The first indication that ASDs are substrates for Pgp came from experiments of Tishler et al. (1995), who found that intracellular phenytoin levels in a MDR1-expressing neuroectodermal cell line were only one-fourth that in MDR1negative cells, suggesting that human Pgp significantly contributes to cell export of phenytoin. Various subsequent in vitro and in vivo studies have indicated that many ASDs are substrates of Pgp, whereas only few are substrates for MRPs or BCRP (Löscher et al., 2011; Zhang et al., 2012; Tang et al., 2017).

However, data on transport of ASDs by BBB efflux transporters such as Pgp are controversial, which is a key reason why the transporter hypothesis is a matter of debate (Löscher et al., 2011). The difficulty in determining which ASDs are substrates of human Pgp is mainly a consequence of the fact that ASDs are highly permeant (lipophilic and small) compounds, which are not easily identified as Pgp substrates in in vitro models of the BBB, such as monolayer (Transwell) efflux assays. By using a modified assay (concentration equilibrium transport assay), which minimizes the influence of high transcellular permeability, two groups have independently demonstrated that most major ASDs are transported by human Pgp (Löscher et al., 2011; Zhang et al., 2012). Importantly, it was demonstrated in these studies that Pgp-mediated transport highly depends on the ASD concentration and may not be identified if concentrations below or above the therapeutic range are used. In line with these findings, by using an in vitro BBB model with human capillary endothelial cells from either normal brain or drugresistant epileptic brain, Cucullo et al. (2007) reported a dramatically reduced permeability of phenytoin across the in vitro BBB formed from endothelial cells of patients with DRE, which could be partially counteracted by the selective Pgp inhibitor tariquidar, substantiating transport of ASDs by human Pgp.

By using either $m d r 1 a / b$ knockout mice or brain microdialysis with Pgp inhibitors, Pgp-mediated efflux of ASDs at the BBB was also demonstrated in vivo (Löscher et al., 2011). In view of the overexpressed efflux transporters found in epileptogenic brain tissue of patients with pharmacoresistant epilepsy and animal models of epilepsy, another important question was whether this overexpression indeed lowers brain uptake of ASDs, as suggested. By using the intraperitoneal kainate model of TLE in mice, Rizzi et al. (2002) demonstrated that the significant increase in $m d r 1$ mRNA expression measured by reverse-transcription polymerase chain reaction in the hippocampus after kainate-induced seizures was associated with a $30 \%$ decrease in the brain/plasma ratio of phenytoin, thus substantiating the view that Pgp alterations significantly affect concentrations of ASDs in the brain. Comparing phenytoin brain/plasma ratio in $m d r 1$ knockout mice with this ratio in mice with kainateinduced overexpression of Pgp indicated that Pgp can affect up to about $70 \%$ of phenytoin brain uptake (Löscher et al., 2011). In epileptic rats, van Vliet et al. (2007) reported decreased brain levels of phenytoin that were restricted to brain regions with increased expression of Pgp, which could be counteracted by inhibiting Pgp. In patients with oxcarbazepine (OXC)resistant epilepsy, the brain tissue expression of $A B C B 1$ mRNA was found to be inversely correlated with brain levels of 10,11-dihydro-10-hydroxy-5H-dibenzo(b,f)azepine5 -carboxamide, the active metabolite of $\mathrm{OXC}$, indicating that Pgp may play a role in the pharmacoresistance to OXC by causing insufficient concentrations of its active metabolite at neuronal targets (Marchi et al., 2005).

A further important step in the evaluation of the multidrug transporter hypothesis of DRE was the 


\section{Selection of ASD responders and nonresponders in a rat TLE model}

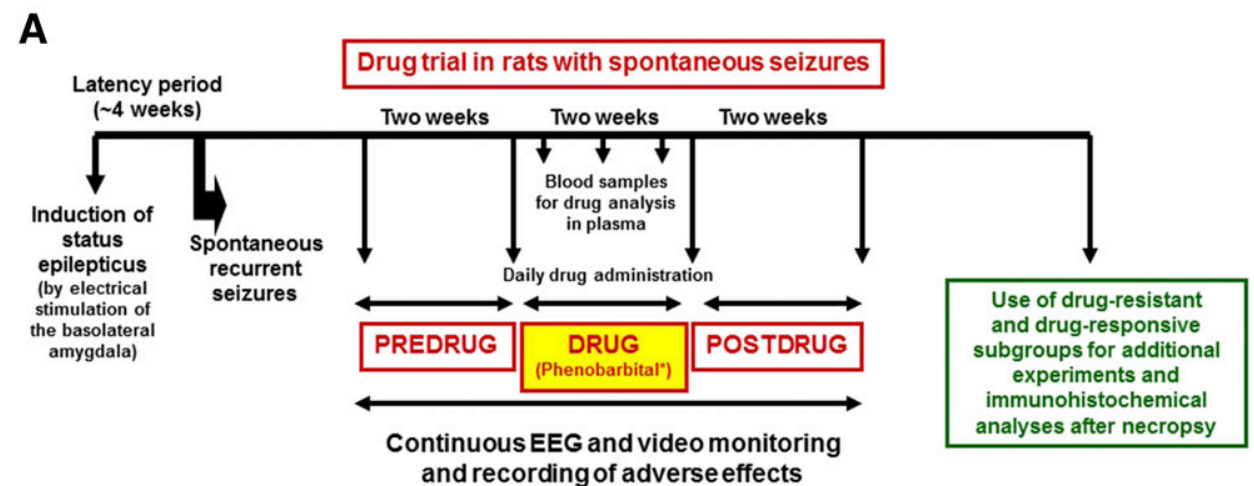

B

Selection of PB responders and nonresponders from a group of 33 epileptic rats
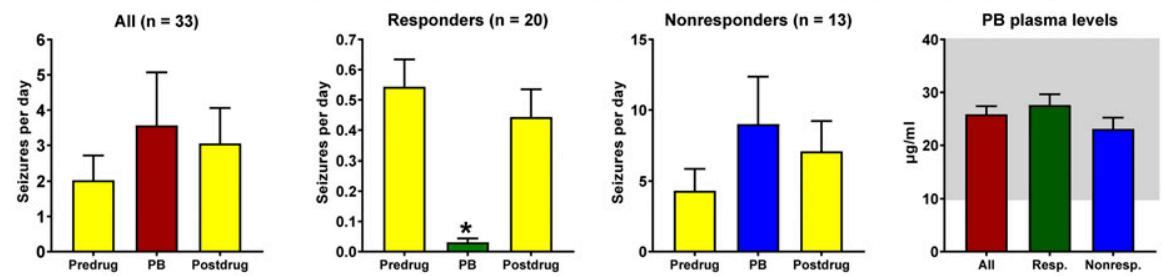

C

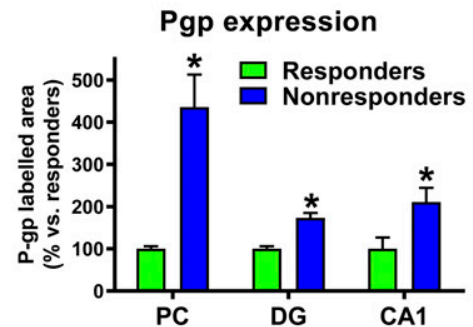

D

Effect of add-on treatment with the Pgp inhibitor tariquidar in PB nontresponders

PB-Nonresponders

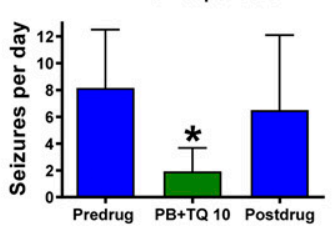

PB-Nonresponders

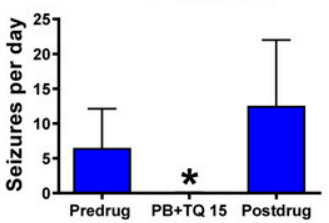

PB-Nonresponders

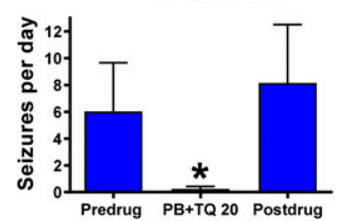

Fig. 5. Selection and characterization of ASD responders and nonresponders by phenobarbital in a rat model of TLE in which spontaneous recurrent seizures (SRS) develop following sustained electrical stimulation of the basolateral amygdala. (A) Schematic illustration of selection of drug-resistant and drug-responsive epileptic rats by prolonged administration of phenobarbital. (B) Effect of phenobarbital (PB) on SRS. About 5 months after the electrically induced SE, SRS were recorded over a period of 2 weeks before onset of PB treatment (predrug control), followed by drug treatment of 2 weeks and then a 2 -week postdrug control period. All data are shown as means \pm S.E.M. The graphs in (B) show 1) average seizure data from 33 epileptic rats from three prospective experiments, 2) respective data from 20 responders, 3) data from 13 nonresponders, and 4) average plasma concentration of $\mathrm{PB}$ from the blood samples taken at the end of the treatment period. The shaded area indicates the therapeutic plasma concentration range of $\mathrm{PB}$. In the responder group, PB significantly suppressed SRS compared with the pre- and postdrug periods $(* P<0.001)$. Note the higher average frequency of SRS in nonresponders versus responders. (C) Pgp expression in brain capillary endothelial cells of responders and nonresponders. Significant differences are indicated by asterisk $\left({ }^{*} P<0.05\right)$. (D) Coadministration of PB and the Pgp inhibitor tariquidar lead to a significant $(* P<0.05)$ suppression of SRS in PB nonresponders. Three different doses of tariquidar $(10,15$, and $20 \mathrm{mg} / \mathrm{kg}) \mathrm{were}$ used, demonstrating a dose-dependent effect. Data are from Brandt et al. (2004), Volk and Löscher (2005), Brandt et al. (2006), Bethmann et al. (2007), and Brandt and Löscher (2014).

demonstration that rats that do not respond to ASDs exhibit significantly higher expression levels of Pgp in brain capillary endothelial cells of the BBB than ASDresponsive rats (Potschka et al., 2004; Volk and Löscher, 2005). This was demonstrated for two different rat models of TLE: phenytoin-resistant kindled rats and phenobarbital-resistant rats with spontaneous recurrent seizures (Fig. 4).

If drug resistance is due to increased transporter expression and functionality, it should be possible to demonstrate that the inhibition or avoidance of the resistance-mediating mechanism counteracts drug 
resistance in epilepsy. Some indirect, correlative evidence came from experiments with diverse ASDs in pharmacoresistant kindled rats, selected by repeated testing with phenytoin (Löscher, 2002). These phenytoinresistant rats have an increased expression of Pgp in focal epileptogenic brain tissue (Potschka et al., 2004). All ASDs that were substrates for Pgp showed absent or low antiseizure efficacy in phenytoin nonresponders (Löscher and Potschka, 2002). More importantly, we examined whether Pgp inhibitors counteract multidrug resistance. For this purpose, we used epileptic rats that were either responsive or resistant to phenobarbital (Brandt et al., 2006). As shown in Fig. 5, in resistant animals, coadministration of the selective Pgp inhibitor tariquidar together with phenobarbital reversed resistance, leading to seizure control in animals that were resistant to phenobarbital alone. That such a strategy may be relevant in patients with epilepsy is suggested by several recent promising reports in whom the nonselective Pgp inhibitor verapamil was added to the ASD regimen (section V. D. Targeting of Transporter Function and Expression). In addition to inhibiting Pgp, the recently clarified signaling cascade that explains seizureinduced overexpression of Pgp raises the possibility of direct manipulation of this overexpression, e.g., by inhibiting N-methyl-D-aspartate (NMDA) glutamate receptors or cyclooxygenase (COX) 2 (Potschka, 2010). Indeed, both NMDA antagonists and COX-2 inhibitors, such as celecoxib, have been shown to prevent the seizureinduced increase in Pgp expression and functionality, and celecoxib reversed ASD-resistance in rats (Potschka, 2010). Details on the link between neuroinflammation and Pgp overexpression are provided in the section on neuroinflammation below.

In summary, the available clinical evidence for the transporter hypothesis includes numerous reports that Pgp and other efflux transporters are overexpressed in epileptogenic brain regions of patients with intractable epilepsy and that various ASDs are transported by human Pgp. The experimental evidence fulfills all of the criteria described in Table 3; i.e., ASD nonresponders exhibit higher expression of Pgp at the BBB than responders in rat models, various ASDs are transported by rodent Pgp, overexpression of Pgp is associated with lower brain levels of ASDs in rodents, and, most importantly, inhibition of Pgp by tariquidar counteracts resistance to ASDs in a rat model of TLE. However, at present, aspects of the transporter hypothesis are still controversial, and further research is needed to determine the clinical relevance of efflux transporter overexpression at the BBB (Tang et al., 2017).

\section{Alterations of Pharmacokinetics in the Periphery}

The "pharmacokinetic hypothesis" proposes that overexpression of efflux transporters in peripheral organs such as intestine, liver, and kidney decreases ASD plasma levels in DRE patients, thereby reducing the amount of ASD available to cross the BBB (Tang et al., 2017). Indeed, alterations in expression and functionality of multidrug transporters in patients with intractable epilepsy need not necessarily be restricted to the brain but could also occur in other tissues, such as the small intestine, where Pgp is thought to form a barrier against entrance of drugs from the intestinal lumen into the bloodstream, thereby limiting their oral bioavailability (Fromm, 2004). In this respect, it is interesting to note that Lazarowski et al. (2007) have reported persistent subtherapeutic plasma levels of ASDs (including phenytoin and phenobarbital) despite aggressive and continuous ASD administration in patients with DRE that was associated with overexpression of MDR1. However, the pharmacokinetic hypothesis suggested by Lazarowski et al. (2007) is based on only two case studies, and it is unclear at this point if their observation is limited to these cases or is a wider phenomenon. Support for the pharmacokinetic hypothesis comes from studies showing persistently low ASD levels in patients with DRE, which, however, relate to drug metabolizing enzymes rather than to efflux transporters such as Pgp (Tang et al., 2017). In this respect, it is important to note that cytochrome $\mathrm{P} 450$ metabolic enzymes not only occur in the periphery but also in the brain parenchyma and endothelial cells of the BBB, thus adding to the barrier function (Ghosh et al., 2011). Changes in the cerebrovascular hemodynamic conditions can affect expression of cytochrome P450 enzymes and multidrug-resistance transporters, leading to a synergistic role in drug resistance (Ghosh et al., 2011).

Animal studies do not support the pharmacokinetic hypothesis. In these studies, ASD plasma concentrations were not different between ASD responders and nonresponders (Löscher, 2017c) (Fig. 5B), although, in rare instances, single ASD-resistant rats exhibited lower plasma levels, necessitating increased ASD dosing. However, these experiments were done with intraperitoneal not oral administration. Overall, the evidence for the pharmacokinetic hypothesis of Lazarowski et al. (2007) is quite limited (Table 3).

\section{Neural Network Hypothesis}

The "neural network hypothesis," first proposed by Fang et al. (2011), suggests that epilepsy-associated structural alterations (including neurodegeneration, axonal sprouting, synaptic reorganization, neurogenesis, and gliosis) contribute to the formation of an abnormal neural network, thereby reducing ASD efficacy. Hippocampal sclerosis is a common finding in patients with pharmacoresistant TLE, so it had often been suggested that hippocampal sclerosis plays a causal role in the mechanisms underlying ASD resistance long before the neural network hypothesis was proposed (Schmidt and Löscher, 2005). Indeed, following resection of the affected temporal lobe, $\sim 60 \%$ of patients with formerly drug-resistant TLE become 
seizure free with continued medical treatment (Wiebe and Jette, 2012), thus providing a proof-of-concept of the neural network hypothesis. Furthermore, malformations in cortical development are often associated with pharmacoresistant epilepsy (Barkovich et al., 2015). However, the major weakness of this hypothesis is that alterations in the neural network do not lead to refractoriness in all epilepsy patients (Tang et al., 2017). Furthermore, not all ASD-resistant patients become ASD responders following epilepsy surgery, although this may be due, at least in part, to incomplete resection of affected tissue such as the piriform cortex (Galovic et al., 2019).

To address directly whether hippocampal sclerosis is causally related to ASD resistance, we compared hippocampal damage in epileptic rats that either responded or did not respond to ASD treatment (Volk et al., 2006; Bethmann et al., 2008). As shown in Fig. 4, in most ( $>90 \%)$ nonresponders of this model, we determined a significant loss of neurons in the CA1, CA3c/ $\mathrm{CA} 4$, and dentate hilus, whereas most ( $>90 \%)$ responders did not differ in hippocampal morphology from nonepileptic controls, which was a highly significant difference. Based on these observations, it appears that the functional alterations in hippocampal pyramidal neurons and in the dentate gyrus developing as a response to hilar cell loss are critically involved in the mechanisms underlying the refractoriness of seizures to ASD treatment. Such structural and functional network changes will also affect ASD targets, as discussed in the section on target alterations.

In summary, clinical evidence for the neural network hypothesis is convincing in that, in TLE, hippocampal sclerosis is often associated with drug resistance and resection of the affected tissue often reverses resistance (Table 3). Experimental evidence includes the finding that hippocampal damage is associated with ASD resistance in a rat model of pharmacoresistant epilepsy.

\section{E. Intrinsic Severity Hypothesis}

Rogawski and Johnson (2008) proposed that ASD resistance is not due to specific pharmacoresistance factors but rather that epilepsy severity exists on a continuum and that more severe epilepsies are more difficult to treat. This "intrinsic severity hypothesis" was subsequently updated by Rogawski (2013), who postulates that pharmacoresistance is an inherent property of the epilepsy related to disease severity. Seizure frequency is one marker of severity, and high seizure frequency or density before onset of ASD therapy is the single most important factor associated with a low chance of longterm remission of seizures on treatment (Rogawski and Johnson, 2008). Interestingly, as shown in Fig. 4, similar observations were made in the rat model of basolateral amygdala stimulation that allows differentiating rats with different ASD responses (Löscher and Brandt, 2010). Epileptic rats that responded to treatment exhibited a relatively low, uniform seizure frequency; none of the responders had a high seizure frequency. In contrast, many nonresponders exhibited very high seizure frequencies. However, there were some nonresponders who also exhibited low seizure frequencies comparable to those of ASD-responsive animals. As in the clinical situation (Sillanpää and Schmidt, 2009), although high seizure frequency is a reliable predictor of pharmacoresistance, it is clearly not the only determinant of pharmacoresistance. Rogawski (2013) mentioned other measures of epilepsy severity, such as the extent of structural lesions (e.g., hippocampal damage) or the behavioral phenotype, that also predict ASD resistance.

Although the intrinsic severity hypothesis appears biologically plausible, it does not adequately apply to epilepsy types that demonstrate a fluctuating or evolving pattern of ASD resistance (Löscher and Schmidt, 2016). In addition, there is little evidence supporting a direct mechanistic link between the severity of epilepsy and ASD response (Schmidt and Löscher, 2009). Thus, overall, the evidence for this hypothesis is quite limited (Table 3 ).

\section{F. Gene Variant Hypothesis}

A strong candidate mechanism for the target hypothesis of drug resistance, and a plausible reason for drug resistance on first principles, is that there is endogenous variation in people with epilepsy that, through whatever mechanism, reduces the chances of ASDs controlling seizures. The best understood source of internal variation in people with epilepsy is the genome. Variation in the genome may be classed as rare or common. There are around 10,000,000 single nucleotide polymorphisms (SNPs) in the human genome, nucleotides that differ between people, with a minor allele frequency of $>5 \%$; this class of variant is the best studied type of common variation in the genome. Such variation can be neutral or can affect the function of the gene in some way. Thus, for example, an SNP in the gene SCN1A might affect conformation, binding or other activity of the encoded protein, or stability of the transcribed mRNA, leading eventually to reduced response to sodium channel-blocking ASDs. Studies of common variation may focus on a single SNP, SNPs in a gene or set of genes, or across the entire genome and typically seek to test the hypothesis that there is an association between the distribution of the genetic variation and the phenotype in question. There have been many association studies published in epilepsy, and a good proportion address aspects of drug resistance. The difficulty with most is the study design; the fundamental hypothesis is based on weak evidence, sample sizes are small, and there are methodological failings and a lack of replication, among other issues (for a review, see Gambardella et al., 2017; Balestrini and Sisodiya, 2018). These issues limit the value of many 
association studies undertaken in epilepsy, including those addressing the phenotype of drug resistance.

The Epilepsy Genetic Association Database (epiGAD; www.epigad.org) is an online repository of data related to association studies in the epilepsies and is supported by the ILAE Genetics Commission. It is regularly updated and is a good source of information, obviating the need to reproduce a rapidly out-of-date list of such studies here. Moreover, so far, there have been no robust, generally accepted genetic associations for drug resistance across the spectrum of the epilepsies to support the model of broad, syndrome-independent mechanisms of drug resistance driven by genetic variation. Published studies are, on the whole, of limited size, differing patient groups and definitions, and selected SNPs and are lacking replication. Genes of particular interest in this area have included $S C N 1 A$ and $A B C B 1$, encoding Pgp (Löscher et al., 2009; Orlandi et al., 2018). Evaluation of the latter is instructive. Deriving justification from work in cancer, animal models, and tissue studies in human epileptogenic brain tissue, the first association of $A B C B 1$ was a single SNP study in 2003 (Siddiqui et al., 2003) of a cohort considered small by today's standards. Many further single and multiple SNP-based associations were published of different patient groups, varying case and control definitions, and, generally, small sample sizes. Some studies supported the original association, whereas others did not; meta-analyses of many such studies remain equivocal (Haerian et al., 2011; Sun et al., 2014; Chouchi et al., 2017), but it is still the case that the correctly designed, adequately controlled, and credibly powered study has not yet been undertaken. There are no common genetic variants associated with drug resistance currently in use to predict this phenotype. However, the search should continue; in the absence of selection pressure acting against such variants (because exposure of the human species to medication has been short in comparison with the duration of exposure to other environmental agents), there is no a priori reason to think that common genetic variation does not contribute to drug resistance.

Consideration of the contribution of rare variation to drug resistance opens up new problems and questions. Until recent large-scale efforts (Epi25 Collaborative. Electronic address: s.berkovic@unimelb.edu.au; Epi25 Collaborative, 2019), sample sizes from most studies were simply too small to even consider rare variant association studies, especially as most such studies were skewed toward people with epilepsies at the more severe end of the spectrum. But, in addition, rare variation has more typically been considered in the context of genetic causation of the epilepsy itself rather than a facet of the epilepsy such as drug resistance, but this raises interesting questions. For example, a hypothetical patient may have epilepsy because of a rare deleterious variant in a gene encoding a neuropeptide receptor; currently used ASDs do not target this system, as far as we know, and their actions on the downstream pathophysiological processes shared across the epilepsies, such as disordered inhibition, may not be sufficiently potent to prevent seizures from occurring. In this scenario, the receptor gene mutation might be considered causal for the epilepsy and responsible for the drug resistance it shows. Then, if rare variant studies have to be large to have meaningful power, there is a risk that such causes of drug resistance might be lost in the heterogeneity of rare variant causes likely to comprise the large study sample in the first place. Here, drug resistance and "precision medicine" can be considered to overlap, and this is considered further below. Moreover, rare variations may have additional complexities to be considered, such as organ-specific genomic change (somatic mutation) and organ-specific regional variation (spatial microheterogeneity), areas we have barely begun to explore.

\section{G. The Epigenetic Hypothesis}

The genome is one source of endogenous variation, contributing to different disease risks between different people. There are, however, other sources of variation, such as "omes" beyond the genome: the epigenome, transcriptome, proteome, microbiome, and so on. Some of these "omes" have been interrogated for their role in drug resistance in epilepsy, but it must be acknowledged at this point that the data available are even more sparse than for most genome-based studies and that, currently, none of these "omes" have been proven to influence drug resistance.

The epigenome is a set of molecules that regulates gene expression across the genome. In contrast to the genome, which is considered for the purposes of epilepsy to be largely (but not completely) fixed over time and across tissues, the epigenome can be very dynamic, varying even during short time periods (Guo et al., 2011) and across (and potentially within) organs. Studying epigenomic contribution to drug resistance in epilepsy (Kobow et al., 2013; Kobow and Blümcke, 2018), which is likely to be due to processes in the brain, is therefore very challenging. Among classes of molecules constituting the epigenome are histones and noncoding RNAs, both long and shorter, including microRNAs. The latter contribute to RNA silencing and post-transcriptional regulation of gene expression, altering expression levels of multiple proteins. A central problem in studying the epigenome in humans is to disentangle cause from effect and relevance either way from epiphenomena. Thus, although a series of microRNAs have been shown to associate with human TLE (Miller-Delaney et al., 2015), the studied tissue had been surgically resected from people with drug resistance, and cause and effect (for either disease susceptibility or drug resistance) could not be distinguished. In animal models, manipulation of specific microRNAs can 


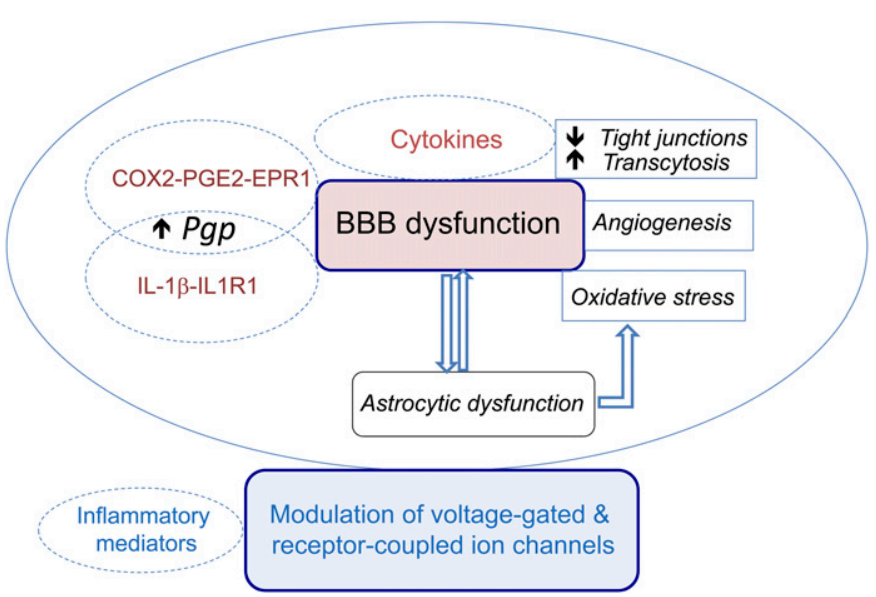

Fig. 6. Schematic representation of the evidence-based pathologic links between inflammatory mediators and mechanisms of drug resistance. Inflammatory mediators (including but not limited to cytokines) may contribute to drug-resistant seizures mainly by three (nonmutually exclusive) pathways: 1) the induction of $\mathrm{BBB}$ dysfunction by promoting breakdown of tight junctions or inducing transocytosis, aberrant angiogenesis generating "leaky" vessels, and oxidative stress. The inflammatory phenotype of astrocytes is pivotal for these actions to take place, and reciprocally, $\mathrm{BBB}$ permeability changes may promote the expression of inflammatory molecules in astrocytes. This vicious cycle contributes to recurrent seizures, cell loss, and maladaptive neuronal network plasticity, therefore contributing to increase the "intrinsic severity" of the disease. Morever, BBB dysfunction will enhance albumin brain extravasation into the brain parenchyma and potentially increase the "buffering" effect of albumin binding to drugs, thus decreasing functionally relevant unbound drug levels at brain target sites. 2) Another mechanism is the induction of Pgp in endothelial cells, and likely in perivascular astrocytes, by specific inflammatory pathways involving COX2-PGE2-EP1R and the IL-1beta-IL-1R1 axis, thus contributing to the transporter hypothesis of drug resistance. 3) Inflammatory mediators can also induce post-translational modifications in voltagegated and receptor-operated ion channels resulting in less responsive ASD targets, which may contribute to the pharmacodynamic (target) hypothesis of drug resistance. Details and references are reported in the main text.

influence seizures and disease (Morris et al., 2019), though some data are less supportive (Haenisch et al., 2016); however, whether this would be the case in human epilepsy, and specifically whether this approach would counter drug resistance, remains unknown.

The microbiome has also attracted much interest recently in neuropsychiatric diseases (Iannone et al., 2019). Studies of the microbiome may seem simple and enticing, but there are many complexities and pitfalls. Nevertheless, potential interaction between the gut microbiota and human disease is an intriguing one, with unreplicated early studies suggesting links through the microbiome between the effect of the ketogenic diet and seizure control in epilepsy (Olson et al., 2018), a direct effect of microbiome variation and DRE (Peng et al., 2018), and other links (Lum et al., 2020). More data are needed before therapeutic manipulation of the gut microbiome might be considered a treatment.

\section{H. Neuroinflammation and Blood-Brain Barrier Dysfunction as Potential Mechanisms}

$\mathrm{BBB}$ permeability is enhanced during experimental $\mathrm{SE}$ and in chronic epilepsy foci in experimental and clinical conditions. Furthermore, BBB dysfunction can be experimentally induced, for example, by intravenous injections of mannitol in rodents, which induces the development of epileptic foci (Friedman and Heinemann, 2012; van Vliet et al., 2015). In all these conditions, BBB dysfunction is associated with Pgp induction in brain vessels and astrocytes as well as with a concomitant neuroinflammatory response in the same tissue districts. There is experimental evidence that neuroinflammation may be a causative factor both for inducing a dysfunctional BBB and an upregulation of Pgp in DRE, as reported below. The main mechanisms discussed in the following are illustrated in Fig. 6.

1. Pathophysiological Link between Neuroinflammation and Blood-Brain Barrier Dysfunction in Epilepsy. Neuroinflammation and BBB dysfunction are hallmarks of human epileptogenic foci in various forms of DRE as well as in animal models of acquired epilepsies (for comprehensive reviews, see Friedman and Heinemann, 2012; Broekaart et al., 2018; Vezzani et al., 2019; Löscher and Friedman, 2020). These two phenomena are mechanistically linked as shown in in vivo and in vitro experimental models. For example, the induction of a neuroinflammatory response caused by an increased brain expression of interleukin (IL)- $1 \beta$ or tumor necrosis factor (TNF) in rodents has been shown to result in enhanced BBB permeability to blood macromolecules such as albumin, which is normally excluded from the brain (Yang et al., 1999; Ferrari et al., 2004). Although the underlying mechanisms linking neuroinflammation to BBB dysfunction are not fully elucidated, there is evidence that IL- $1 \beta$ induces breakdown of tight junctions, such as zonula occludens (ZO)1 , by activating IL-1 receptor type 1 (IL-1R1) expressed by endothelial cells (Ferrari et al., 2004; Ravizza and Vezzani, 2006; Morin-Brureau et al., 2011; Librizzi et al., 2012). This signal activation induces, together with vascular endothelial growth factor (VEGF) receptor (VEGFR) 2, the release of ceramide from plasma membrane and the subsequent Src (sarc) kinase protein activation, which is responsible for ZO-1 downregulation (Morin-Brureau et al., 2011). Notably, the ceramide-Src kinase pathway induced by the activation of the IL- $1 \beta$ IL-1R1 axis in neurons leads to increased excitability and excitotoxicity and promotes seizures mediated by NMDA receptor subunit N2B subunit phosphorylation and enhanced neuronal $\mathrm{Ca}^{2+}$ influx through NMDA receptors (Viviani et al., 2003; Balosso et al., 2008). Therefore, an increase in brain IL- $1 \beta$ couples neuronal hyperexcitability in response to glutamate to $\mathrm{BBB}$ dysfunction.

An alternative but not mutually exclusive mechanism links cytokines, e.g., TNF, to BBB permeability changes via endothelial cell transcytosis by enhanced vesicular transport (Abbott, 2000). Additional mechanisms underlying $\mathrm{BBB}$ alterations in epilepsy, and in other central nervous system diseases, include direct injury 
to endothelial cells such as in stroke and during seizures, edema, oxidative stress, alterations in pericytes, and angiogenesis (Friedman and Heinemann, 2012; Klement et al., 2019; Swissa et al., 2019). In particular, angiogenesis in epileptogenic brain tissue is coupled with overexpression of VEGF in neurons and astrocytes and induction of VEGFR2 in neurons and brain vessels (Rigau et al., 2007). Angiogenesis is induced by epileptic activity and neuroinflammation (Marcon et al., 2009; Morin-Brureau et al., 2011; Dudvarski Stankovic et al., 2016). The activation of the VEGFVEGFR2 axis in astrocytes and vessels alters extracellular matrix and tight junctions, respectively, thereby contributing to BBB dysfunction (reviewed in Sandoval and Witt, 2008).

A direct causative link between seizures, neuroinflammation, and increased BBB permeability to serum albumin was established in the isolated guinea pig brain preparation, in which recurrent seizures were evoked by arterial perfusion of bicuculline (Librizzi et al., 2012). In this in vitro whole brain preparation, seizures triggered the expression of IL- $1 \beta$ in astrocytes, and this phenomenon caused the brain extravasation of arterially perfused albumin, a phenomenon that was prevented by blockade of IL-1R1 with IL-1 receptor antagonist (IL-1Ra). These events were associated with ZO-1 downregulation in endothelial cells and were independent on either circulating leukocytes or bloodborn inflammatory molecules (Librizzi et al., 2012).

Conversely, BBB dysfunction results in pathophysiological changes in perivascular brain tissue mainly involving astrocytes. A sequence of events has been described that involves the brain extravasation of serum albumin, which, in turn, activates the tumor growth factor (TGF)- $\beta$ receptor type 2 -Smad 2 mediated signaling in perivascular astrocytes. The activation of this pathway promotes the transcription of inflammatory genes and the downregulation of $\mathrm{Kir}_{4.1}$ and aquaporin 4 channels as well as glutamate transporter 1 and glutamate-aspartate transporter (reviewed in Friedman and Heinemann, 2012). These phenotypic changes in astrocytes impair the glia ability to buffer extracellular $\mathrm{K}^{+}$and glutamate and to maintain water homeostasis, thus resulting in neuronal hyperexcitability and reducing seizure threshold (Friedman and Heinemann, 2012; Frigerio et al., 2012). Recent evidence has shown that the activation of TGF- $\beta$ in astrocytes is also involved in remodeling of the extracellular matrix, leading to reactive excitatory synaptogenesis and degradation of perineuronal nets around GABAergic neurons. Overall, these alterations favor pathologic hyperexcitability underlying seizure generation and recurrence (Weissberg et al., 2015; Kim et al., 2017; Vezzani et al., 2019).

Accordingly, animal studies have shown that neuroinflammation, $\mathrm{BBB}$ permeability changes, and astrocytic cell dysfunctions contribute to epileptogenesis and epilepsy progression because pharmacological interventions with drugs that prevent or reverse these phenomena reduce the incidence of epilepsy and the frequency or duration of spontaneous seizures in rodents [reviewed in Vezzani et al. (2019) and Bar-Klein et al. (2014, 2017)]. The evidence that neuroinflammation contributes to pathologic hyperexcitability and disease severity raises the possibility that it may contribute to drug resistance according to the "intrinsic severity" hypothesis, as previously proposed.

The following paragraphs report experimental evidence for additional mechanisms that may mediate the role of neuroinflammation in drug resistance.

2. Neuroinflammation and Blood-Brain Barrier Dysfunction: Role in Drug Resistance. The extravasation of serum albumin in the brain parenchyma because of $\mathrm{BBB}$ disruption might have functional consequences on the therapeutic effects of ASDs. Evidence from acute rat entorhinal cortex-hippocampal slices has shown that phenytoin and carbamazepine failed to suppress seizure-like events induced by 4-aminopyridine in the presence of tissue perfusion with albumin. This effect was attributed to a "buffering-like" effect of albumin binding to the drugs, which could be overcome by increasing the drug concentration to supratherapeutic doses (Salar et al., 2014).

Release of inflammatory mediators and glutamate by astrocytes and neurons because of brain injury or due to recurrent seizures may increase multidrug transport proteins in the BBB, thereby contributing to resistance to some ASDs in epilepsy, as described above for the transporter hypothesis. More specifically, there is experimental evidence in support of a link between neuroinflammatory molecules and Pgp induction, as shown in studies focusing on COX-2 and IL- $1 \beta$ signals.

3. Cyclooxygenase 2-Prostaglandin E2-Prostaglandin E2 Receptor 1 Axis. BBB dysfunction is associated with Pgp induction in brain vessels and astrocytes and with increased COX-2 protein and prostaglandin (PG) E2 levels in the same epileptogenic regions (Bauer et al., 2008; Zibell et al., 2009; Schlichtiger et al., 2010; van Vliet et al., 2010). A strict association between COX-2 expression in neurons and glia, COX-1 expression in microglia, and increased Pgp and BCRP expression in microvessels was recently reported in surgical brain tissue from patients with drug-resistant mesial TLE (Weidner et al., 2018). The EP1 receptor (EP1R) for PGE2 seems to be a key factor mediating the COX-2 induced upregulation of Pgp. In fact, the increase in Pgp in the hippocampus of a rat model of SE was precluded in animals treated with an EP1R antagonist despite sustained seizures (Pekcec et al., 2009). Consistent with these in vivo data, in vitro experiments showed an increase in both Pgp expression and drug transport activity in isolated rodent brain capillaries exposed to glutamate. The increase in Pgp was dependent on NMDA receptors and $\mathrm{Ca}^{2+}$-dependent activation of phospholipase A2, arachidonic acid release, and COX-2-mediated 
production of PGE2 acting on EP1R (Bauer et al., 2008; Potschka, 2010). Indeed, cerebral endothelial cells express glutamate receptor subtypes, and brain extracellular glutamate levels raise rapidly during seizures; therefore, the overactivation of endothelial glutamate receptors might be one of the earliest triggers that lead to Pgp upregulation in brain vessels in vivo.

4. Interleukin-1 $\beta$-Interleukin-1-Receptor Type 1 Axis. A link between the activation of IL- $1 \beta-$ IL-1R1 signaling and Pgp induction was recently provided by a study showing that the expression of Pgp transcript and protein level in the hippocampus and cerebral cortex microvessels of rats exposed to SE was downregulated by a local injection of a synthetic mimic of the microRNA miR146a (Deng et al., 2019). miR146a is a negative regulator of the IL- $1 \beta-\mathrm{IL}-1 \mathrm{R} 1$ signaling, as it reduces the protein levels of IL-1 receptor-associated protein kinases-1 and TNF receptor-associated factor 6 , which are pivotal for signal transduction in IL-1R1-expressing cells. The modulation of Pgp expression by IL- $1 \beta$ was dependent on the transcriptional factor NF-kB (Deng et al., 2019).

Notably, miR146a is induced in neurons and astrocytes by SE and in animal models of chronic epilepsy as well as in human TLE. The intracerebroventricular injection of its synthetic mimic was shown to reduce carbamazepine-resistant seizures in a murine model of epilepsy (Iori et al., 2017).

I. Other potential mechanisms of drug resistance. Several other mechanisms (Fig. 3), including disease etiology and progression (Löscher and Schmidt, 2016), psychiatric comorbidities (Hitiris et al., 2007), and loss of drug efficacy (tolerance) during chronic drug exposure (Löscher and Schmidt, 2006), may contribute to ASD resistance in patients with epilepsy, enhancing the complexity of this condition. These mechanisms have been discussed in detail elsewhere.

\section{How to Overcome Drug Resistance?}

Despite the development of numerous new ASDs in recent decades, still $\sim 30 \%$ of people with epilepsy have seizures that remain drug-resistant, even if ASDs with different mechanisms of action are combined (Kwan et al., 2011; Löscher and Schmidt, 2011; Golyala and Kwan, 2017). This would seem to indicate that mechanisms of resistance operative in the brain of patients with DRE are not specific for single ASDs but rather affect a variety of such drugs. In this respect, it is important to note that the hypotheses discussed above are not mutually exclusive, but instead that several mechanisms of resistance may occur in the same patient or group of patients. Thus, overcoming drug resistance is a challenging task. Some of the current approaches of identifying more effective treatments for
ASD-resistant epilepsy are discussed in the following sections.

\section{A. Development of New Antiseizure Drugs by Using New Drug-Screening Paradigms}

For over 40 years, the NINDS/NIH-funded Anticonvulsant Screening Program (ASP) has provided a preclinical screening service for participants worldwide that helped identify/characterize new ASDs, a number of which advanced to the market for the treatment of epilepsy (Kehne et al., 2017; Löscher, 2017a; Porter and Kupferberg, 2017). However, the identification part of this program relied on simple seizure tests, such as the MES test that are not likely to discover new compounds with higher efficacy against DRE (Löscher and Schmidt, 2011). Therefore, as described above, a revised NINDS/ $\mathrm{NIH}$-funded program was implemented in 2016 and termed ETSP (Kehne et al., 2017). Since then, an External Consultant Board provides ongoing individual feedback to the program. In response to the clinical need of more effective therapies for DRE and based on the input of the External Consultant Board and other reviewers, the ETSP has developed a more refined flowchart to evaluate the potential of new compounds for treating DRE (Kehne et al., 2017; Löscher, 2017a). As shown in Fig. 5, in the initial "Identification" phase, the $6-\mathrm{Hz} 44 \mathrm{~mA}$ mouse test of difficult-to-treat partial seizures has been included to raise the threshold for advancing compounds for the management of pharmacoresistant epilepsy, thereby increasing the probability that agents with improved efficacy relative to existing agents will be detected. Additional assay options available in the Identification phase include the corneal kindled mouse and a hippocampal/entorhinal cortexcontaining brain slice with spontaneous electrical bursting prepared from kainate treated rats. Compounds with good activity in the Identification phase advance into the "Differentiation" phase, which is currently composed of three chronic assays, one in mice and two in rats (Kehne et al., 2017). The Differentiation phase models include the intrahippocampal kainate mouse model of mesial TLE; the lamotrigine-resistant amygdala-kindled rat; and the chronically epileptic rat, in which epilepsy develops after systemic administration of kainate. All three models offer the added advantage of being models of chronic seizure activity induced by chemical or electrical insult. Moreover, all three models replicate numerous clinical aspects of TLE to provide a more etiologically relevant approach to the further characterization of promising investigational ASDs (Kehne et al., 2017). In addition, the ETSP has incorporated into its test battery an etiologically relevant mouse model of epilepsy associated with viralinduced encephalitis. Collectively, the data generated from these models create a pharmacological profile that identifies promising investigational compounds for further development and potential treatment of 
pharmacoresistant epilepsy. However, this promise has yet to be realized.

An inherent problem of the ETSP strategy is the focus on TLE-related in vitro and in vivo models and the lack of models that resemble human causes more closely, such as models of acquired epilepsy developing after traumatic brain injury or stroke. Furthermore, for efficacy testing of novel molecular targeting approaches, animal models may not be that relevant because of major species differences in the target molecules and the need for specific modulators (e.g., targeting of species-specific regulatory RNAs). Here, the use of patient-derived iPSCs and other novel approaches, such as genetically engineered zebrafish and mouse models, may be of value (Baraban and Löscher, 2014; Du and Parent, 2015; Grone and Baraban, 2015; Parent and Anderson, 2015; Demarest and Brooks-Kayal, 2018). This, for instance, concerns the targeting of the natural antisense transcript (NAT) class of long noncoding RNAs by antagoNAT oligonucleotides, which can be designed to inhibit cis-acting lncRNA, thereby increasing the expression of a selected protein. This approach is of particular interest for therapeutic management of haploinsufficiencies as a cause of epileptic encephalopathies. Hsiao et al. (2016) recently tested a similar approach in a Dravet mouse model, in African Green

TABLE 4

Potential etiology-specific drugs ("precision medicine") that are currently used or discussed for treatment of severe pediatric-onset epilepsies

Drugs are listed according to mutated genes. For a source of references, please refer to Wang et al. (2017) and Mesraoua et al. (2019). Note that mutations of the same gene may result in different clinical phenotypes, as recently shown for KCNQ2 mutation, in which the majority of patients have loss-of-function mutations but a small percentage have gain-of-function mutations associated with a different phenotype (Demarest and Brooks-Kayal, 2018). Except for everolimus in TSC-associated focal epilepsy and for

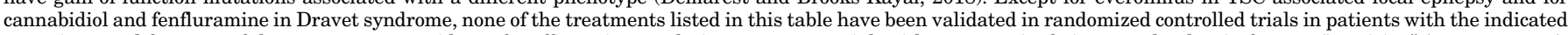

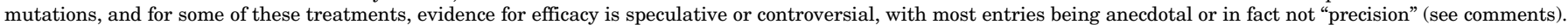
Clinicians should not consider this table as constituting support for treatment with these agents.

\begin{tabular}{|c|c|c|c|c|c|}
\hline $\begin{array}{l}\text { Mutated } \\
\text { gene }\end{array}$ & Gene name & $\begin{array}{l}\text { Encoded protein } \\
\text { function }\end{array}$ & Type of epilepsy & Potentially beneficial therapy & Comments \\
\hline CHRNA4 & $\begin{array}{l}\text { Cholinergic receptor } \\
\text { nicotinic alpha } 4 \\
\text { subunit }\end{array}$ & $\begin{array}{l}\text { Nicotinergic } \\
\text { acetylcholine } \\
\text { receptor }\end{array}$ & $\begin{array}{l}\text { Nocturnal frontal } \\
\text { lobe epilepsy }\end{array}$ & $\begin{array}{l}\text { Zonisamide, } \\
\text { acetazolamide, and } \\
\text { nicotine patches }\end{array}$ & $\begin{array}{l}\text { Zonisamide and acetazolamide are } \\
\text { not really "precision." } \\
\text { Nicotinergic agents are } \\
\text { theoretically of possible use, but } \\
\text { none have been proven to be of } \\
\text { value currently }\end{array}$ \\
\hline GRIN2A & $\begin{array}{l}\text { Glutamate ionotropic } \\
\text { receptor N-methyl-D- } \\
\text { aspartate (NMDA) } \\
\text { type subunit } 2 \mathrm{~A}\end{array}$ & $\begin{array}{l}\text { Glutamate }(\mathrm{NMDA}) \\
\text { receptor }\end{array}$ & $\begin{array}{l}\text { Focal epilepsy and } \\
\text { speech disorder } \\
\text { with or without } \\
\text { mental } \\
\text { retardation }\end{array}$ & Memantine & $\begin{array}{l}\text { Has been proposed on the basis of } \\
\text { two studies only, none published } \\
\text { since } 2015\end{array}$ \\
\hline$K C N Q 2$ & $\begin{array}{l}\text { Potassium voltage-gated } \\
\text { channel subfamily } \mathrm{Q} \\
\text { member } 2\end{array}$ & Potassium channel & $\begin{array}{l}\text { Benign familial } \\
\text { neonatal seizures } \\
\text { or, in infancy and } \\
\text { childhood, EIEE }\end{array}$ & Retigabine/ezogabine & $\begin{array}{l}\text { Has in vitro evidence to support its } \\
\text { use in gain-of-function mutants, } \\
\text { but prospective controlled trials } \\
\text { are still lacking }\end{array}$ \\
\hline$K C N T 1$ & $\begin{array}{l}\text { Potassium sodium- } \\
\text { activated channel } \\
\text { subfamily } \mathrm{T} \text { member } 1\end{array}$ & Potassium channel & EIEE & Quinidine & $\begin{array}{l}\text { The evidence is equivocal, with } \\
\text { many negative reports after the } \\
\text { initial reports of benefit }\end{array}$ \\
\hline PCDH19 & Protocadherin 19 & $\begin{array}{l}\text { Cell adhesion } \\
\text { molecule }\end{array}$ & EIEE & $\begin{array}{l}\text { Potassium bromide, } \\
\text { clobazam }\end{array}$ & $\begin{array}{l}\text { Only anecdotal evidence. Better } \\
\text { rationale for hormonal treatment } \\
\text { with allopregnanolone. }\end{array}$ \\
\hline$P L C B 1$ & Phospholipase $\mathrm{C}$ beta 1 & Enzyme & EIEE & Inositol & Not any evidence for this in humans \\
\hline PRRT2 & $\begin{array}{l}\text { Proline-rich } \\
\text { transmembrane } \\
\text { protein } 2\end{array}$ & Unclassified & $\begin{array}{l}\text { Benign familial } \\
\text { infantile seizures }\end{array}$ & $\begin{array}{l}\text { Carbamazepine, } \\
\text { oxcarbazepine }\end{array}$ & $\begin{array}{l}\text { Not really precision (mechanism- } \\
\text { based) treatments }\end{array}$ \\
\hline$S C N 1 A$ & $\begin{array}{l}\text { Sodium voltage-gated } \\
\text { channel alpha } \\
\text { subunit } 1\end{array}$ & $\begin{array}{l}\text { Voltage-gated } \\
\text { sodium channel }\end{array}$ & Dravet syndrome & $\begin{array}{l}\text { GABAergic drugs, } \\
\text { fenfluramine, } \\
\text { cannabidiol }\end{array}$ & $\begin{array}{l}\text { Fenfluramine and cannabidiol } \\
\text { cannot be considered precision } \\
\text { (mechanism-based) treatments }\end{array}$ \\
\hline$S C N 2 A$ & $\begin{array}{l}\text { Sodium voltage-gated } \\
\text { channel alpha } \\
\text { subunit } 2\end{array}$ & $\begin{array}{l}\text { Voltage-gated } \\
\text { sodium channel }\end{array}$ & $\begin{array}{l}\text { Benign familial } \\
\text { infantile seizures } \\
\text { or EIEE }\end{array}$ & $\begin{array}{l}\text { High levels of phenytoin; } \\
\text { levetiracetam }\end{array}$ & $\begin{array}{l}\text { Not yet clear whether levetiracetam } \\
\text { can be considered precision } \\
\text { (mechanism-based) treatment }\end{array}$ \\
\hline$S C N 2 A$ & $\begin{array}{l}\text { Sodium voltage-gated } \\
\text { channel alpha } \\
\text { subunit } 2\end{array}$ & $\begin{array}{l}\text { Voltage-gated } \\
\text { sodium channel }\end{array}$ & $\begin{array}{l}\text { EIEE, status } \\
\text { epilepticus }\end{array}$ & Lidocaine, acetazolamide & $\begin{array}{l}\text { Evidence for precision (mechanism- } \\
\text { based) treatment status limited }\end{array}$ \\
\hline$S C N 8 A$ & $\begin{array}{l}\text { Sodium voltage-gated } \\
\text { channel alpha } \\
\text { subunit } 8\end{array}$ & $\begin{array}{l}\text { Voltage-gated } \\
\text { sodium channel }\end{array}$ & $\begin{array}{l}\text { Benign familial } \\
\text { infantile seizures } \\
\text { or EIEE }\end{array}$ & $\begin{array}{l}\text { High levels of phenytoin } \\
\text { or carbamazepine; } \\
\text { amitriptyline, } \\
\text { nilvadipine, carvedilol }\end{array}$ & $\begin{array}{l}\text { Based on one study for one } \\
\text { mutation in SCN8A }\end{array}$ \\
\hline$S L C 2 A 1$ & $\begin{array}{l}\text { Solute carrier family } 2 \\
\text { member } 1\end{array}$ & Transporter & $\begin{array}{l}\text { Idiopathic } \\
\text { generalized } \\
\text { epilepsy }\end{array}$ & Ketogenic diet & $\begin{array}{l}\text { Bypasses the pathophysiology to } \\
\text { provide an alternative energy } \\
\text { supply to the brain }\end{array}$ \\
\hline$S T X B P 1$ & $\begin{array}{l}\text { Syntaxin-binding } \\
\text { protein } 1\end{array}$ & $\begin{array}{l}\text { Membrane } \\
\text { trafficking }\end{array}$ & EIEE & $\begin{array}{l}\text { Levetiracetam, folinic } \\
\text { acid, vigabatrin }\end{array}$ & Only anecdotal evidence \\
\hline $\begin{array}{l}\text { TSC1 } \\
\quad \text { and } 2\end{array}$ & $\begin{array}{l}\text { TSC (tuberous sclerosis } \\
\text { complex) subunits } \\
1 \text { and } 2\end{array}$ & $\begin{array}{l}\text { Unclassified; } \\
\text { mutations lead to } \\
\text { increased activity } \\
\text { of mTOR }\end{array}$ & Tuberous sclerosis & Everolimus & $\begin{array}{l}\text { A precision treatment with support } \\
\text { from clinical trials and licensed } \\
\text { for particular uses in tuberous } \\
\text { sclerosis complex }\end{array}$ \\
\hline
\end{tabular}

EIEE, early infantile epileptic encephalopathy. 
Monkeys, and in patient-derived fibroblast lines. As the authors emphasized, primate- and mouse-specific antagoNATs had to be selected for the different experiments. This example nicely illustrates that flexible approaches are necessary for specific indications and molecular targeting approaches. Nevertheless, the major advantage of the ETSP is its capacity to screen hundreds of structurally and mechanistically diverse compounds per year at the major contract site (University of Utah), which increases the chance of identifying a new "nextgeneration" compound that really makes a difference for drug-resistant patients.

\section{B. Precision Medicine}

Precision medicine is a treatment approach in which disease treatment and prevention is tailored to individual variability in genes, environment, and lifestyle for each person (National Research Council US Committee on A Framework for Developing a New Taxonomy of Disease, 2011). Despite much recent discussion about precision medicine, in concept, it is how clinical medicine should always have been practiced at any time in the modern era, taking into consideration all the apparently relevant contemporary information about the patient, their circumstances, and investigations. The advent of potent genomic technologies now allows us to add genomic sequence data to all the other data available for decision-making; in due course, other "omic" data (e.g., epigenomic information) may also be added to the mix. Enthusiasm for precision medicine currently stems largely from discoveries from genetics about the causation of some of the rare, severe, typically early-onset epilepsies, including the developmental and epileptic encephalopathies. The list of genes carrying pathogenic rare variants is growing at a rapid pace. These discoveries have in some cases led to better understanding of disease biology, and, occasionally, rational treatment strategies have been devised, including better selection from existing ASDs or repurposing of drugs licensed but previously not for use in epilepsy, sometimes with dramatic responses (Demarest and Brooks-Kayal, 2018; Møller et al., 2019; Table 4). However, this enthusiasm needs to be tempered by the fact that most such reports are anecdotal and short-term, and for many of the newly explained genetic epilepsies, a precision medicine approach employing a theoretically ideal treatment is not available or, in fact, fails (Sisodiya, 2020). Nevertheless, the approach of identifying the cause of a particular epilepsy and establishing a rational treatment option remains attractive and may offer a novel strategy for epilepsies that were previously resistant to treatment. Perhaps the best example of this is the understanding of disease biology and patterns of response to existing ASDs that has emerged from the now well-established finding that most cases of Dravet syndrome are due to loss-of-function pathogenic variants in SCN1A (Ziobro et al., 2018), though there is still a need for better treatments (Brigo et al., 2018; Mantegazza and Broccoli, 2019). Whether the paradigm that Dravet syndrome so nicely illustrates will be commonly replicated for other such defined epilepsies remains to be seen. The precision medicine approach might also extend to developments that specifically seek to target the underlying pathophysiology, some of which we highlight below.

Though several ASDs targeting sodium channels are already available, the identification and design of selective sodium channel modulators may offer novel therapeutic opportunities for patients with gain- or loss-offunction mutations in genes encoding a specific sodium channel isoform. These compounds include XEN901 and Prax330 as $\mathrm{Na}_{\mathrm{v}} 1.6$-selective sodium channel modulators developed for management of SCN8A-related epileptic encephalopathy caused by gain-of-function mutation (Bialer et al., 2018; Wengert et al., 2019). Another drug discovery program seeks to identify compounds that selectively activate $\mathrm{Na}_{\mathrm{v}} 1.1$ (Frederiksen et al., 2017). In this context, the spider venom peptide heteroscodratoxin-1 (Hm1a) has also been characterized as a $\mathrm{Na}_{\mathrm{v}} 1$.1-selective sodium channel activator (Richards et al., 2018). Drug candidates that target $\mathrm{Na}_{\mathrm{v}} 1.1$ would be of particular interest for people with Dravet syndrome caused by loss-offunction variants in SCN1A.

Other approaches aim to increase expression rates of functional proteins in patients with genetic deficiencies. Readthrough compounds such as ataluren increase the generation of a functional protein despite a nonsense mutation in the encoding gene (Namgoong and Bertoni, 2016). Although originally developed for therapeutic management of Duchenne muscle dystrophy, clinical trials have been registered for Dravet syndrome and cyclin-dependent kinase-like 5 deficiency (https:// clinicaltrials.gov/ct2/show/NCT02758626).

Another therapeutic concept for patients with haploinsufficiencies is based on targeting of a cis-acting lncRNA based on administration of an antagoNAT. The antagonNAT binds and inhibits the gene-specific lncRNA, thereby limiting the suppression of gene expression from the intact allele. The antagoNAT CUR-1916 has been shown to increase Scn1a expression in a Dravet mouse model and in patient-derived cells (Hsiao et al., 2016).

Interestingly, success of therapeutic trials in individual patients may also guide the development of precision medicine approaches. Following case reports describing a responsiveness of febrile infection-related epilepsy syndrome (FIRES) with super-refractory SE to the human recombinant form of IL-1Ra, anakinra (Kenney-Jung et al., 2016; Dilena et al., 2019), a recent study provided evidence for a functional deficiency of the endogenous IL-1Ra in patients with FIRES, and sequencing in one index patient revealed genetic variants 
that might be linked with this functional deficiency (Clarkson et al., 2019). Though this example requires further support linking genetics, pathophysiology, and the therapeutic concept, it nevertheless represents an elegant example of how individual cases can guide research strategies in the development of novel precision medicine approaches. An even more impressive example for precision medicine is everolimus, an inhibitor of the mammalian target of rapamycin (mTOR), which has been approved for treatment of seizures in patients with mutations in tuberous sclerosis complex (TSC) genes, which are causally linked to activation of the mTOR signaling cascade (Table 4). Several other examples of precision (mechanism-based) treatments are shown in Table 4, although the clinical evidence is often limited.

\section{Development of More Effective Antiseizure Drugs by Revised Target-Based Drug Discovery}

The recent advance of developing etiology-specific drugs (precision medicine) for severe pediatric epilepsies is an excellent example of new target-based drug discovery strategies. However, monogenic epilepsies individually are rare, so more effective ASDs are urgently needed for the more common polygenic and nongenetic (acquired) epilepsies as well. Unfortunately, principles of precision medicine cannot be used yet for therapy selection in common types of epilepsy because resistance or response to a specific ASD cannot be predicted, thus preventing stratification of individuals into subpopulations based on likely differences in treatment response (Tang et al., 2017). Obviously, the various mechanisms by which currently used ASDs act (Table 1) are not effective in at least $30 \%$ of patients with such epilepsies. So how do we identify targets for more effective drugs? Here, several lines of evidence and modern technology are relevant, including recent advances in understanding the pathophysiological mechanisms underpinning pharmacoresistance and the epilepsies; systems-level, multi-omic, and big data approaches; and tissues, cells, or organoids from drugresistant patients. In addition, iPSCs from individuals with specific genetic variants constitute a promising model for both mechanistic studies at the cellular and network level as well as a potential platform for highthroughput drug development. Importantly, any novel or repositioned candidate ASD, including those identified by "big data" computational approaches, will need to be validated in complex animal models, such as those described above. Two recent examples of how modern technology can provide interesting novel target-based therapies are described in the following.

In the first example, a medicinal chemistry program was initiated to rationally design compounds with high affinity for presynaptic SV2 proteins and low-to-moderate affinity for the postsynaptic benzodiazepine binding site on $\mathrm{GABA}_{\mathrm{A}}$ receptors, resulting in the first-in-class compound padsevonil (Wood et al., 2020). The rationale for targeting these proteins was based on observations that the SV2A ligand levetiracetam markedly potentiated the activity of ASDs acting via GABAergic transmission, notably benzodiazepines, in several animal models, resulting in an improved efficacy/safety ratio (Kaminski et al., 2009). In contrast to benzodiazepines, which typically act as high-affinity full agonists at the benzodiazepine binding site on $\mathrm{GABA}_{\mathrm{A}}$ receptors, padsevonil acts as a low-affinity partial agonist at this site, with only $40 \%$ intrinsic efficacy compared with full agonists (Wood et al., 2020). This profile was intended to reduce tolerance and dependence liability as previously shown for other low-affinity partial agonists (Rundfeldt and Löscher, 2014). Padsevonil also differs from levetiracetam because it acts not only at SV2A but also SV2B and SV2C isotypes of the SV proteins (Wood et al., 2020). As a consequence of this novel profile, padsevonil was more effective in blocking seizures in various animal models, including models of ASD-resistant seizures, than levetiracetam and brivaracetam or combinations of these SV2A ligands with benzodiazepines (Leclercq et al., 2020). A recent clinical proof-of-concept trial confirmed the superior efficacy of padsevonil in 55 patients with frequent multidrug-resistant partial seizures (Bialer et al., 2018). Currently, the drug is undergoing a phase III trial, which will determine whether padsenovil is efficacious in patients with DRE.

In the second example, Srivastava et al. (2018) used a novel gene network approach for identifying mechanistically new drug targets for epilepsy from diseaserelated gene expression data. Starting from genomewide gene expression profiling of hippocampi from pilocarpine-treated epileptic mice, they first identified coexpression networks (modules) associated with the epileptic condition. Twelve modules were found to be significantly differentially coexpressed between the epileptic and control hippocampus. The cell-type specificity of these modules and their functional processes was assessed using enrichment analyses. Nine of the 12 modules correlated with seizures, and of those, module 18 (enriched for inflammatory processes and expressed in microglia) was the module most significantly positively correlated with seizures. Seven modules, including module 18 , were also differentially coexpressed in the hippocampus of humans with TLE, supporting the relevance of the pilocarpine mouse model of TLE to human TLE. From the pragmatic perspective of drug discovery, Srivastava et al. (2018) then set out to identify regulators of each of these modules as potential ASD targets. Of the many membrane receptors predicted to significantly influence the expression of module genes in a direction-specified manner, the tyrosine kinase receptor CSF1R (also known as macrophage colony-stimulating factor receptor) was predicted to be a regulator of two of the seven prioritized candidate epilepsy modules, including module 18 . It was hypothesized that blockade of CSF1R should be therapeutic in 
epilepsy (i.e., reduce seizures). The availability of the known CSF1R inhibitor PLX3397 provided a tool to experimentally test this hypothesis. PLX3397 and similar CSF1R inhibitors have been shown to deplete brain microglia at high doses (Elmore et al., 2014). However, at the low doses of PLX3397 used by Srivastava et al. (2018), microglia were not depleted, but by downregulating module 18 genes, the epilepsyinduced changes in microglia phenotype were reversed. Next, the antiseizure efficacy of PLX3397 was demonstrated in two mouse models of TLE, the pilocarpine and the intrahippocampal kainate models. In both models, PLX3797 significantly reduced the frequency or duration of spontaneous seizures. In contrast, PLX3397 did not suppress seizures in acute seizure models in nonepileptic mice, i.e., the MES model, the $6-\mathrm{Hz}$ seizure model, and the PTZ model. These data clearly distinguish PLX3397 from most presently used ASDs, which are typically effective in such acute seizure models. Overall, this is an impressive study, which resulted from a concerted effort between scientists, clinicians, and industry, demonstrating that restoration of disease-related module expression toward health is predictive of therapeutic benefit, allowing "target" validation at the earliest stage of the drug discovery process. It remains to be proven whether the approach used by Srivastava et al. (2018) leads to more effective and tolerable ASDs in people with epilepsy.

Several other novel ASDs with mechanisms different from those illustrated in Table 1 are currently in the preclinical or clinical pipeline (Golyala and Kwan, 2017; Bialer et al., 2018; Löscher and Klein, 2020). Clinical studies of cenobamate, which was recently approved for the treatment of partial-onset seizures in adults (Fig. 1), showed approximately $20 \%$ of patients experienced seizure freedom, which is very impressive compared with previous add-on clinical trials with various other novel ASDs in patients with DRE (Krauss et al., 2020). Cenobamate is thought to work through a dual mechanism, enhancing inhibitory currents through $\mathrm{GABA}_{\mathrm{A}}$ receptor modulation and decreasing excitatory currents by inhibiting the persistent component of the sodium current (Golyala and Kwan. 2017). A similar impressive antiseizure effect has been observed with the novel ASD fenfluramine in Dravet syndrome, in which approximately $25 \%$ of patients had long-term seizure freedom, suggesting that the long hoped-for breakthrough is a feasible goal (Polster, 2019). In addition to novel ASDs, add-on treatment with drugs that act on mechanisms of ASD resistance, such as coadministration of Pgp inhibitors or anti-inflammatory drugs with ASDs, is a promising therapeutic avenue to overcome drug resistance, which will be discussed in the following.

\section{Targeting of Transporter Function and Expression}

Based on the transporter hypothesis, one strategy to counteract pharmacoresistance in epilepsy is the adjunctive use of Pgp inhibitors (Schmidt and Löscher, 2009; Tang et al., 2017; see also section IV. B. Alteration of Drug Uptake into the Brain). That such a strategy may be relevant in patients with epilepsy is suggested by several anecdotal reports on single patients with intractable epilepsy in whom the nonselective Pgp inhibitor verapamil was added to the ASD regimen (Tang et al., 2017). One pilot non-placebo-controlled open-label study in 19 adult patients with drugresistant TLE found that adding verapamil $(120 \mathrm{mg}$ daily in 13 patients and $240 \mathrm{mg}$ daily in six patients) to the existing ASD treatment improved seizure control in a dose-dependent manner (Asadi-Pooya et al., 2013). However, in a randomized, double-blinded, placebocontrolled trial on once-daily $240 \mathrm{mg}$ verapamil as an add-on therapy in DRE patients with focal onset seizures, no statistically significant decrease in seizure frequency was observed (Borlot et al., 2014). A more recent non-placebo-controlled open-label study, which explored the efficacy of low-dose verapamil (20 mg three times daily) as adjunctive treatment in DRE, reported that 10 out of 19 patients achieved $50 \%$ or more seizure reduction (Narayanan et al., 2016). Importantly, in none of these studies was it shown that drug resistance was due to Pgp overactivity in the first place or that verapamil was actually modulating Pgp activity. Clinical proof-of-concept trials with more selective Pgp inhibitors such as tariquidar or elacridar are needed, although the risks of such an approach need to be considered. In this respect, it is important to note that Feldmann et al. (2013) demonstrated that ASDresistant patients with increased Pgp functionality in epileptogenic brain regions can be identified by PET, thus selecting those patients who may benefit most from add-on treatment with a Pgp inhibitor.

However, as shown in clinical cancer trials, the use of Pgp-specific inhibitors such as tariquidar or elacridar is not without concerns, as systemic inhibition of Pgp could increase plasma and tissue levels of drugs and toxins, potentially leading to systemic toxicity (Chung et al., 2016; Tang et al., 2017). Another approach we and others suggested is modulating transporter regulation in epilepsy without affecting basal transporter expression and function (Bauer et al., 2008; Potschka, 2010; Hartz et al., 2017; Tang et al., 2017). Such strategies aim to target the signaling cascades that upregulate transporter expression in response to seizure activity. As further outlined below, confirmation of the potential of this approach came from experimental studies in rodent models and from assessment in human capillaries from people with epilepsy undergoing therapeutic surgery (e.g., Potschka, 2012; Avemary et al., 2013).

As discussed above, clinical trials on such strategies would benefit from the use of PET imaging to enrich the trial population with people with increased Pgp function in the brain. Furthermore, developing new ASDs that are not substrates of efflux transporters is an 
option. For this option, it is important to note that Pgp is not the only major efflux transporter at the human $\mathrm{BBB}$ and that BCRP is even more highly expressed (Uchida et al., 2011). As shown recently, lamotrigine is a substrate of mouse and human BCRP (Römermann et al., 2015), and the same may be true for other ASDs not yet tested in this respect. Furthermore, MRPs may be involved in ASD efflux at the BBB (Potschka et al., 2003a,b).

\section{E. Anti-Inflammatory Drugs and Strategies to Repair the $B B B$}

The causal and reciprocal link between neuroinflammation and BBB dysfunction and their potential involvement in drug-resistant seizure mechanisms has fostered therapeutic interest in developing drugs that target pathologic inflammatory pathways or re-establish the physiologic permeability properties of the BBB.

1. Cyclooxygenase 2-Prostaglandin E2 Signaling. The role of COX-2 in Pgp upregulation in epilepsy was demonstrated by molecular studies (see previous section) and was reinforced by pharmacological data showing that treatments of epileptic rats with selective COX-2 inhibitors could reverse Pgp upregulation (Schlichtiger et al., 2010). Notably, COX-2 inhibitors administered to epileptic rats with enhanced Pgp expression in brain vessels also increased the brain delivery of systemic phenytoin, a substrate of Pgp (van Vliet et al., 2010). Moreover, COX-2 inhibition by celecoxib was able to restore pharmacosensitivity of seizures to phenobarbital in a chronic rat model of DRE and to decrease Pgp expression in hippocampal vessels of drug-resistant rats to control levels (Schlichtiger et al., 2010).

Among the various prostanoids deriving from COX-2 activation, PGE2 appears to be the key molecule modulating Pgp expression though EP1R activation. Pharmacological EP1R blockade in a rat kindling model of epileptogenesis resulted in anticonvulsive effects of a phenobarbital dose that was otherwise ineffective in the absence of EP1R blockade (Pekcec et al., 2009). This strategy might also be of value for reducing the risk of developing SE; constitutive EP1R gene knockout mice displayed a reduced likelihood to enter SE, and EP1R knockout mice that did experience SE showed both reduced hippocampal neurodegeneration and neuroinflammatory response (Rojas et al., 2014). Drugs that block EP1R should be safer than COX-2 inhibitors that may be associated with cardiotoxicity, and some COX-2 inhibitors were reported to worsen spontaneous seizures or increase mortality after SE in animal models (Holtman et al., 2009, 2010).

2. Interleukin-1 $\beta$-Interleukin-1-Receptor Type 1 Signaling. This inflammatory pathway is involved in the generation of the neuroinflammatory cascade in epilepsy and plays a significant role in seizure generation and recurrence in animal models (Vezzani et al., $2011,2019)$. In the acute experimental setting, the human recombinant form of IL-1Ra, i.e., anakinra, a drug in medical use for autoinflammatory and autoimmune diseases, was shown to enhance the efficacy of diazepam for reducing duration and severity of benzodiazepine-resistant SE in mice (Xu et al., 2016). The anti-ictogenic activity of IL-1Ra in various experimental models of acute seizures (Vezzani et al., 1999, 2000; Marchi et al., 2009) led to clinical application of anakinra for controlling drug-resistant seizures in children with FIRES and in other DRE forms (Jyonouchi and Geng, 2016; Kenney-Jung et al., 2016; DeSena et al., 2018; Dilena et al., 2019; Sa et al., 2019). Another example of clinical translation is a phase II study in focal onset drug-resistant adult epilepsy with belnacasan (VX-765), an inhibitor of caspase-1, which is the enzyme involved in the biosynthesis of the ictogenic cytokine IL-1 $\beta$ (Bialer et al., 2013). The trial reported a $50 \%$ reduction in seizures in $31.3 \%$ of subjects in the VX-765 group versus $8.3 \%$ in the placebo group; $12.5 \%$ of the VX-765 subjects were seizure-free versus $0 \%$ in the placebo group. The same drug was proven effective in mice with chronic pharmacoresistant nonconvulsive seizures (Maroso et al., 2011).

3. Other Anti-Inflammatory Strategies. Recent clinical studies have reported therapeutic effects on drugresistant seizures of various anti-inflammatory drugs that target specific inflammatory pathways activated in human epilepsy and in animal studies [reviewed in Terrone et al. (2017), van Vliet et al. (2018)]. The inflammatory targets include COX-1/2 (aspirin), TNF (adalimumab), IL-6R (tocilizumab), anti- $\alpha 4$ integrin antibody (natalizumab), and the broad-spectrum microglia inhibitor (minocycline) (reviewed in Vezzani et al., 2019).

4. Molecular Mechanisms of Therapeutic Effects. Except for the molecular studies on COX-2-PGE2-EP1R axis and its relationship with Pgp expression and activity, we do not know whether the mechanisms by which anti-inflammatory drugs inhibit drug-resistant seizures involve drug transport proteins. However, experimental evidence has repeatedly shown that neuroinflammation may decrease seizure threshold by a rapid onset and persistent modulation of voltagegated ion channels as well as by mediating changes in phosphorylation and molecular assembly of both glutamate and GABA receptor-coupled ion channels in neuronal membranes (Roseti et al., 2013, 2015; Vezzani and Viviani, 2015; Frigerio et al., 2018). These neuromodulatory effects of cytokines such as IL- $1 \beta$ and TNF, which are permissive for hyperexcitability, may be involved, for example, in reducing target susceptibility to classic ASDs that act on voltage-gated channels (Rogawski and Löscher, 2004) or play a role in SE refractoriness to benzodiazepines and the associated changes in $\mathrm{GABA}_{\mathrm{A}}$ receptor subunits (Niquet et al., 2016).

5. Strategies to Repair the BBB. Neuroinflammation contributes to $\mathrm{BBB}$ permeability modifications (see 
above), which, in turn, may change pharmacokinetics of ASDs by reducing their brain delivery at cellular and molecular targets, thereby decreasing their efficacy (Löscher and Potschka, 2005; Löscher, 2007). Thus, anti-inflammatory drugs that repair BBB permeability dysfunction by reducing cytokine and COX-2 signals may improve seizure response to some therapeutic drugs.

Targeting of the albumin-activated TGF- $\beta$ signaling in astrocytes is another option for blocking the BBB dysfunction and the potential consequences for pharmacoresistance. In particular, losartan (Bar-Klein et al., 2014, 2017), or the more specific TGF- $\beta$-pathway inhibitor SJN2511 (Weissberg et al., 2015), respectively, prevented the microvascular changes and the pathologic consequences of BBB dysfunction, such as excitatory synaptogenesis, in epilepsy models. These treatments also reduced the incidence of epilepsy and the number of spontaneous seizures in the animals and reduced the neuroinflammatory response. However, it remains to be tested whether the epileptic seizures still developing in treated animals were more sensitive to ASDs than seizures occurring in untreated animals.

Finally, broad spectrum imunosuppressive and antiinflammatory steroids, diet-based treatments such as the ketogenic diet, and neurostimulation such as the vagal nerve stimulation may control drug-resistant seizures in a proportion of epilepsy patients, particularly in the pediatric population (French et al., 2017). These therapeutic approaches are endowed of antiinflammatory effects, and steroids also repair BBB dysfunction and vessel inflammation by reducing the brain extravasation of leukocytes. Although there is no clear demonstration that these anti-inflammatory and BBB-repairing actions do mediate the therapeutic effects of these interventions, these actions likely contribute to seizure control, as supported by preclinical studies and by evidence based on the use of more specific antiinflammatory drugs in human DRE.

\section{Conclusions}

Despite the introduction of various novel ASDs, drug resistance remains one of the major challenges in epilepsy treatment. In this review, we critically discuss various theories that have been proposed to explain the mechanisms underlying DRE. Furthermore, we discuss several possible strategies to overcome drug resistance. There are various nonpharmacological options, including epilepsy surgery, electrical stimulation, ketogenic diet, and gene therapy, which are not discussed here (for review, see Devisnsky et al., 2018). It is important to consider that ASD resistance is very probably not caused by a single mechanism in all patients but is rather more likely due to several mechanisms, which may even occur together in the same patient. Thus, overcoming ASD resistance is unlikely to be an easy task but will necessitate combined efforts of basic and clinical epileptologists. For improved therapy of seizures in people with DRE, factors specific to individual patients, such as disease etiology, medical history, drug response, temporal patterns of refractoriness, comorbidities, and the multifactorial nature of pharmacoresistance, need to be taken into account, thus placing more emphasis on personalizing the therapy (Tang et al., 2017). Novel imaging techniques might help to increase our understanding of the mechanisms of drug resistance active in people with epilepsy and guide treatment in individual patients. In addition, based on the availability of various new ASDs, there is increasing evidence that the old concept of "rational polytherapy," combining ASDs that work by different mechanisms, may provide a reasonable approach to managing DRE (Brodie, 2016). The fact that, despite numerous new ASDs, the proportion of patients with epilepsy who do not respond to treatments has changed little should not discourage efforts to develop ASDs with novel mechanisms, as underlined by the promising studies with cenobamate, fenfluramine, or padsevonil discussed above. Similarly, the ongoing development of strategies focused on specific disease mechanisms might soon result in a paradigm shift for management of certain genetic epilepsies.

\section{Authorship Contributions}

Wrote or contributed to the writing of the manuscript: Löscher, Potschka, Sisodiya, Vezzani.

\section{References}

Abbott NJ (2000) Inflammatory mediators and modulation of blood-brain barrier permeability. Cell Mol Neurobiol 20:131-147.

Abbott NJ (2013) Blood-brain barrier structure and function and the challenges for CNS drug delivery. J Inherit Metab Dis 36:437-449.

Asadi-Pooya AA, Razavizadegan SM, Abdi-Ardekani A, and Sperling MR (2013) Adjunctive use of verapamil in patients with refractory temporal lobe epilepsy: a pilot study. Epilepsy Behav 29:150-154

Avemary J, Salvamoser JD, Peraud A, Rémi J, Noachtar S, Fricker G, and Potschka $\mathrm{H}$ (2013) Dynamic regulation of P-glycoprotein in human brain capillaries. $\mathrm{Mol}$ Pharm 10:3333-3341.

Balestrini S and Sisodiya SM (2018) Pharmacogenomics in epilepsy. Neurosci Lett 667:27-39

Balosso S, Maroso M, Sanchez-Alavez M, Ravizza T, Frasca A, Bartfai T, and Vezzani A (2008) A novel non-transcriptional pathway mediates the proconvulsive effects of interleukin-1beta. Brain 131:3256-3265.

Bankstahl M, Bankstahl JP, and Löscher W (2012) Inter-individual variation in the anticonvulsant effect of phenobarbital in the pilocarpine rat model of temporal lobe epilepsy. Exp Neurol 234:70-84.

Bankstahl M, Bankstahl JP, and Löscher W (2013) Pilocarpine-induced epilepsy in mice alters seizure thresholds and the efficacy of antiepileptic drugs in the 6-Hertz psychomotor seizure model. Epilepsy Res 107:205-216.

Baraban S and Löscher W (2014) What new modeling approaches will help us identify promising drug treatments? Adv Exp Med Biol 813:283-294.

Bar-Klein G, Cacheaux LP, Kamintsky L, Prager O, Weissberg I, Schoknecht K, Cheng P, Kim SY, Wood L, Heinemann U, et al. (2014) Losartan prevents acquired epilepsy via TGF- $\beta$ signaling suppression. Ann Neurol 75:864-875.

Bar-Klein G, Lublinsky S, Kamintsky L, Noyman I, Veksler R, Dalipaj H, Senatorov VV Jr., Swissa E, Rosenbach D, Elazary N, et al. (2017) Imaging blood-brain barrier dysfunction as a biomarker for epileptogenesis. Brain 140:1692-1705.

Barkovich AJ, Dobyns WB, and Guerrini R (2015) Malformations of cortical development and epilepsy. Cold Spring Harb Perspect Med 5:a022392.

Barton ME, Klein BD, Wolf HH, and White HS (2001) Pharmacological characterization of the $6 \mathrm{~Hz}$ psychomotor seizure model of partial epilepsy. Epilepsy Res 47: 217-227.

Bauer B, Hartz AM, Pekcec A, Toellner K, Miller DS, and Potschka H (2008) Seizureinduced up-regulation of P-glycoprotein at the blood-brain barrier through glutamate and cyclooxygenase-2 signaling. Mol Pharmacol 73:1444-1453.

Bauer M, Karch R, Zeitlinger M, Liu J, Koepp M, Asselin M-C, Sisodiya S, Hainfellner J, Wadsak W, Mitterhauser M, et al. (2014) In vivo P-glycoprotein function before and after epilepsy surgery. Neurology 83:1326-1331. 
Ben-Ari Y, Khalilov I, Kahle KT, and Cherubini E (2012) The GABA excitatory/ inhibitory shift in brain maturation and neurological disorders. Neuroscientist 18: 467-486.

Berendt M, Farquhar R, Mandigers P, Pakozdy A, Bhatti S, De Risio L, Fischer A, Long S, Matiasek K, Muñana K, et al. (2015) International veterinary epilepsy task force consensus report on epilepsy definition, classification and terminology in companion animals. BMC Vet Res 11:182.

Berg AT, Langfitt J, Shinnar S, Vickrey BG, Sperling MR, Walczak T, Bazil C, Pacia SV, and Spencer SS (2003) How long does it take for partial epilepsy to become intractable? Neurology 60:186-190.

Bethmann K, Brandt C, and Löscher W (2007) Resistance to phenobarbital extends to phenytoin in a rat model of temporal lobe epilepsy. Epilepsia 48:816-826.

Bethmann K, Fritschy JM, Brandt C, and Löscher W (2008) Antiepileptic drug resistant rats differ from drug responsive rats in GABA A receptor subunit expression in a model of temporal lobe epilepsy. Neurobiol Dis 31:169-187.

Bialer M, Johannessen SI, Levy RH, Perucca E, Tomson T, and White HS (2013) Progress report on new antiepileptic drugs: a summary of the Eleventh Eilat Conference (EILAT XI). Epilepsy Res 103:2-30.

Bialer M, Johannessen S, Koepp M, Levy R, Perucca E, Tomson T, and White H (2018) Progress report on new antiepileptic drugs: A summary of the Fourteenth Eilat Conference on New Antiepileptic Drugs and Devices (EILAT XIV). I. Drugs in preclinical and early clinical development. Epilepsia 59:1811-1841.

Blanco MM, dos Santos JG Jr., Perez-Mendes P, Kohek SR, Cavarsan CF, Hummel M, Albuquerque C, and Mello LE (2009) Assessment of seizure susceptibility in pilocarpine epileptic and nonepileptic Wistar rats and of seizure reinduction with pentylenetetrazole and electroshock models. Epilepsia 50:824-831.

Borlot F, Wither RG, Ali A, Wu N, Verocai F, and Andrade DM (2014) A pilot doubleblind trial using verapamil as adjuvant therapy for refractory seizures. Epilepsy Res 108:1642-1651.

Brandt C, Bethmann K, Gastens AM, and Löscher W (2006) The multidrug transporter hypothesis of drug resistance in epilepsy: proof-of-principle in a rat model of temporal lobe epilepsy. Neurobiol Dis 24:202-211.

Brandt C and Löscher W (2014) Antiepileptic efficacy of lamotrigine in phenobarbital-resistant and -responsive epileptic rats: a pilot study. Epilepsy Res 108:1145-1157.

Brandt C, Volk HA, and Löscher W (2004) Striking differences in individual anticonvulsant response to phenobarbital in rats with spontaneous seizures after status epilepticus. Epilepsia 45:1488-1497.

Brigo F, Striano P, Balagura G, and Belcastro V (2018) Emerging drugs for the treatment of Dravet syndrome. Expert Opin Emerg Drugs 23:261-269.

Brodie MJ (2016) Pharmacological treatment of drug-resistant epilepsy in adults: a practical guide. Curr Neurol Neurosci Rep 16:82.

Broekaart DWM, Anink JJ, Baayen JC, Idema S, de Vries HE, Aronica E, Gorter JA and van Vliet EA (2018) Activation of the innate immune system is evident throughout epileptogenesis and is associated with blood-brain barrier dysfunction and seizure progression. Epilepsia 59:1931-1944.

Brooks-Kayal AR, Shumate MD, Jin H, Rikhter TY, and Coulter DA (1998) Selective changes in single cell $\mathrm{GABA}_{\mathrm{A}}$ ) receptor subunit expression and function in temporal lobe epilepsy. Nat Med 4:1166-1172.

Brown WC, Schiffman DO, Swinyard EA, and Goodman LS (1953) Comparative assay of an antiepileptic drugs by psychomotor seizure test and minimal electroshock threshold test. J Pharmacol Exp Ther 107:273-283.

Brückl TM and Uhr M (2016) ABCB1 genotyping in the treatment of depression. Pharmacogenomics 17:2039-2069.

Chen Z, Brodie MJ, Liew D, and Kwan P (2018) Treatment outcomes in patients with newly diagnosed epilepsy treated with established and new antiepileptic drugs: a 30-year longitudinal cohort study. JAMA Neurol 75:279-286.

Chouchi M, Kaabachi W, Klaa H, Tizaoui K, Turki IB, and Hila L (2017) Relationship between ABCB1 3435TT genotype and antiepileptic drugs resistance in Epilepsy: updated systematic review and meta-analysis. BMC Neurol 17:32.

Chung FS, Santiago JS, Jesus MF, Trinidad CV, and See MF (2016) Disrupting P-glycoprotein function in clinical settings: what can we learn from the fundamental aspects of this transporter? Am J Cancer Res 6:1583-1598.

Clarkson B, LaFrance-Corey R, Kahoud R, Farias-Moeller R, Payne E, and Howe C (2019) Functional deficiency in endogenous interleukin-1 receptor antagonist in patients with febrile infection-related epilepsy syndrome. Ann Neurol 85:526-537.

Cohen I, Navarro V, Clemenceau S, Baulac M, and Miles R (2002) On the origin of interictal activity in human temporal lobe epilepsy in vitro. Science $\mathbf{2 9 8}$ 1418-1421.

Coulter DA (2000) Mossy fiber zinc and temporal lobe epilepsy: pathological association with altered "epileptic" gamma-aminobutyric acid A receptors in dentate granule cells. Epilepsia 41 (Suppl 6):S96-S99.

Coulter DA (2001) Epilepsy-associated plasticity in gamma-aminobutyric acid receptor expression, function, and inhibitory synaptic properties. Int Rev Neurobiol 45:237-252.

Cucullo L, Hossain M, Rapp E, Manders T, Marchi N, and Janigro D (2007) Development of a humanized in vitro blood-brain barrier model to screen for brain penetration of antiepileptic drugs. Epilepsia 48:505-516.

Dalic L and Cook MJ (2016) Managing drug-resistant epilepsy: challenges and solutions. Neuropsychiatr Dis Treat 12:2605-2616.

Demarest ST and Brooks-Kayal A (2018) From molecules to medicines: the dawn of targeted therapies for genetic epilepsies. Nat Rev Neurol 14:735-745.

Deng X, Shao Y, Xie Y, Feng Y, Wu M, Wang M, and Chen Y (2019) MicroRNA-146a$5 \mathrm{p}$ downregulates the expression of P-glycoprotein in rats with lithium-pilocarpineinduced status epilepticus. Biol Pharm Bull 42:744-750.

DeSena AD, Do T, and Schulert GS (2018) Systemic autoinflammation with in tractable epilepsy managed with interleukin-1 blockade. J Neuroinflammation $\mathbf{1 5}$

Devinsky O, Vezzani A, O’Brien TJ, Jette N, Scheffer IE, De Curtis M, and Perucca P (2018) Epilepsy. Nat Rev Dis Primers 4, doi: 10.1038/nrdp.2018.24.
Dilena R, Mauri E, Aronica E, Bernasconi P, Bana C, Cappelletti C, Carrabba G, Ferrero S, Giorda R, Guez S, et al (2019) Therapeutic effect of Anakinra in the relapsing chronic phase of febrile infection-related epilepsy syndrome. Epilepsia Open 4:344-350.

Doeser A, Dickhof G, Reitze M, Uebachs M, Schaub C, Pires NM, Bonifácio MJ, Soares-da-Silva P, and Beck H (2015) Targeting pharmacoresistant epilepsy and epileptogenesis with a dual-purpose antiepileptic drug. Brain 138 371-387.

Du X and Parent JM (2015) Using patient-derived induced pluripotent stem cells to model and treat epilepsies. Curr Neurol Neurosci Rep 15:71.

Dudvarski Stankovic N, Teodorczyk M, Ploen R, Zipp F, and Schmidt MHH (2016) Microglia-blood vessel interactions: a double-edged sword in brain pathologies. Acta Neuropathol 131:347-363.

Duveau V, Pouyatos B, Bressand K, Bouyssieres C, Chabrol T, Roche Y, Depaulis A, and Roucard C (2016) Differential effects of antiepileptic drugs on focal seizures in the intrahippocampal kainate mouse model of mesial temporal lobe epilepsy. CNS Neurosci Ther 22:497-506.

Eastman CL, Verley DR, Fender JS, Stewart TH, Nov E, Curia G, and D'Ambrosio R (2011) Antiepileptic and antiepileptogenic performance of carisbamate after head injury in the rat: blind and randomized studies. J Pharmacol Exp Ther 336: $779-790$.

Ellerkmann RK, Remy S, Chen J, Sochivko D, Elger CE, Urban BW, Becker A, and Beck $\mathrm{H}(2003)$ Molecular and functional changes in voltage-dependent $\mathrm{Na}(+)$ channels following pilocarpine-induced status epilepticus in rat dentate granule cells. Neuroscience 119:323-333.

Elmore M, Najafi A, Koike M, Dagher N, Spangenberg E, Rice R, Kitazawa M, Matusow B, Nguyen H, West B, et al. (2014) Colony-stimulating factor 1 receptor signaling is necessary for microglia viability, unmasking a microglia progenitor cell in the adult brain. Neuron 82:380-397.

Epi25 Collaborative. Electronic address: s.berkovic@unimelb.edu.au; Epi25 Collaborative (2019) Ultra-rare genetic variation in the epilepsies: a whole-exome sequencing study of 17,606 individuals. Am J Hum Genet 105:267-282.

Fang M, Xi ZQ, Wu Y, and Wang XF (2011) A new hypothesis of drug refractory epilepsy: neural network hypothesis. Med Hypotheses 76:871-876.

Feldmann M, Asselin MC, Liu J, Wang S, McMahon A, Anton-Rodriguez J, Walker M, Symms M, Brown G, Hinz R, et al. (2013) P-glycoprotein expression and function in patients with temporal lobe epilepsy: a case-control study. Lancet Neurol 12: $777-785$

Ferrari CC, Depino AM, Prada F, Muraro N, Campbell S, Podhajcer O, Perry VH, Anthony DC, and Pitossi FJ (2004) Reversible demyelination, blood-brain barrier breakdown, and pronounced neutrophil recruitment induced by chronic IL-1 expression in the brain. Am J Pathol 165:1827-1837.

Frederiksen K, Lu D, Yang J, Jensen H, Bastlund J, Larsen P, Liu H, Crestey F, Dekermendjian K, Badolo L, et al. (2017) A small molecule activator of $\mathrm{Na}_{\mathrm{v}} 1.1$ channels increases fast-spiking interneuron excitability and GABAergic transmission in vitro and has anti-convulsive effects in vivo. Eur $J$ Neurosci 46 $1887-1896$.

French JA, Koepp M, Naegelin Y, Vigevano F, Auvin S, Rho JM, Rosenberg E, Devinsky O, Olofsson PS, and Dichter MA (2017) Clinical studies and antiinflammatory mechanisms of treatments. Epilepsia 58 (Suppl 3):69-82.

Friedman A and Heinemann U (2012) Role of blood-brain barrier dysfunction in epileptogenesis. SourceJasper's Basic Mechanisms of the Epilepsies, National Center for Biotechnology Information (US), Bethesda, MD.

Frigerio F, Flynn C, Han Y, Lyman K, Lugo JN, Ravizza T, Ghestem A, Pitsch J, Becker A, Anderson AE, et al. (2018) Neuroinflammation alters integrative properties of rat hippocampal pyramidal cells. Mol Neurobiol 55:7500-7511.

Frigerio F, Frasca A, Weissberg I, Parrella S, Friedman A, Vezzani A, and Noé FM (2012) Long-lasting pro-ictogenic effects induced in vivo by rat brain exposure to serum albumin in the absence of concomitant pathology. Epilepsia 53:1887-1897. Fromm MF (2004) Importance of P-glycoprotein at blood-tissue barriers. Trends Pharmacol Sci 25:423-429.

Galanopoulou AS and Moshé SL (2015) Pathogenesis and new candidate treatments for infantile spasms and early life epileptic encephalopathies: a view from preclinical studies. Neurobiol Dis 79:135-149.

Galovic M, Baudracco I, Wright-Goff E, Pillajo G, Nachev P, Wandschneider B, Woermann F, Thompson P, Baxendale S, McEvoy AW, et al. (2019) Association of piriform cortex resection with surgical outcomes in patients with temporal lobe epilepsy. JAMA Neurol 76:690-700

Gambardella A, Labate A, Mumoli L, Lopes-Cendes I, and Cendes F (2017) Role of pharmacogenomics in antiepileptic drug therapy: current status and future perspectives. Curr Pharm Des 23:5760-5765.

Ghosh C, Puvenna V, Gonzalez-Martinez J, Janigro D, and Marchi N (2011) Bloodbrain barrier P450 enzymes and multidrug transporters in drug resistance: a synergistic role in neurological diseases. Curr Drug Metab 12:742-749.

Giacomini KM, Huang SM, Tweedie DJ, Benet LZ, Brouwer KL, Chu X, Dahlin A, Evers R, Fischer V, Hillgren KM, et al.; International Transporter Consortium (2010) Membrane transporters in drug development. Nat Rev Drug Discov 9 $215-236$.

Golyala A and Kwan P (2017) Drug development for refractory epilepsy: the past 25 years and beyond. Seizure 44:147-156.

Goodkin HP, Yeh JL, and Kapur J (2005) Status epilepticus increases the intracellular accumulation of GABAA receptors. J Neurosci 25:5511-5520.

Griffin A, Hamling KR, Hong S, Anvar M, Lee LP, and Baraban SC (2018) Preclinical animal models for Dravet syndrome: seizure phenotypes, comorbidities and drug screening. Front Pharmacol 9:573.

Grone B and Baraban S (2015) Animal models in epilepsy research: legacies and new directions. Nat Neurosci 18:339-343.

Guo JU, Ma DK, Mo H, Ball MP, Jang MH, Bonaguidi MA, Balazer JA, Eaves HL, Xie B, Ford E, et al. (2011) Neuronal activity modifies the DNA methylation landscape in the adult brain. Nat Neurosci 14:1345-1351. 
Haenisch S, von Rüden EL, Wahmkow H, Rettenbeck ML, Michler C, Russmann V, Bruckmueller H, Waetzig V, Cascorbi I, and Potschka H (2016) miRNA-187-3pMediated regulation of the KCNK10/TREK-2 potassium channel in a rat epilepsy model. ACS Chem Neurosci 7:1585-1594.

Haerian BS, Lim KS, Tan CT, Raymond AA, and Mohamed Z (2011) Association of $\mathrm{ABCB} 1$ gene polymorphisms and their haplotypes with response to antiepileptic drugs: a systematic review and meta-analysis. Pharmacogenomics 12:713-725.

Hartz AM, Pekcec A, Soldner EL, Zhong Y, Schlichtiger J, and Bauer B (2017) P-gp protein expression and transport activity in rodent seizure models and human epilepsy. Mol Pharm 14:999-1011.

Hitiris N, Mohanraj R, Norrie J, Sills GJ, and Brodie MJ (2007) Predictors of pharmacoresistant epilepsy. Epilepsy Res 75:192-196.

Holtman L, van Vliet EA, Edelbroek PM, Aronica E, and Gorter JA (2010) Cox-2 inhibition can lead to adverse effects in a rat model for temporal lobe epilepsy. Epilepsy Res 91:49-56.

Holtman L, van Vliet EA, van Schaik R, Queiroz CM, Aronica E, and Gorter JA (2009) Effects of SC58236, a selective COX-2 inhibitor, on epileptogenesis and spontaneous seizures in a rat model for temporal lobe epilepsy. Epilepsy Res 84: 56-66.

Hsiao J, Yuan TY, Tsai MS, Lu CY, Lin YC, Lee ML, Lin SW, Chang FC, Liu Pimentel H, Olive C, et al. (2016) Upregulation of haploinsufficient gene expression in the brain by targeting a long non-coding RNA improves seizure phenotype in a model of Dravet syndrome. EBioMedicine 9:257-277.

Iannone LF, Preda A, Blottière HM, Clarke G, Albani D, Belcastro V, Carotenuto M, Cattaneo A, Citraro R, Ferraris C, et al. (2019) Microbiota-gut brain axis in volvement in neuropsychiatric disorders. Expert Rev Neurother 19:1037-1050.

Iori V, Iyer AM, Ravizza T, Beltrame L, Paracchini L, Marchini S, Cerovic M, Hill C, Ferrari M, Zucchetti M, et al. (2017) Blockade of the IL-1R1/TLR4 pathway mediates disease-modification therapeutic effects in a model of acquired epilepsy. Neurobiol Dis 99:12-23.

Jandová K, Päsler D, Antonio LL, Raue C, Ji S, Njunting M, Kann O, Kovács R, Meencke HJ, Cavalheiro EA, et al. (2006) Carbamazepine-resistance in the epileptic dentate gyrus of human hippocampal slices. Brain 129:3290-3306.

Jeub M, Beck H, Siep E, Rüschenschmidt C, Speckmann EJ, Ebert U, Potschka H, Freichel C, Reissmüller E, and Löscher W (2002) Effect of phenytoin on sodium and calcium currents in hippocampal CA1 neurons of phenytoin-resistant kindled rats. Neuropharmacology 42:107-116.

Jyonouchi $\mathrm{H}$ and Geng L (2016) Intractable epilepsy (IE) and responses to anakinra a human recombinant IL-1 receptor antagonist (IL-1Ra): case reports. J Clin Cell Immunol 7:456-460

Kahle KT, Staley KJ, Nahed BV, Gamba G, Hebert SC, Lifton RP, and Mount DB (2008) Roles of the cation-chloride cotransporters in neurological disease. Nat Clin Pract Neurol 4:490-503.

Kalilani L, Sun X, Pelgrims B, Noack-Rink M, and Villanueva V (2018) The epidemiology of drug-resistant epilepsy: a systematic review and meta-analysis. Epilepsia 59:2179-2193.

Kaminski RM, Matagne A, Patsalos PN, and Klitgaard H (2009) Benefit of combination therapy in epilepsy: a review of the preclinical evidence with levetiracetam. Epilepsia 50:387-397.

Keezer MR, Sisodiya SM, and Sander JW (2016) Comorbidities of epilepsy: current concepts and future perspectives. Lancet Neurol 15:106-115.

Kehne JH, Klein BD, Raeissi S, and Sharma S (2017) The National Institute of neurological disorders and stroke (NINDS) epilepsy therapy screening program (ETSP). Neurochem Res 42:1894-1903.

Kelley MS, Jacobs MP, and Lowenstein DH; NINDS Epilepsy Benchmark Stewards (2009) The NINDS epilepsy research benchmarks. Epilepsia 50:579-582.

Kenney-Jung DL, Vezzani A, Kahoud RJ, LaFrance-Corey RG, Ho ML, Muskardin TW, Wirrell EC, Howe CL, and Payne ET (2016) Febrile infection-related epilepsy syndrome treated with anakinra. Ann Neurol 80:939-945.

Kim SY, Senatorov VV Jr., Morrissey CS, Lippmann K, Vazquez O, Milikovsky DZ, Gu F, Parada I, Prince DA, Becker AJ, et al. (2017) TGF 3 signaling is associated with changes in inflammatory gene expression and perineuronal net degradation around inhibitory neurons following various neurological insults. Sci Rep 7:7711.

Klein S, Bankstahl M, and Löscher W (2015) Inter-individual variation in the effect of antiepileptic drugs in the intrahippocampal kainate model of mesial temporal lobe epilepsy in mice. Neuropharmacology 90:53-62.

Klement W, Blaquiere M, Zub E, deBock F, Boux F, Barbier E, Audinat E, LernerNatoli M, and Marchi N (2019) A pericyte-glia scarring develops at the leaky capillaries in the hippocampus during seizure activity. Epilepsia 60:1399-1411.

Kobow K and Blümcke I (2018) Epigenetics in epilepsy. Neurosci Lett 667:40-46.

Kobow K, El-Osta A, and Blümcke I (2013) The methylation hypothesis of pharmacoresistance in epilepsy. Epilepsia 54 (Suppl 2):41-47.

Koepp MJ (2014) Neuroimaging of drug resistance in epilepsy. Curr Opin Neurol 27: $192-198$

Koepp MJ, Årstad E, Bankstahl JP, Dedeurwaerdere S, Friedman A, Potschka H, Ravizza T, Theodore WH, and Baram TZ (2017) Neuroinflammation imaging markers for epileptogenesis. Epilepsia 58 (Suppl 3):11-19.

Koneval Z, Knox KM, White HS, and Barker-Haliski M (2018) Lamotrigine-resistant corneal-kindled mice: a model of pharmacoresistant partial epilepsy for moderatethroughput drug discovery. Epilepsia 59:1245-1256.

König J, Müller F, and Fromm MF (2013) Transporters and drug-drug interactions: important determinants of drug disposition and effects. Pharmacol Rev 65:944-966.

Kovács R and Heinemann U (2014) Models in research of pharmacoresistant epilepsy: present and future in development of antiepileptic drugs. Curr Med Chem 21:689-703.

Krauss GL, Klein P, Brandt C, Lee SK, Milanov I, Milovanovic M, Steinhoff BJ, and Kamin M (2020) Safety and efficacy of adjunctive cenobamate (YKP3089) in patients with uncontrolled focal seizures: a multicentre, double-blind, randomised, placebo-controlled, dose-response trial. Lancet Neurol 19:38-48.
Kwan P, Arzimanoglou A, Berg AT, Brodie MJ, Allen Hauser W, Mathern G, Moshé SL, Perucca E, Wiebe S, and French J (2010) Definition of drug resistant epilepsy: consensus proposal by the ad hoc Task Force of the ILAE Commission on Therapeutic Strategies. Epilepsia 51:1069-1077.

Kwan P, Schachter SC, and Brodie MJ (2011) Drug-resistant epilepsy. N Engl J Med 365:919-926.

Lazarowski A, Czornyj L, Lubienieki F, Girardi E, Vazquez S, and D'Giano C (2007) $\mathrm{ABC}$ transporters during epilepsy and mechanisms underlying multidrug resistance in refractory epilepsy. Epilepsia 48 (Suppl 5):140-149.

Leclercq K, Afrikanova T, Langlois M, De Prins A, Buenafe OE, Rospo CC, Van Eeckhaut A, de Witte PA, Crawford AD, Smolders I, et al. (2015) Cross-species pharmacological characterization of the allylglycine seizure model in mice and larval zebrafish. Epilepsy Behav 45:53-63.

Leclercq K and Kaminski RM (2015) Status epilepticus induction has prolonged effects on the efficacy of antiepileptic drugs in the 6-Hz seizure model. Epilepsy Behav 49:55-60.

Leclercq K, Matagne A, and Kaminski RM (2014) Low potency and limited efficacy of antiepileptic drugs in the mouse $6 \mathrm{~Hz}$ corneal kindling model. Epilepsy Res 108: 675-683.

Leclercq K, Matagne A, Provins L, Klitgaard H, and Kaminski R (2020) Pharmacological profile of the antiepileptic drug candidate padsevonil - characterization in rodent seizure and epilepsy models. J Pharmacol Exp Ther 372:11-20.

Lévesque M and Avoli M (2013) The kainic acid model of temporal lobe epilepsy. Neurosci Biobehav Rev 37:2887-2899.

Librizzi L, Noè F, Vezzani A, de Curtis M, and Ravizza T (2012) Seizure-induced brain-borne inflammation sustains seizure recurrence and blood-brain barrier damage. Ann Neurol 72:82-90.

Liu JY, Thom M, Catarino CB, Martinian L, Figarella-Branger D, Bartolomei F, Koepp M, and Sisodiya SM (2012) Neuropathology of the blood-brain barrier and pharmaco-resistance in human epilepsy. Brain 135:3115-3133.

Löscher W (1997) Animal models of intractable epilepsy. Prog Neurobiol 53: $239-258$

Löscher W (2002) Animal models of drug resistant epilepsy, in Mechanisms of Drug Resistance in Epilepsy: Lessons from Oncology (Ling V 149-159, Wiley, Chichester.

Löscher W (2007) Drug transporters in the epileptic brain. Epilepsia 48 (Suppl 1): 8-13.

Löscher W (2016) Fit for purpose application of currently existing animal models in the discovery of novel epilepsy therapies. Epilepsy Res 126:157-184.

Löscher W (2017a) Animal models of seizures and epilepsy: past, present, and future role for the discovery of antiseizure drugs. Neurochem Res 42:1873-1888.

Löscher W (2017b) The search for new screening models of pharmacoresistant epilepsy: is induction of acute seizures in epileptic rodents a suitable Approach? Neurochem Res 42:1926-1938.

Löscher W (2017c) Animal models of drug-refractory epilepsy, in Models of Seizures and Epilepsy (Pitkänen A, Buckmaster PS, Galanopoulou AS, and Moshé SL 743-760, Academic Press, London.

Löscher W (2011) Critical review of current animal models of seizures and epilepsy used in the discovery and development of new antiepileptic drugs. Seizure $\mathbf{2 0}$ 359-368.

Löscher W and Brandt C (2010) High seizure frequency prior to antiepileptic treatment is a predictor of pharmacoresistant epilepsy in a rat model of temporal lobe epilepsy. Epilepsia 51:89-97.

Löscher W and Friedman A (2020) Structural, molecular and functional alterations of the blood-brain barrier during epileptogenesis and epilepsy: a cause, consequence or both? Int J Mol Sci 21:591.

Löscher W and Klein P (2020) The feast and famine: epilepsy treatment and treatment gaps in early 21 st century. Neuropharma In press.

Löscher W, Klitgaard H, Twyman RE, and Schmidt D (2013a) New avenues for antiepileptic drug discovery and development. Nat Rev Drug Discov 12:757-776.

Löscher W, Klotz U, Zimprich F, and Schmidt D (2009) The clinical impact of pharmacogenetics on the treatment of epilepsy. Epilepsia 50:1-23.

Löscher W, Luna-Tortós C, Römermann K, and Fedrowitz M (2011) Do ATP-binding cassette transporters cause pharmacoresistance in epilepsy? Problems and approaches in determining which antiepileptic drugs are affected. Curr Pharm Des 17:2808-2828.

Löscher W and Potschka H (2002) Role of multidrug transporters in pharmacoresistance to antiepileptic drugs. J Pharmacol Exp Ther 301:7-14.

Löscher W and Potschka H (2005) Drug resistance in brain diseases and the role of drug efflux transporters. Nat Rev Neurosci 6:591-602

Löscher W, Puskarjov M, and Kaila K (2013b) Cation-chloride cotransporters NKCC1 and $\mathrm{KCC} 2$ as potential targets for novel antiepileptic and antiepileptogenic treatments. Neuropharmacology 69:62-74.

Löscher W and Rogawski MA (2012) How theories evolved concerning the mechanism of action of barbiturates. Epilepsia $\mathbf{5 3}$ (Suppl 8):12-25.

Löscher W, Rundfeldt C, and Hönack D (1993) Pharmacological characterization of phenytoin-resistant amygdala-kindled rats, a new model of drug-resistant partial epilepsy. Epilepsy Res 15:207-219.

Löscher W and Schmidt D (2011) Modern antiepileptic drug development has failed to deliver: ways out of the current dilemma. Epilepsia 52:657-678.

Löscher W and Schmidt D (2006) Experimental and clinical evidence for loss of effect (tolerance) during prolonged treatment with antiepileptic drugs. Epilepsia $\mathbf{4 7}$ $1253-1284$

Löscher W and Schmidt D (2016) Mechanisms of drug resistance and tolerance, in The Treatment of Epilepsy, 4th ed. (Shorvon S, Perucca E, and Engel J Jr eds) pp 92-102, Wiley Blackwell, Oxford.

Loup F, Wieser HG, Yonekawa Y, Aguzzi A, and Fritschy JM (2000) Selective alterations in GABAA receptor subtypes in human temporal lobe epilepsy. J Neurosci 20:5401-5419.

Lum GR, Olson CA, and Hsiao EY (2020) Emerging roles for the intestinal microbiome in epilepsy. Neurobiol Dis 135:104576. 
Lybrand Z, Goswami S, and Hsieh J (2019) Stem cells: a path towards improved epilepsy therapies. Neuropharmacology 107781.

Mahler B, Carlsson S, Andersson T, and Tomson T (2018) Risk for injuries and accidents in epilepsy: a prospective population-based cohort study. Neurology 90:e779-e789.

Mahringer A and Fricker G (2016) ABC transporters at the blood-brain barrier. Expert Opin Drug Metab Toxicol 12:499-508.

Mantegazza M and Broccoli V (2019) SCN1A/NaV 1.1 channelopathies: mechanisms in expression systems, animal models, and human IPSC models. Epilepsia 60: S25-S38.

Marchi N, Fan Q, Ghosh C, Fazio V, Bertolini F, Betto G, Batra A, Carlton E, Najm I, Granata T, et al. (2009) Antagonism of peripheral inflammation reduces the severity of status epilepticus. Neurobiol Dis 33:171-181.

Marchi N, Guiso G, Rizzi M, Pirker S, Novak K, Czech T, Baumgartner C, Janigro D, Caccia S, and Vezzani A (2005) A pilot study on brain-to-plasma partition of 10,11dyhydro-10-hydroxy-5H-dibenzo(b,f)azepine-5-carboxamide and MDR1 brain expression in epilepsy patients not responding to oxcarbazepine. Epilepsia 46 $1613-1619$.

Marcon J, Gagliardi B, Balosso S, Maroso M, Noé F, Morin M, Lerner-Natoli M, Vezzani A, and Ravizza T (2009) Age-dependent vascular changes induced by status epilepticus in rat forebrain: implications for epileptogenesis. Neurobiol Dis 34:121-132.

Margineanu DG and Klitgaard H (2009) Mechanisms of drug resistance in epilepsy: relevance for antiepileptic drug discovery. Expert Opin Drug Discov 4:23-32.

Maroso M, Balosso S, Ravizza T, Iori V, Wright CI, French J, and Vezzani A (2011) Interleukin-1 $\beta$ biosynthesis inhibition reduces acute seizures and drug resistant chronic epileptic activity in mice. Neurotherapeutics 8:304-315.

Matagne A and Klitgaard H (1998) Validation of corneally kindled mice: a sensitive screening model for partial epilepsy in man. Epilepsy Res 31:59-71.

Mesraoua B, Deleu D, Kullmann D, Shetty A, Boon P, Perucca E, Mikati M, and Asadi-Pooya A (2019) Novel therapies for epilepsy in the pipeline. Epilepsy Behav 97:282-290.

Metcalf CS, Huff J, Thomson KE, Johnson K, Edwards SF, and Wilcox KS (2019) Evaluation of antiseizure drug efficacy and tolerability in the rat lamotrigineresistant amygdala kindling model. Epilepsia Open 4:452-463.

Metcalf CS, West PJ, Thomson KE, Edwards SF, Smith MD, White HS, and Wilcox KS (2017) Development and pharmacologic characterization of the rat $6 \mathrm{~Hz}$ model of partial seizures. Epilepsia 58:1073-1084.

Miller-Delaney SF, Bryan K, Das S, McKiernan RC, Bray IM, Reynolds JP, Gwinn R, Stallings RL, and Henshall DC (2015) Differential DNA methylation profiles of coding and non-coding genes define hippocampal sclerosis in human temporal lobe epilepsy. Brain 138:616-631.

Møller RS, Hammer TB, Rubboli G, Lemke JR, and Johannesen KM (2019) From next-generation sequencing to targeted treatment of non-acquired epilepsies. $E x$ pert Rev Mol Diagn 19:217-228.

Morin-Brureau M, Lebrun A, Rousset MC, Fagni L, Bockaert J, de Bock F, and Lerner-Natoli M (2011) Epileptiform activity induces vascular remodeling and zonula occludens 1 downregulation in organotypic hippocampal cultures: role of VEGF signaling pathways. J Neurosci 31:10677-10688.

Morris G, Reschke CR, and Henshall DC (2019) Targeting microRNA-134 for seizure control and disease modification in epilepsy. EBioMedicine 45:646-654.

Mula M, Zaccara G, Galimberti CA, Ferrò B, Canevini MP, Mascia A, Mecarelli O, Michelucci R, Pisani LR, Specchio LM, et al. (2019) Validated outcome of treatment changes according to International League against Epilepsy criteria in adults with drug-resistant focal epilepsy. Epilepsia 60:1114-1123.

Murray MI, Halpern MT, and Leppik IE (1996) Cost of refractory epilepsy in adults in the USA. Epilepsy Res 23:139-148.

Namgoong JH and Bertoni C (2016) Clinical potential of Ataluren in the treatment of Duchenne muscular dystrophy. Degener Neurol Neuromuscul 6:37-48.

Narayanan J, Frech R, Walters S, Patel V, Frigerio R, and Maraganore DM (2016) Low dose verapamil as an adjunct therapy for medically refractory epilepsy - an open label pilot study. Epilepsy Res 126:197-200.

National Research Council (US) Committee on A Framework for Developing a New Taxonomy of Disease (2011) Toward Precision Medicine: Building a Knowledge Network for Biomedical Research and a New Taxonomy of Disease, National Academies Press, Washington, DC.

Naylor DE, Liu H, and Wasterlain CG (2005) Trafficking of GABA(A) receptors, loss of inhibition, and a mechanism for pharmacoresistance in status epilepticus. J Neurosci 25:7724-7733.

Neuwelt EA, Bauer B, Fahlke C, Fricker G, Iadecola C, Janigro D, Leybaert L, Molnár Z, O’Donnell ME, Povlishock JT, et al. (2011) Engaging neuroscience to advance translational research in brain barrier biology. Nat Rev Neurosci 12 169-182.

Niquet J, Baldwin R, Suchomelova L, Lumley L, Naylor D, Eavey R, and Wasterlain CG (2016) Benzodiazepine-refractory status epilepticus: pathophysiology and principles of treatment. Ann N Y Acad Sci 1378:166-173.

O'Brien FE, Dinan TG, Griffin BT, and Cryan JF (2012) Interactions between antidepressants and P-glycoprotein at the blood-brain barrier: clinical significance of in vitro and in vivo findings. Br J Pharmacol 165:289-312.

Olson CA, Vuong HE, Yano JM, Liang QY, Nusbaum DJ, and Hsiao EY (2018) The gut microbiota mediates the anti-seizure effects of the ketogenic diet. Cell 173: 1728-1741.e13.

Orlandi A, Paolino MC, Striano P, and Parisi P (2018) Clinical reappraisal of the influence of drug-transporter polymorphisms in epilepsy. Expert Opin Drug Metab Toxicol 14:505-512.

Parent JM and Anderson SA (2015) Reprogramming patient-derived cells to study the epilepsies. Nat Neurosci 18:360-366.

Pekcec A, Unkrüer B, Schlichtiger J, Soerensen J, Hartz AM, Bauer B, van Vliet EA, Gorter JA, and Potschka H (2009) Targeting prostaglandin E2 EP1 receptors prevents seizure-associated P-glycoprotein up-regulation. J Pharmacol Exp Ther 330:939-947.
Peng A, Qiu X, Lai W, Li W, Zhang L, Zhu X, He S, Duan J, and Chen L (2018) Altered composition of the gut microbiome in patients with drug-resistant epilepsy. Epilepsy Res 147:102-107.

Pirker S, Schwarzer C, Czech T, Baumgartner C, Pockberger H, Maier H, Hauer B, Sieghart W, Furtinger S, and Sperk G (2003) Increased expression of GABA(A) receptor beta-subunits in the hippocampus of patients with temporal lobe epilepsy. $J$ Neuropathol Exp Neurol 62:820-834.

Polster T (2019) Individualized treatment approaches: fenfluramine, a novel antiepileptic medication for the treatment of seizures in Dravet syndrome. Epilepsy Behav 91:99-102

Porter BE, Zhang G, Celix J, Hsu FC, Raol YH, Telfeian A, Gallagher PR, Coulter DA, and Brooks-Kayal AR (2005) Heterogeneous GABAA receptor suxWbunit expression in pediatric epilepsy patients. Neurobiol Dis 18:484-491.

Porter RJ and Kupferberg HJ (2017) The Anticonvulsant Screening Program of the National Institute of Neurological Disorders and Stroke, NIH: history and contributions to clinical care in the twentieth century and beyond. Neurochem Res 42 : 1889-1893.

Postma T, Krupp E, Li XL, Post RM, and Weiss SR (2000) Lamotrigine treatment during amygdala-kindled seizure development fails to inhibit seizures and diminishes subsequent anticonvulsant efficacy. Epilepsia 41:1514-1521.

Potschka H (2010) Modulating P-glycoprotein regulation: future perspectives for pharmacoresistant epilepsies? Epilepsia 51:1333-1347.

Potschka H (2012) Role of CNS efflux drug transporters in antiepileptic drug delivery: overcoming CNS efflux drug transport. Adv Drug Deliv Rev 64:943-952.

Potschka H (2013) Animal and human data: where are our concepts for drugresistant epilepsy going? Epilepsia 54 (Suppl 2):29-32.

Potschka H, Fedrowitz M, and Löscher W (2003a) Multidrug resistance protein MRP2 contributes to blood-brain barrier function and restricts antiepileptic drug activity. J Pharmacol Exp Ther 306:124-131.

Potschka H, Fedrowitz M, and Löscher W (2003b) Brain access and anticonvulsant efficacy of carbamazepine, lamotrigine, and felbamate in ABCC2/MRP2-deficient TR- rats. Epilepsia 44:1479-1486

Potschka H, Fischer A, von Rüden EL, Hülsmeyer V, and Baumgärtner W (2013) Canine epilepsy as a translational model? Epilepsia 54:571-579.

Potschka H, Volk HA, and Löscher W (2004) Pharmacoresistance and expression of multidrug transporter P-glycoprotein in kindled rats. Neuroreport 15:1657-1661.

Pressler RM, Boylan GB, Marlow N, Blennow M, Chiron C, Cross JH, de Vries LS, Hallberg B, Hellström-Westas L, Jullien V, et al.; NEonatal seizure treatment with Medication Off-patent (NEMO) consortium (2015) Bumetanide for the treatment of seizures in newborn babies with hypoxic ischaemic encephalopathy (NEMO): an open-label, dose finding, and feasibility phase 1/2 trial. Lancet Neurol 14:469-477.

Pugliatti M, Beghi E, Forsgren L, Ekman M, and Sobocki P (2007) Estimating the cost of epilepsy in Europe: a review with economic modeling. Epilepsia 48: $2224-2233$

Puskarjov M, Kahle KT, Ruusuvuori E, and Kaila K (2014) Pharmacotherapeutic targeting of cation-chloride cotransporters in neonatal seizures. Epilepsia 55: 806-818.

Ravizza T and Vezzani A (2006) Status epilepticus induces time-dependent neuronal and astrocytic expression of interleukin-1 receptor type I in the rat limbic system. Neuroscience 137:301-308.

Regesta G and Tanganelli P (1999) Clinical aspects and biological bases of drugresistant epilepsies. Epilepsy Res 34:109-122.

Remy S and Beck H (2006) Molecular and cellular mechanisms of pharmacoresistance in epilepsy. Brain 129:18-35.

Remy S, Gabriel S, Urban BW, Dietrich D, Lehmann TN, Elger CE, Heinemann U, and Beck H (2003a) A novel mechanism underlying drug resistance in chronic epilepsy. Ann Neurol 53:469-479.

Remy S, Urban BW, Elger CE, and Beck H (2003b) Anticonvulsant pharmacology of voltage-gated $\mathrm{Na}+$ channels in hippocampal neurons of control and chronically epileptic rats. Eur J Neurosci 17:2648-2658.

Riban V, Bouilleret V, Pham-Lê BT, Fritschy JM, Marescaux C, and Depaulis A (2002) Evolution of hippocampal epileptic activity during the development of hippocampal sclerosis in a mouse model of temporal lobe epilepsy. Neuroscience 112: 101-111.

Richards K, Milligan C, Richardson R, Jancovski N, Grunnet M, Jacobson L, Undheim E, Mobli M, Chow C, Herzig V, et al. (2018) Selective Nav1.1 activation rescues Dravet syndrome mice from seizures and premature death. Proc Natl Acad Sci USA 115:E8077-E8085.

Richter S, Garner J, and Wurbel H (2009) Environmental standardization: cure or cause of poor reproducibility in animal experiments? Nat Methods 6:257-261.

Rigau V, Morin M, Rousset MC, de Bock F, Lebrun A, Coubes P, Picot MC, BaldyMoulinier M, Bockaert J, Crespel A, et al. (2007) Angiogenesis is associated with blood-brain barrier permeability in temporal lobe epilepsy. Brain 130:1942-1956.

Rizzi M, Caccia S, Guiso G, Richichi C, Gorter JA, Aronica E, Aliprandi M, Bagnati R, Fanelli R, D'Incalci M, et al. (2002) Limbic seizures induce P-glycoprotein in rodent brain: functional implications for pharmacoresistance. $J$ Neurosci 22:5833-5839.

Rogawski MA (2013) The intrinsic severity hypothesis of pharmacoresistance to antiepileptic drugs. Epilepsia 54 (Suppl 2):33-40.

Rogawski MA and Johnson MR (2008) Intrinsic severity as a determinant of antiepileptic drug refractoriness. Epilepsy Curr 8:127-130.

Rogawski MA and Löscher W (2004) The neurobiology of antiepileptic drugs. Nat Rev Neurosci 5:553-564.

Rogawski MA, Löscher W, and Rho JM (2016) Mechanisms of action of antiseizure drugs and the ketogenic diet. Cold Spring Harb Perspect Med 6

Rojas A, Gueorguieva P, Lelutiu N, Quan Y, Shaw R, and Dingledine R (2014) The prostaglandin EP1 receptor potentiates kainate receptor activation via a protein kinase C pathway and exacerbates status epilepticus. Neurobiol Dis 70:74-89.

Römermann K, Helmer R, and Löscher W (2015) The antiepileptic drug lamotrigine is a substrate of mouse and human breast cancer resistance protein (ABCG2). Neuropharmacology 93:7-14. 
Roseti C, Fucile S, Lauro C, Martinello K, Bertollini C, Esposito V, Mascia A, Catalano M, Aronica E, Limatola C, et al. (2013) Fractalkine/CX3CL1 modulates GABAA currents in human temporal lobe epilepsy. Epilepsia 54:1834-1844.

Roseti C, van Vliet EA, Cifelli P, Ruffolo G, Baayen JC, Di Castro MA, Bertollini C, Limatola C, Aronica E, Vezzani A, et al. (2015) GABAA currents are decreased by IL-1 $\beta$ in epileptogenic tissue of patients with temporal lobe epilepsy: implications for ictogenesis. Neurobiol Dis 82:311-320.

Rowley N and White H (2010) Comparative anticonvulsant efficacy in the corneal kindled mouse model of partial epilepsy: correlation with other seizure and epilepsy models. Epilepsy Res 92:163-169.

Rundfeldt C and Löscher W (2014) The pharmacology of imepitoin: the first partial benzodiazepine receptor agonist developed for the treatment of epilepsy. Cns Drugs 28:29-43.

Ryvlin P, Rheims S, and Lhatoo SD (2019) Risks and predictive biomarkers of sudden unexpected death in epilepsy patient. Curr Opin Neurol 32:205-212.

Sa M, Singh R, Pujar S, D'Arco F, Desai N, Eltze C, Hughes E, Al Obaidi M, Eleftheriou D, Tisdall M, et al. (2019) Centromedian thalamic nuclei deep brain stimulation and anakinra treatment for FIRES - two different outcomes. Eur J Paediatr Neurol 23:749-754.

Salar S, Maslarova A, Lippmann K, Nichtweiss J, Weissberg I, Sheintuch L, Kunz WS, Shorer Z, Friedman A, and Heinemann U (2014) Blood-brain barrier dysfunction can contribute to pharmacoresistance of seizures. Epilepsia 55:1255-1263.

Sandoval KE and Witt KA (2008) Blood-brain barrier tight junction permeability and ischemic stroke. Neurobiol Dis 32:200-219.

Saunders NR, Habgood MD, Møllgård K, and Dziegielewska KM (2016) The biological significance of brain barrier mechanisms: help or hindrance in drug delivery to the central nervous system? F1000 Res 5.

Schaub C, Uebachs M, and Beck H (2007) Diminished response of CA1 neurons to antiepileptic drugs in chronic epilepsy. Epilepsia 48:1339-1350.

Schlichtiger J, Pekcec A, Bartmann H, Winter P, Fuest C, Soerensen J, and Potschka $\mathrm{H}$ (2010) Celecoxib treatment restores pharmacosensitivity in a rat model of pharmacoresistant epilepsy. Br J Pharmacol 160:1062-1071.

Schmidt D and Löscher W (2005) Drug resistance in epilepsy: putative neurobiologic and clinical mechanisms. Epilepsia 46:858-877.

Schmidt D and Löscher W (2009) New developments in antiepileptic drug resistance: an integrative view. Epilepsy Curr 9:47-52

Siddiqui A, Kerb R, Weale ME, Brinkmann U, Smith A, Goldstein DB, Wood NW, and Sisodiya SM (2003) Association of multidrug resistance in epilepsy with a polymorphism in the drug-transporter gene ABCB1. $N$ Engl $J$ Med 348: 1442-1448.

Sillanpää M and Schmidt D (2009) Early seizure frequency and aetiology predict long-term medical outcome in childhood-onset epilepsy. Brain 132:989-998.

Sisodiya SM, Heffernan J, and Squier MV (1999) Over-expression of P-glycoprotein in malformations of cortical development. Neuroreport 10:3437-3441.

Sisodiya SM, Lin WR, Harding BN, Squier MV, and Thom M (2002) Drug resistance in epilepsy: expression of drug resistance proteins in common causes of refractory epilepsy. Brain 125:22-31.

Sills G and Rogawski M (2020) Mechanisms of action of currently used antiseizure drugs. Neuropharmacology In press.

Sisodiya SM (2020) Epilepsy genetics and the precision medicine matrix. Lancet Neurol 19:29-30.

Sisodiya SM (2003) Mechanisms of antiepileptic drug resistance. Curr Opin Neurol 16:197-201.

Smyth MD, Barbaro NM, and Baraban SC (2002) Effects of antiepileptic drugs on induced epileptiform activity in a rat model of dysplasia. Epilepsy Res 50:251-264.

Srivastava AK, Alex AB, Wilcox KS, and White HS (2013) Rapid loss of efficacy to the antiseizure drugs lamotrigine and carbamazepine: a novel experimental model of pharmacoresistant epilepsy. Epilepsia 54:1186-1194.

Srivastava P, van Eyll J, Godard P, Mazzuferi M, Delahaye-Duriez A, Van Steenwinckel J, Gressens P, Danis B, Vandenplas C, Foerch P, et al (2018) A systemslevel framework for drug discovery identifies Csf1R as an anti-epileptic drug target. Nat Commun 9:3561.

Sun G, Sun X, and Guan L (2014) Association of MDR1 gene C3435T polymorphism with childhood intractable epilepsy: a meta-analysis. J Neural Transm (Vienna) 121:717-724.

Swissa E, Serlin Y, Vazana U, Prager O, and Friedman A (2019) Blood-brain barrier dysfunction in status epileptics: Mechanisms and role in epileptogenesis. Epilepsy Behav 101:106285.

Tang F, Hartz AMS, and Bauer B (2017) Drug-resistant epilepsy: multiple hypotheses, few answers. Front Neurol 8:301.

Terrone G, Salamone A, and Vezzani A (2017) Inflammation and epilepsy: preclinical findings and potential clinical translation. Curr Pharm Des 23:5569-5576.

Tishler DM, Weinberg KI, Hinton DR, Barbaro N, Annett GM, and Raffel C (1995) MDR1 gene expression in brain of patients with medically intractable epilepsy. Epilepsia 36:1-6.

Töllner K, Wolf S, Löscher W, and Gernert M (2011) The anticonvulsant response to valproate in kindled rats is correlated with its effect on neuronal firing in the substantia nigra pars reticulata: a new mechanism of pharmacoresistance. $J \mathrm{Neu}$ rosci 31:16423-16434.

Uchida Y, Ohtsuki S, Katsukura Y, Ikeda C, Suzuki T, Kamiie J, and Terasaki T (2011) Quantitative targeted absolute proteomics of human blood-brain barrier transporters and receptors. J Neurochem 117:333-345.

van Vliet EA, Aronica E, and Gorter JA (2015) Blood-brain barrier dysfunction, seizures and epilepsy. Semin Cell Dev Biol 38:26-34.

van Vliet EA, Aronica E, Vezzani A, and Ravizza T (2018) Review: neuroinflammatory pathways as treatment targets and biomarker candidates in epilepsy: emerging evidence from preclinical and clinical studies. Neuropathol Appl Neurobiol 44:91-111. van Vliet EA, van Schaik R, Edelbroek PM, Voskuyl RA, Redeker S, Aronica E, Wadman WJ, and Gorter JA (2007) Region-specific overexpression of P-glycoprotein at the blood-brain barrier affects brain uptake of phenytoin in epileptic rats. J Pharmacol Exp Ther 322:141-147.

van Vliet EA, Zibell G, Pekcec A, Schlichtiger J, Edelbroek PM, Holtman L, Aronica E, Gorter JA, and Potschka H (2010) COX-2 inhibition controls P-glycoprotein expression and promotes brain delivery of phenytoin in chronic epileptic rats. Neuropharmacology 58:404-412.

Vezzani A, Balosso S, and Ravizza T (2019) Neuroinflammatory pathways as treatment targets and biomarkers in epilepsy. Nat Rev Neurol 15:459-472.

Viviani B, Bartesaghi S, Gardoni F, Vezzani A, Behrens MM, Bartfai T, Binaglia M, Corsini E, Di Luca M, Galli CL, et al. (2003) Interleukin-1beta enhances NMDA receptor-mediated intracellular calcium increase through activation of the Src family of kinases. J Neurosci 23:8692-8700.

Vezzani A, Conti M, De Luigi A, Ravizza T, Moneta D, Marchesi F, and De Simoni MG (1999) Interleukin-1beta immunoreactivity and microglia are enhanced in the rat hippocampus by focal kainate application: functional evidence for enhancement of electrographic seizures. J Neurosci 19:5054-5065.

Vezzani A, Maroso M, Balosso S, Sanchez MA, and Bartfai T (2011) IL-1 receptor/Tolllike receptor signaling in infection, inflammation, stress and neurodegeneration couples hyperexcitability and seizures. Brain Behav Immun 25:1281-1289.

Vezzani A, Moneta D, Conti M, Richichi C, Ravizza T, De Luigi A, De Simoni MG, Sperk G, Andell-Jonsson S, Lundkvist J, et al. (2000) Powerful anticonvulsant action of IL-1 receptor antagonist on intracerebral injection and astrocytic overexpression in mice. Proc Natl Acad Sci USA 97:11534-11539.

Vezzani A and Viviani B (2015) Neuromodulatory properties of inflammatory cytokines and their impact on neuronal excitability. Neuropharmacology 96 (Pt A): 70-82.

Voelkl B, Vogt L, Sena E, and Wurbel H (2018) Reproducibility of preclinical animal research improves with heterogeneity of study samples. PLoS Biol 16:e2003693.

Volk HA, Arabadzisz D, Fritschy JM, Brandt C, Bethmann K, and Löscher W (2006) Antiepileptic drug-resistant rats differ from drug-responsive rats in hippocampal neurodegeneration and GABA(A) receptor ligand binding in a model of temporal lobe epilepsy. Neurobiol Dis 21:633-646.

Volk HA and Löscher W (2005) Multidrug resistance in epilepsy: rats with drugresistant seizures exhibit enhanced brain expression of P-glycoprotein compared with rats with drug-responsive seizures. Brain 128:1358-1368.

Wahab A, Albus K, Gabriel S, and Heinemann U (2010) In search of models of pharmacoresistant epilepsy. Epilepsia 51 (Suppl 3):154-159.

Wang J, Lin Z, Liu L, Xu H, Shi Y, Yi Y, He N, and Liao W (2017) Epilepsy-associated genes. Seizure 44:11-20.

Watila MM, Balarabe SA, Ojo O, Keezer MR, and Sander JW (2018) Overall and cause-specific premature mortality in epilepsy: a systematic review. Epilepsy Behav 87:213-225.

Weidner LD, Kannan P, Mitsios N, Kang SJ, Hall MD, Theodore WH, Innis RB, and Mulder $\mathrm{J}$ (2018) The expression of inflammatory markers and their potentia influence on efflux transporters in drug-resistant mesial temporal lobe epilepsy tissue. Epilepsia 59:1507-1517.

Weissberg I, Wood L, Kamintsky L, Vazquez O, Milikovsky DZ, Alexander A, Oppenheim H, Ardizzone C, Becker A, Frigerio F, et al. (2015) Albumin induces excitatory synaptogenesis through astrocytic TGF-3/ALK5 signaling in a model of acquired epilepsy following blood-brain barrier dysfunction. Neurobiol Dis 78: $115-125$

Wengert ER, Saga AU, Panchal PS, Barker BS, and Patel MK (2019) Prax330 reduces persistent and resurgent sodium channel currents and neuronal hyperexcitability of subiculum neurons in a mouse model of SCN8A epileptic encephalopathy. Neuropharmacology 158:107699.

West PJ, Saunders GW, Billingsley P, Smith MD, White HS, Metcalf CS, and Wilcox KS (2018) Recurrent epileptiform discharges in the medial entorhinal cortex of kainate-treated rats are differentially sensitive to antiseizure drugs. Epilepsia $\mathbf{5 9}$ : 2035-2048.

Wiebe S and Jette N (2012) Pharmacoresistance and the role of surgery in difficult to treat epilepsy. Nat Rev Neurol 8:669-677.

Wilcox K, West P, and Metcalf C (2020) The current approach of the epilepsy therapy screening program cntract site for identifying improved therapies for the treatment of pharmacoresistant seizures in epilepsy. Neuropharmacology In press.

Wood M, Daniels V, Provins L, Wolff C, Kaminski R, and Gillard M (2020) Pharmacological profile of the novel antiepileptic drug candidate Padsevonil: interactions with synaptic vesicle 2 proteins and the GABA receptor. $J$ Pharmacol Exp Ther 372:1-10.

Xu ZH, Wang Y, Tao AF, Yu J, Wang XY, Zu YY, Zhang SH, and Chen Z (2016) Interleukin-1 receptor is a target for adjunctive control of diazepam-refractory status epilepticus in mice. Neuroscience 328:22-29.

Yang GY, Gong C, Qin Z, Liu XH, and Lorris Betz A (1999) Tumor necrosis factor alpha expression produces increased blood-brain barrier permeability following temporary focal cerebral ischemia in mice. Brain Res Mol Brain Res 69:135-143.

Zaccara G, Mula M, Ferrò B, Consoli D, Elia M, Giallonardo AT, Iudice A, La Neve A Meletti S, Tinuper P, et al. (2019) Do neurologists agree in diagnosing drug resistance in adults with focal epilepsy? Epilepsia 60:175-183.

Zhang C, Kwan P, Zuo Z, and Baum L (2012) The transport of antiepileptic drugs by P-glycoprotein. Adv Drug Deliv Rev 64:930-942.

Zibell G, Unkrüer B, Pekcec A, Hartz AM, Bauer B, Miller DS, and Potschka H (2009) Prevention of seizure-induced up-regulation of endothelial P-glycoprotein by COX2 inhibition. Neuropharmacology 56:849-855.

Ziobro J, Eschbach K, Sullivan JE, and Knupp KG (2018) Current treatment strategies and future treatment options for Dravet syndrome. Curr Treat Options Neurol 20:52. 